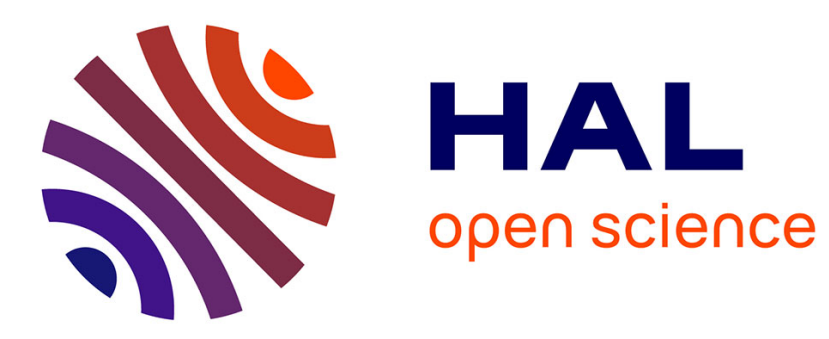

\title{
Partially Covalent Two-Electron/Multicentric Bonding between Semiquinone Radicals
}

\author{
Krešimir Molčanov, Christian Jelsch, Bruno Landeros-Rivera, Jesús \\ Hernández-Trujillo, Emmanuel Wenger, Vladimir Stilinović, Biserka \\ Kojić-Prodić, Eduardo Escudero-Adán
}

\section{To cite this version:}

Krešimir Molčanov, Christian Jelsch, Bruno Landeros-Rivera, Jesús Hernández-Trujillo, Emmanuel Wenger, et al.. Partially Covalent Two-Electron/Multicentric Bonding between Semiquinone Radicals. Crystal Growth \& Design, 2018, 19 (1), pp.391-402. 10.1021/acs.cgd.8b01484 . hal-02356050

\section{HAL Id: hal-02356050 https://hal.science/hal-02356050}

Submitted on 8 Nov 2019

HAL is a multi-disciplinary open access archive for the deposit and dissemination of scientific research documents, whether they are published or not. The documents may come from teaching and research institutions in France or abroad, or from public or private research centers.
L'archive ouverte pluridisciplinaire HAL, est destinée au dépôt et à la diffusion de documents scientifiques de niveau recherche, publiés ou non, émanant des établissements d'enseignement et de recherche français ou étrangers, des laboratoires publics ou privés. 
Published in Crystal Growth \& Design, 19(1), 391-402. DOI 10.1021/acs.cgd.8b01484

\title{
Partially covalent two-electron/multicentric bonding between semiquinone radicals
}

\author{
Krešimir Molčanov *a ${ }^{*}$ Christian Jelsch ${ }^{* b}$, Bruno Landeros-Riverac ${ }^{c}$, Jesús Hernández-Trujillo ${ }^{c}$, \\ Emmanuel Wenger ${ }^{b}$, Vladimir Stilinović ${ }^{d}$, Biserka Kojić-Prodića ${ }^{a}$ Eduardo C. Escudero-Adán ${ }^{e}$
}

${ }^{a}$ Department of Physical Chemistry, Rudjer Bošković Institute, Bijenička 54, HR-10000 Zagreb, Croatia

${ }^{\mathrm{b}}$ Cristallographie, Résonance Magnetique et Modélisations, UMR 7036, Institut Jean Barriol, CNRS and Université de Lorraine BP 70239, F54506 Vandoeuvre-les-Nancy CEDEX, France

c Departamento de Física y Química Teórica, Facultad de Química, UNAM, Mexico City, 04510 Mexico

${ }^{\mathrm{d}}$ Department of Chemistry, Faculty of Science, University of Zagreb, Horvatovac 102a, HR10000 Zagreb, Croatia

${ }^{\mathrm{e}}$ The Barcelona Institute of Science and Technology, Institute of Chemical Research of Catalonia (ICIQ),

Avgda. Països Catalans 16, 43007 Tarragona, Spain

e-mail:kmolcano@irb.hr, christian.jelsch@univ-lorraine.fr 
KEYWORDS semiquinone, charge density, crystallography, pancake bonding, cycle stacking, DFT calculations

ABSTRACT X-ray charge density was determined and analyzed for two polymorphs of the $\mathrm{N}$ methylpyridinium salt of the tetrachlorosemiquinone radical anion and its analogous closed-shell relatives, tetrachloroquinone (chloranil) and tetrachlorohydroquinone. The study, which was combined with calculations of electron delocalization, electrostatic potentials, and aromaticity, presents details of electronic structure of the semiquinoid ring. This comparative study reveals that the negative charge is delocalized over the entire semiquinone radical, and that the chlorine substituents play a crucial role in its stabilization through induction effect. In general, the semiquinoid ring has partially delocalized $\pi$-electrons and is approximately half-way between a quinoid and an aromatic ring. In the orthorhombic polymorph with stacks of equidistant radicals electron density between the rings of almost 0.05 e $\AA^{-3}$ and four $(3,-1)$ saddle points between the contiguous rings were found. In the diamagnetic triclinic polymorph, comprising strongly bound radical dimers (with significant covalent character - 'pancake bond'), maximum electron density between the rings exceeds 0.095 e $\AA^{-3}$ and multiple $(3,-1)$ critical points are found. However, only negligible electron density is observed between the dimers. Thus, in the radical anion stacks spin coupling, along with dispersive and polarization effects, defines interplanar distance and magnetic behaviour, whereas intermolecular electrostatic potential determines the ring offset. 


\section{INTRODUCTION}

Quinones and semiquinone radicals are well-known electron carriers because they easily undergo reversible oxidation-reduction reactions. Highly pronounced electron dynamics of such systems enable a wide range of redox reactions and charge transfers at close and long distances; many of them have been used by Nature in crucial life processes. For instance, new evidence of enzymes using quinones as prosthetic groups or substrates and understanding of their mechanisms will demonstrate how simple quinone molecule can exhibit very complex chemical reactions responsible for respiration, photosynthesis, and many protective mechanisms against radicals. Coenzyme Q, the ubiquinone, is present in animals, plants, and microorganisms and is involved in electron transfer photosynthesis, oxidative phosphorylation, the bioactivity of vitamin $\mathrm{K}$, and many others. ${ }^{[1,2]}$ Studies of mechanism for extracting photosynthetic electrons (photo system II) using exogenous quinones to produce an amenable electric current can be a bio-inspired model for green-energy production. This type of research has been put forward by using X-ray free electron laser (XFEL) revealing dynamics of photo system II macromolecular complex. ${ }^{[3]}$ Many cellular oxidoreductases participate in metabolism of quinone compounds catalysing one or two-electron reduction, such as in cytochrome $\mathrm{P} 450$ reductase. The two-electron reduction of quinones is an important protective mechanism against radicals in mammals. ${ }^{[4]}$ In living cells quinones play crucial roles as redox mediators and to discuss their activities ${ }^{[5,6]}$ would be out of the topic of this work.

The standard redox potentials of (semi)quinone system are influenced by substituents on the (semi)quinoid ring due to an induction effect. Electronegative substituents (such as halogens, nitrile and nitro groups) raise the oxidation potential, while electron-donating ones (such as hydroxyl or methyl) lower it. Therefore, quinones with four electronegative substituents are easily 
reduced and form stable radicals. These unique electron characteristics of quinones are of great importance for chemical synthesis, ${ }^{[7,8]}$ materials design, ${ }^{[9-13]}$ including organic batteries, ${ }^{[14,15]}$ and in essential life processes. ${ }^{[16-19]}$

The electronic structure of the semiquinone ring has been extensively studied by quantum chemical computations, ${ }^{[20-23]}$ however, the results are somewhat ambiguous and depend very much on the method and basis set used. DFT calculations are able to reproduce geometry quite reasonably, ${ }^{[24]}$ but the delocalization of the $\pi$-electron cloud still remains an issue. According to geometry and DFT-calculated harmonic oscillator model of aromaticity (HOMA) ${ }^{[25]}$ and nucleusindependent chemical shifts (NICS ${ }^{[26]}$ indices, the semiquinone ring behaves between an aromatic and a quinoid ring. ${ }^{[24]}$ The three most common planar, conjugated rings are shown in Scheme 1: the quinoid ring (1) has distinguishable single and double bonds, while the aromatic ring of the hydroquinone (3) has a fully delocalized $\pi$-electron system. Semiquinone (2), which appears as an intermediate during reduction of the quinone and oxidation of the hydroquinone, is expected to be approximately half-way between these two. The unpaired electron and the single negative charge are delocalized throughout the ring. However, delocalization of $\pi$-electrons, bond orders, local atomic charges and local dipoles still remain open questions.

Perhalogenated and cyano-substituted semiquinone crystals are easily obtained and are often stable in air and at room temperature, ${ }^{[27-29]}$ and they are extensively used in the design and synthesis of organic molecular magnets and (semi)conductors. ${ }^{[12,27]}$ It is possible to tune their magnetic properties and conductivity by crystal engineering. ${ }^{[27]}$ In these systems, the crucial component is the conjugated $\pi$-electron system; interactions between $\pi$-systems of the radicals play the key role in determining magnetic and electrical properties. ${ }^{[28,30-37]}$ Two types of stacks of semiquinone radicals have been described: ${ }^{[27]}$ (1) stacks with alternating short $(<3.3 \AA)$ and long $(>3.5 \AA)$ inter- 
planar separations comprising dimers with diamagnetically coupled spins and (2) stacks of equidistant radicals with antiferromagnetic coupling (Figure 1). Attempts to modulate $\pi$ interactions of the radicals by crystal engineering are, however, very recent ${ }^{[27-30]}$ and little is known about the interactions between the stacked radical rings. Therefore, we focused on characteristics of electronic structure of semiquinone systems using experimental and theoretical methods.

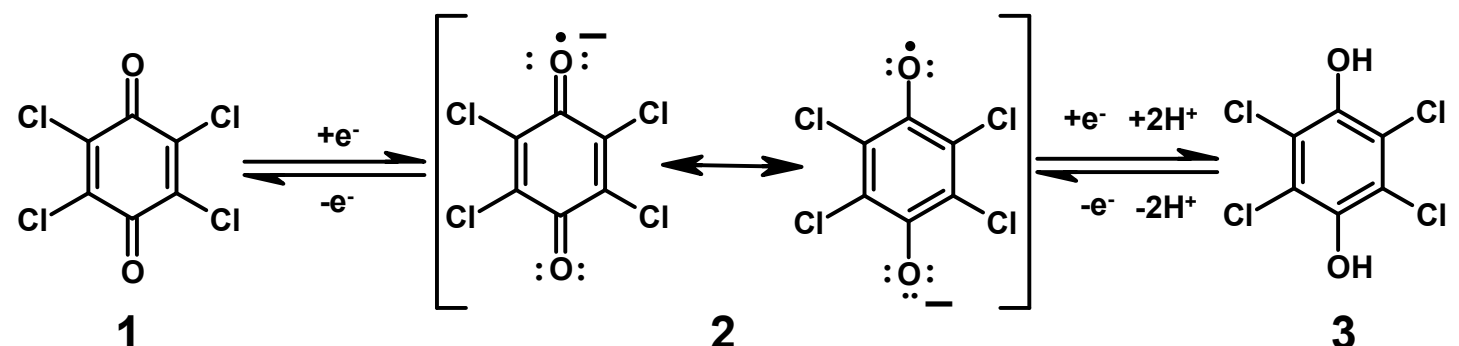

Scheme 1 Three types of planar, conjugated rings studied in this paper: quinoid (tetrachloroquinone, 1), semiquinoid (tetrachlorosemiquinone, 2) and aromatic (tetrachlorohydroquinone, 3 ).

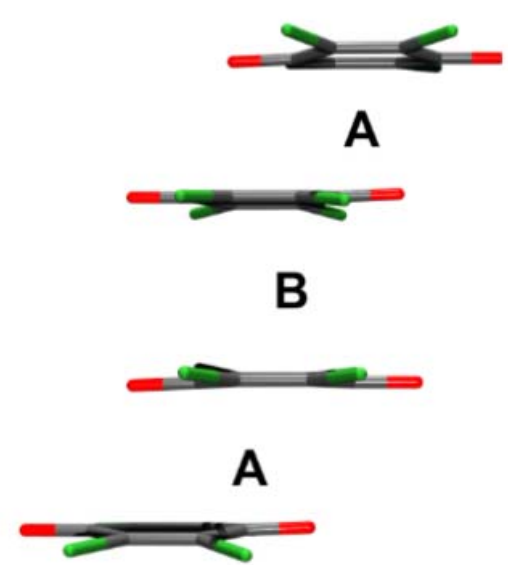

a)

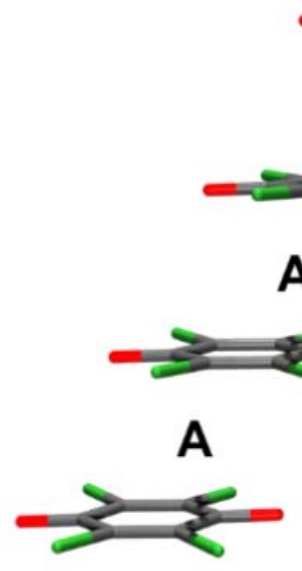

A

b)

Figure 1 Two types of semiquinone radical $\pi$-stacks: ${ }^{[27]}$ a) diamagnetic stacks of closely interacting dimers and b) antiferromagnetic stacks of equidistant radicals. Short $(<3.3 \AA)$ and long (> $3.5 \AA$ ) inter-planar separations have been indicated by letters $\mathbf{A}$ and $\mathbf{B}$, respectively. 


\section{RESULTS AND DISCUSSION}

To gain more insight into the electronic structure of the semiquinoid ring and the subtle intermolecular interactions governing magnetic properties of their crystals, we studied $\mathrm{N}$ methylpyridinium salts of tetrachlorosemiquinone anion radical $(2 \cdot N$-MePy), previously prepared and characterised by $\mathrm{us}^{[27]}$, by a combination of X-ray charge density and quantum chemical calculations. This compound is a suitable research object due to its stability in air at room temperature and because it grows into well-developed single crystals; it also lacks very heavy atoms, which would cause high X-ray absorption. Moreover, two polymorphs of $\mathbf{2} \cdot \mathrm{N}$-MePy are known, one diamagnetic triclinic crystal with radical dimers and an antiferromagnetic one with equidistantly stacked radicals (Figure 1 ), making $2 \cdot N$-MePy an ideal system for study of stacking interactions between semiquinones. To determine the character of the electronic structure of semiquinone ring and its impact on stacking interactions, we supply X-ray charge density data of two closely related compounds, tetrachloroquinone (1) and aromatic tetrachlorohydroquinone (3). Bond orders and interaction energies of stacking were also estimated by DFT calculations and discussed in view of experimental findings.

\section{Electron delocalization in the semiquinone ring}

Several descriptors of electron delocalization were used to quantify electron sharing and aromaticity of the semiquinone ring and to get insight into its stacking interactions. Bond orders are calculated using the three methods shown in Table 1. The topological bond orders ( $\left.n_{\text {topo }}\right)$, as defined by Howard et al. ${ }^{[38]}$ extracted from X-ray electron density of compounds 1-3 are in good agreement with those from quantum chemical Delocalization Indexes (DI) defined in the quantum theory of atoms in molecules (QTAIM) and Wiberg bond orders from NBO analysis. ${ }^{[39-41]}$ 
Tetrachloroquinone $\mathbf{1}$ has a typical quinoid structure with very little $\pi$-electron delocalization: formally single $\mathrm{C}-\mathrm{C}$ bonds have $n_{\text {topo }}$ values of 0.94 and 1.00 , while the formally double ones have bond orders of 1.78. Carbonyl $\mathrm{C}=\mathrm{O}$ bonds have a surprisingly low $n_{\text {topo }}$ of 1.35 , but the maximum electron density at the critical point is $2.862 \mathrm{e} \AA^{-3}$, which is consistent with a double bond (also the bond length is $1.2125(8) \AA$ ). In addition, delocalization indices obtained from quantum calculations also yielded similar bond orders $(1.37-1.38)$ for the carbonyl bond. Therefore, we conclude that this is not a result of poor parametrization or inaccurate experimental data, but a property of quinoid systems. Also, a recent X-ray charge density study of dichloroquinone ${ }^{[42 a]}$, our study of partially charged semiquinones ${ }^{[22 b]}$ and 2,5-dihydroxyquinones ${ }^{[42 c, d]}$ yielded similar values. Tetrachlorohydroquinone $\mathbf{3}$ is an aromatic compound with $\mathrm{C}-\mathrm{C}$ bond lengths nearly equal, and nearly pure single $\mathrm{C}-\mathrm{O}$ bonds (Table 1 ).

In tetrachlorosemiquinone $\mathbf{2}$ there are neither single nor double $\mathrm{C}-\mathrm{C}$ bonds; those that correspond to double bonds in the quinone have an $n$ topo of $1.45-1.50$, while those that correspond to single bonds in the quinone are weaker $\left(n_{\text {topo }}\right.$ of $\left.1.07-1.16\right)$. Two symmetry-equivalent $\mathrm{C}-\mathrm{O}$ bonds have $n_{\text {topo }}$ of approximately 1.5 , which is higher than in compound $\mathbf{1}$; however, the electron density at the critical point is somewhat lower, $c a .2 .7 \mathrm{e} \AA^{-3}$, which is consistent with longer bond lengths of about $1.25 \AA$ (Tables S3 and S4). Delocalization index of these $\mathrm{C}-\mathrm{O}$ bonds is 1.26 , which lies between values for $\mathbf{1}$ and $\mathbf{3}$ (Table 1), as expected. The same trend is observed for the NBO bond orders. Such results indicate a partial delocalization of $\pi$-electrons, which is enhanced compared to the quinone $\mathbf{1}$, but still far from a full delocalization as in the hydroquinone 3 .

Electrostatic potential in the three compounds (Fig. 2) reveals pronounced differences: while in the hydroquinone 3, electrostatic potential around the carbon skeleton is quite uniform, in the quinone 1, the carbonyl $\mathrm{C}$ atoms are strongly electron-depleted (Fig. 2a). The same effect can be 
noticed in atomic charges (Tables S8-S11 in the Supporting Information). Electronic structure of semiquinone ring 2 lies between the two other compounds, however, the carbonyl $\mathrm{C}$ atom is still the most electron-depleted part of the molecule. The charge of the oxygen atom also shows an obvious trend: it takes the most negative value in quinone $\mathbf{1}$ while in the hydroquinone $\mathbf{3}$, the $\mathrm{OH}$ group actually has a total charge of -0.068 e (Tables S8 and S9 in the Supporting Information). Again, the charge of the oxygen atom in the semiquinone $\mathbf{2}$ is between the values for two other compounds. The lower charge of the oxygen atom in the radical anion 2 seems at first counterintuitive. However, we note that the negative charge in $\mathbf{2}$ is delocalized through the entire ring (Tables S10 and S11 in the Supporting Information, Fig. 2), contributing to the stability of the radical anion. The carbonyl carbon is much less electron-depleted in $\mathbf{2}$ than in the quinone $\mathbf{1}$ (Tables S8, S10 and S11 in the Supporting Information). On the other hand, the charges of the chlorine atoms in the radical anion $\mathbf{2}$ are much more negative than in the aromatic hydroquinone and in the quinone, with negative charges increased by more than 0.1 e (Tables S10 and S11 in the Supporting Information). This is an illustrative example of the inductive effect of the electronegative chlorine substituents. Therefore, we can conclude that the electron delocalization extends beyond the carbon skeleton into the $\mathrm{C}-\mathrm{O}$ bonds, and even to the substituents on the ring. Bond orders for the $\mathrm{C}-\mathrm{H}$ and $\mathrm{C}-\mathrm{Cl}$ bonds keep nearly constant values in all crystallographic systems, indicative that these bonds are not strongly affected by electron delocalization. 

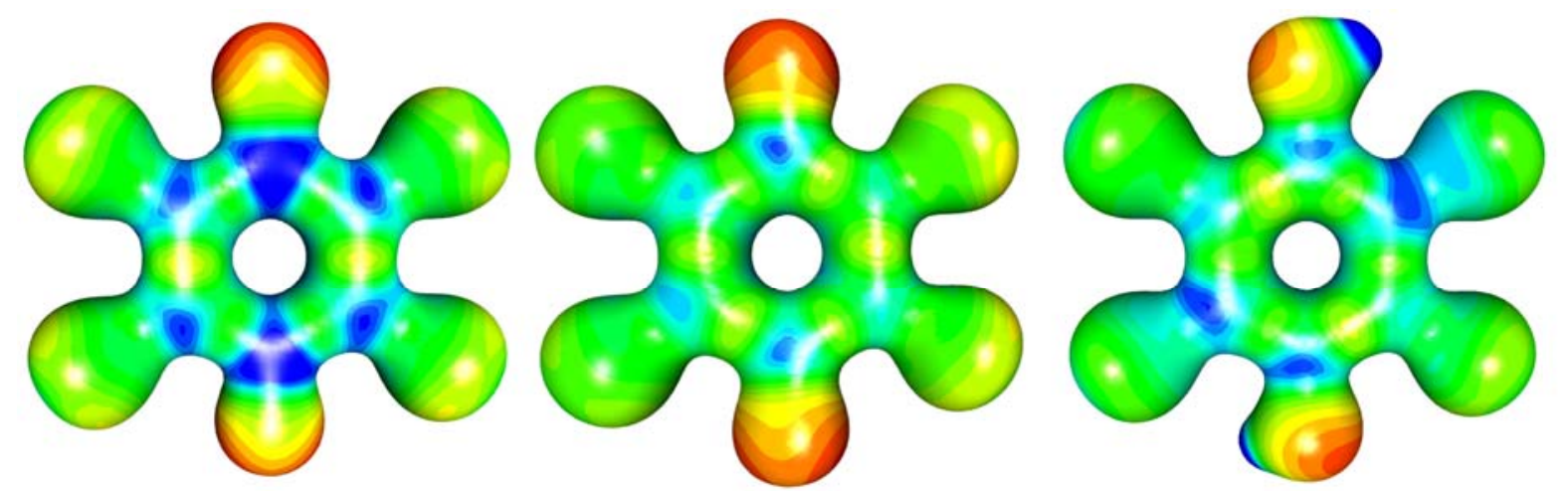

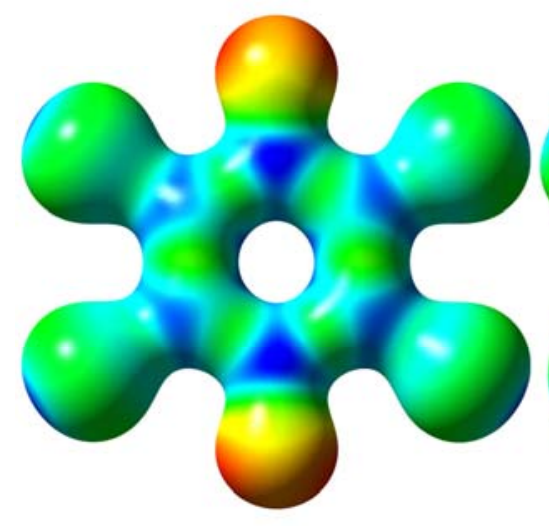

a)

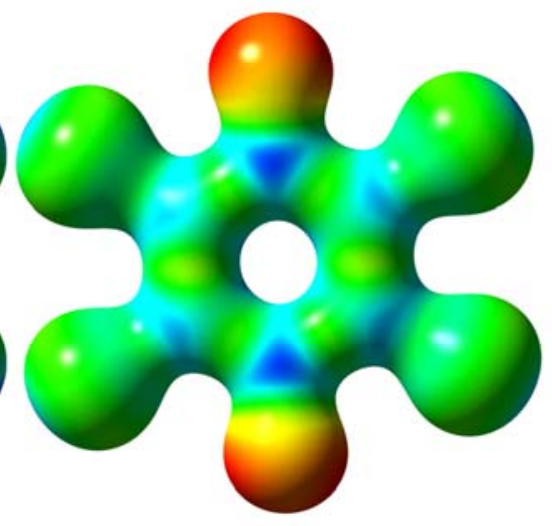

b)

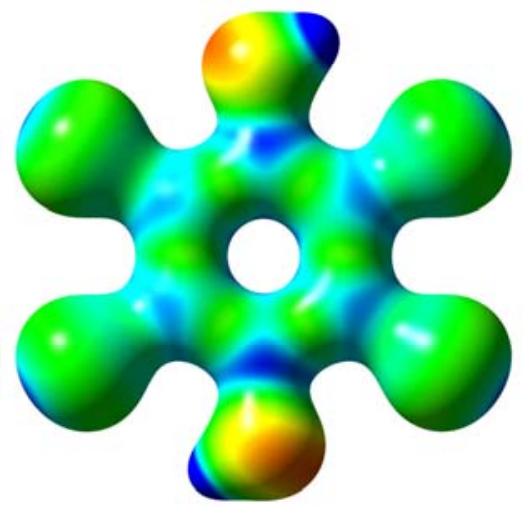

c)

Figure 2. Electrostatic potential plotted on an electron density isosurface of 0.5 e $\AA^{-3}$ of a) tetrachloroquinone $\mathbf{1}$, b) tetrachlorosemiquinone $\mathbf{2}$ from triclinic $\mathbf{2} \cdot N-\mathrm{MePy}$ and c) tetrachlorohydroquinone 3. Top row: experimental data (red: -0.1 , blue: $+1.0 \mathrm{e} / \AA^{-1}$ ), bottom row: DFT-calculated structures ( 1 - red: -0.28 , blue: +0.57 e $\AA^{-1} ; 2$ - red: -0.38 , blue: +0.38 e $\AA^{-1} ; 3$ : red: -0.38 , blue: +0.91 e $\left.\AA^{-1}\right)$.

We propose a set of aromaticity indices that share a common mathematical structure whose values depend on the used bond order definition. This model, called the $\beta_{X}$ index, is calculated as in equation (1). 


$$
\beta_{X}=\frac{1}{\sqrt{6}}\left[\sum_{i}^{6}\left(X_{i}-X_{r e f}\right)^{2}\right]^{1 / 2}
$$

$\mathrm{X}_{i}$ is the bond order value of the $i$ pair of atoms connected in the molecular ring of the studied system and $\mathrm{X}_{r e f}$ is the $\mathrm{C}-\mathrm{C}$ bond order of benzene computed for both given models (DI and NBO), using the same level of theory. The sum runs up to six because all molecules are six-membered rings and the normalization factor $\frac{1}{\sqrt{6}}$ is used to resemble a standard deviation. The $\beta_{X}$ index is defined in a similar way as previously used in term of the electron DI only ${ }^{[34]}$ and measures the amount of electron delocalization with respect to benzene (purely aromatic) in terms of the variations found for bond orders. Values of the $\beta_{X}$ indices calculated with B3LYP are shown in Table 2.

The highest values of $\beta_{X}$ are found for the neutral quinone 1 , which agrees with the alternation of single and double bonds of quinoid rings reported previously. The hydroquinone $\mathbf{3}$ has low $\beta_{X}$ values, which indicates its aromatic character. The semiquinone radicals in both polymorphs of 2 have intermediate values of $\beta_{X}$ between those of $\mathbf{1}$ and $\mathbf{3}$, which means that the semiquinone radical anion has partially delocalized $\pi$-electron system. These results are in agreement with our previous calculations of NICS and HOMA indices of tetrachloro- and tetrabromosemiquinone radical anions, which are also between aromatic and quinoid. ${ }^{[24]}$ Electronic structure of $N$-MePy cation fulfils the Hückel rule and therefore is expected to be aromatic, which is confirmed by the low values of $\beta_{X}$.

Table 1 Topological bond orders ( $n_{\text {topo }}$ ) of compounds $\mathbf{1}-\mathbf{3}$ derived from X-ray charge density (top row, bold), AIM delocalization indices (middle row) and NBO bond orders (bottom row, 
italic) calculated with B3LYP. Similar results were obtained with M06-2X (Supporting Information). *: Symmetry related atom.

\begin{tabular}{|c|c|c|c|c|}
\hline & 1 & 2 & 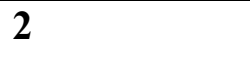 & 3 \\
\hline & & triclinic & orthorhombic & \\
\hline \multirow[t]{3}{*}{ C1-O1 } & 1.35 & 1.50 & 1.47 & 1.06 \\
\hline & 1.38 & 1.26 & 1.26 & 0.93 \\
\hline & 1.79 & 1.53 & 1.53 & 1.06 \\
\hline \multirow[t]{3}{*}{$\mathrm{C} 1-\mathrm{C} 2$} & 1.00 & 1.16 & 0.88 & 1.43 \\
\hline & 0.96 & 1.07 & 1.07 & 1.26 \\
\hline & 1.00 & 1.10 & 1.11 & 1.32 \\
\hline \multirow[t]{3}{*}{$\mathrm{C} 2-\mathrm{C} 3$} & 1.78 & 1.50 & 1.50 & 1.42 \\
\hline & 1.55 & 1.45 & 1.45 & 1.26 \\
\hline & 1.63 & 1.51 & 1.51 & 1.32 \\
\hline $\mathrm{C} 3-\mathrm{C} 1 *$ & 0.94 & 1.08 & 0.88 & 1.31 \\
\hline \multirow[t]{2}{*}{ / C3-C4 } & 0.96 & 1.07 & 1.07 & 1.30 \\
\hline & 1.00 & 1.10 & 1.10 & 1.34 \\
\hline \multirow[t]{3}{*}{$\mathrm{C} 4-\mathrm{C} 5$} & $1.00 *$ & 1.07 & $0.88^{*}$ & $1.43^{*}$ \\
\hline & $0.96^{*}$ & 1.07 & $1.07 *$ & $1.26^{*}$ \\
\hline & $1.00^{*}$ & 1.10 & $1.11^{*}$ & $1.32^{*}$ \\
\hline \multirow[t]{3}{*}{$\mathrm{C} 5-\mathrm{C} 6$} & $1.78^{*}$ & 1.45 & $1.50 *$ & $1.42^{*}$ \\
\hline & $1.55^{*}$ & 1.45 & $1.45^{*}$ & $1.26^{*}$ \\
\hline & $1.63^{*}$ & 1.51 & $1.51 *$ & $1.32^{*}$ \\
\hline \multirow[t]{3}{*}{$\mathrm{C} 6-\mathrm{C} 1 / \mathrm{C} 3 *_{-} \mathrm{C} 1$} & $0.94 *$ & 1.12 & $0.88 *$ & $1.31 *$ \\
\hline & $0.96^{*}$ & 1.07 & $1.07 *$ & $1.30^{*}$ \\
\hline & $1.00^{*}$ & 1.10 & $1.10^{*}$ & $1.34^{*}$ \\
\hline $\mathrm{C} 4-\mathrm{O} 2$ & $1.35^{*}$ & 1.47 & $1.50 *$ & $1.06 *$ \\
\hline
\end{tabular}




$\begin{array}{llll}1.38^{*} & 1.26 & 1.26^{*} & 0.93^{*} \\ 1.79 * & 1.53 & 1.53^{*} & 1.06^{*}\end{array}$

Table $2 \beta_{\mathrm{D}}$ and $\beta_{\mathrm{N}}$ delocalization discrepancy with benzene calculated with B3LYP for all $\mathrm{C}_{6}$ rings belonging to the molecules $\mathbf{1}-\mathbf{3}$ and pyridinium rings analysed in this paper. Similar results were obtained with M06-2X (Supplemental Information). $\beta_{D}$ and $\beta_{N}$ stand for the indices when applying equation (1) to the DI and NBO bond orders, respectively. The corresponding $\boldsymbol{X}_{\boldsymbol{r e f}}$ are 1.39 and 1.45 , respectively.

\begin{tabular}{lll}
\hline Molecule & $\beta_{\mathrm{D}}$ & $\beta_{\mathrm{N}}$ \\
\hline $\mathbf{1 ~} \mathrm{Cl}_{4} \mathrm{Q}$ & 0.36 & 0.38 \\
$\mathbf{2}\left(\mathrm{Cl}_{4} \mathrm{Q}^{-}\right)$, triclinic & 0.26 & 0.28 \\
$\mathbf{2}\left(\mathrm{Cl}_{4} \mathrm{Q}^{-}\right)$, orthorhombic & 0.26 & 0.28 \\
$\quad \mathrm{~N}-\mathrm{MePy}$, triclinic & 0.14 & 0.11 \\
$N$-MePy, orthorhombic & 0.14 & 0.11 \\
$\mathbf{3} \mathrm{H}_{2} \mathrm{Cl}{ }_{4} \mathrm{Q}$ & 0.12 & 0.12 \\
\hline
\end{tabular}

Stacking interaction exhibiting a partially covalent bonding (pancake bonding) in diamagnetic dimers of semiquinone rings

We have already noticed that, in diamagnetic structures, the semiquinone anion has a slightly bent, boat-like conformation with Cremer-Pople ${ }^{[44]}$ puckering parameter $\tau$ of $2.0-4.3^{\circ} \cdot{ }^{[24,28,29]}$ The anions in the dimer are actually bent towards each other, to minimize distance between the carbon atoms of the ring skeletons (Fig. 3), indicating very strong interactions within a dimer. Such a 
concave shape has been observed in dimers for a number of other organic radicals. ${ }^{[45-48]}$ In the antiferromagnetic structures, ${ }^{[29,30]}$ the radicals are essentially planar within the experimental error, or with minor chair-like distortion $\left(\tau<1.5^{\circ}\right)$.
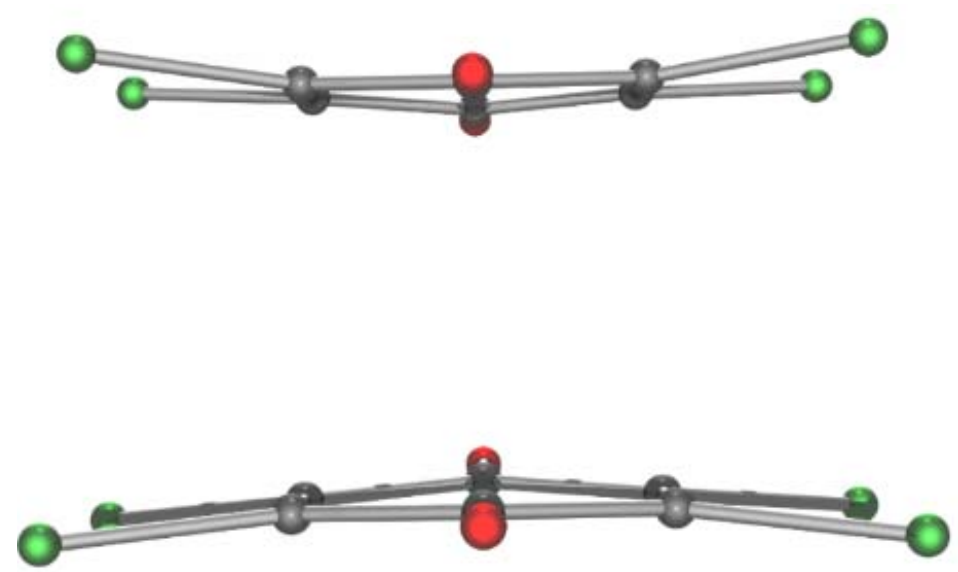

Figure 3 Side-view of a 'pancake-bonded' dimer of radicals in triclinic $\mathbf{2} \cdot N$-MePy viewed approximately along the $\mathrm{O}=\mathrm{C} \cdots \mathrm{C}=\mathrm{O}$ axis showing bent conformation of the rings.

Topological analysis of electron density of triclinic $\mathbf{2} \cdot N$-MePy revealed a profound difference between short intra-dimer and long inter-dimer contacts (Table 3). In the short intra-dimer contact, there are six bond paths and $(3,-1)$ saddle critical points between the rings: two $\mathrm{C} \cdots \mathrm{C}\left[\mathrm{C} 3{ }^{\cdots} \mathrm{C}^{i}\right.$ and $\mathrm{C} 5{ }^{\cdots} \mathrm{C} 3^{i}$; symmetry operator $\left.\left.i\right) 1-x, 2-y, 1-z\right]$, two $\mathrm{C} \cdots \mathrm{O}\left(\mathrm{C} 1 \cdots \mathrm{O} 2^{i}\right.$ and $\left.\mathrm{O} 2 \cdots \mathrm{C} 1^{i}\right)$ and two $\mathrm{Cl} \cdots \mathrm{Cl}$ $\left(\mathrm{Cl} 2 \cdots \mathrm{Cl}^{i}{ }^{i}\right.$ and $\left.\mathrm{Cl} 3{ }^{\cdots} \mathrm{Cl} 2^{i}\right)$, with maximum electron density exceeding 0.095 e $\AA^{-3}$ (Table $\mathrm{S} 14$ in the Supporting Information, Fig. 4). In addition, there are five $(3,+1)$ and two $(3,+3)$ critical points (Table S14 in the Supporting Information, Fig. 4), indicating that the short contacts between two radicals close a space in a form of a cage. Since spin coupling involves some orbital mixing, this type of contact has a partial covalent character and may be regarded as a two-electron multi-centre 
(2e/mc) bond. ${ }^{[45,49,50]}$ For this type of interaction, a colourful term has been proposed, pancake bonding. ${ }^{[45,49,50]}$

Between the dimers, there are only four $(3,-1)$ (corresponding to $\mathrm{C} \cdots \mathrm{Cl}$ contacts) and three $(3,+1)$ critical points; the maximum $\rho_{\text {cp }}$ electron density does not exceed 0.045 e $\AA^{-3}$ (Table S14 in the Supporting Information, Fig. 4). The inter-dimer interactions are therefore similar to ubiquitous stacking of aromatic rings.

Table 3 Geometric parameters of the cycles stacking. Symmetry operators: $(i)-x, 1-y,-z$ : (ii) $x$, $3 / 2-y, z ;($ iii) $1-x, 2-y, 1-z,($ iv) $-x, 2-y, 1-z,(v)-1-x, 1-y, 2-z,(v i) x, y,-1+z$.

\begin{tabular}{|c|c|c|c|c|c|c|c|c|}
\hline$\pi \cdots \pi$ & $\mathrm{Cg}^{\mathrm{a} \cdots \mathrm{Cg} / \AA}$ & $\alpha^{\mathrm{b}}$ & $\beta^{c}$ & $\delta^{\mathrm{d}}$ & $\varepsilon^{\mathrm{e}}$ & $\begin{array}{l}\mathrm{Cg}_{\mathrm{g}} \cdots \text { plane } \\
(\mathrm{Cg} 2) / \AA\end{array}$ & $\begin{array}{l}\text { Offset } \\
/ \AA\end{array}$ & $\begin{array}{l}\text { Symm } \\
\cdot \quad \text { op. } \\
\text { on } \\
\text { Cg2 }\end{array}$ \\
\hline $2 \cdot N-\mathrm{MePy}$ & triclinic & & & & & & & \\
\hline $\begin{array}{l}\mathrm{C} 1 \rightarrow \mathrm{C} 6 \cdots \mathrm{C} 1 \\
\rightarrow \mathrm{C} 6 \text { short }\end{array}$ & $3.5351(1)$ & 0 & 35.9 & 0 & 0 & $2.8642(4)$ & 2.072 & (iii) \\
\hline $\begin{array}{l}\mathrm{C} 1 \rightarrow \mathrm{C} 6 \cdots \mathrm{C} 1 \\
\rightarrow \mathrm{C} 6 \text { long }\end{array}$ & $4.5860(1)$ & 0 & 38.3 & 0 & 84.7 & $3.5993(4)$ & 2.842 & (iv) \\
\hline $\begin{array}{l}\mathrm{N} 1 \rightarrow \mathrm{C} 11 \cdots \mathrm{N} 1 \rightarrow \\
\mathrm{C} 11\end{array}$ & $3.5499(1)$ & 0 & 15.0 & - & - & $3.4295(4)$ & 0.917 & $(v)$ \\
\hline 2·N-MePy, & orthorhombic & & & & & & & \\
\hline $\begin{array}{l}\mathrm{C} 1 \rightarrow \mathrm{C}^{i} \cdots \mathrm{C} 1 \\
\rightarrow \mathrm{C} 3^{i}\end{array}$ & $3.7767(2)$ & 0 & 33.0 & 0 & 0 & $3.1675(1)$ & 2.057 & (vi) \\
\hline$\underset{i i}{\mathrm{~N} 1} \rightarrow \mathrm{C} 44^{i i} \cdots \mathrm{N} 1 \rightarrow \mathrm{C} 4$ & $3.7767(2)$ & 0 & 4.2 & - & - & $\begin{array}{l}3.7664(2 \\
)\end{array}$ & 0.279 & (vi) \\
\hline
\end{tabular}

\footnotetext{
${ }^{\mathrm{a}} \mathrm{Cg}=$ centre of gravity of the ring; ${ }^{\mathrm{b}} \alpha=$ angle between planes of two contiguous rings; ${ }^{\mathrm{c}} \beta=$ angle between $\mathrm{Cg} \cdots \mathrm{Cg}$ line and normal to the plane of the first ring; ${ }^{\mathrm{d}} \delta=$ angle between
} 
$\mathrm{O}=\mathrm{C} \cdots \mathrm{C}=\mathrm{O}$ axes of contiguous rings, as defined in ref. $29 ;{ }^{\mathrm{e}} \varepsilon=$ angle between direction of the offset and $\mathrm{O}=\mathrm{C} \cdots \mathrm{C}=\mathrm{O}$ axis, as defined in ref. 29 .

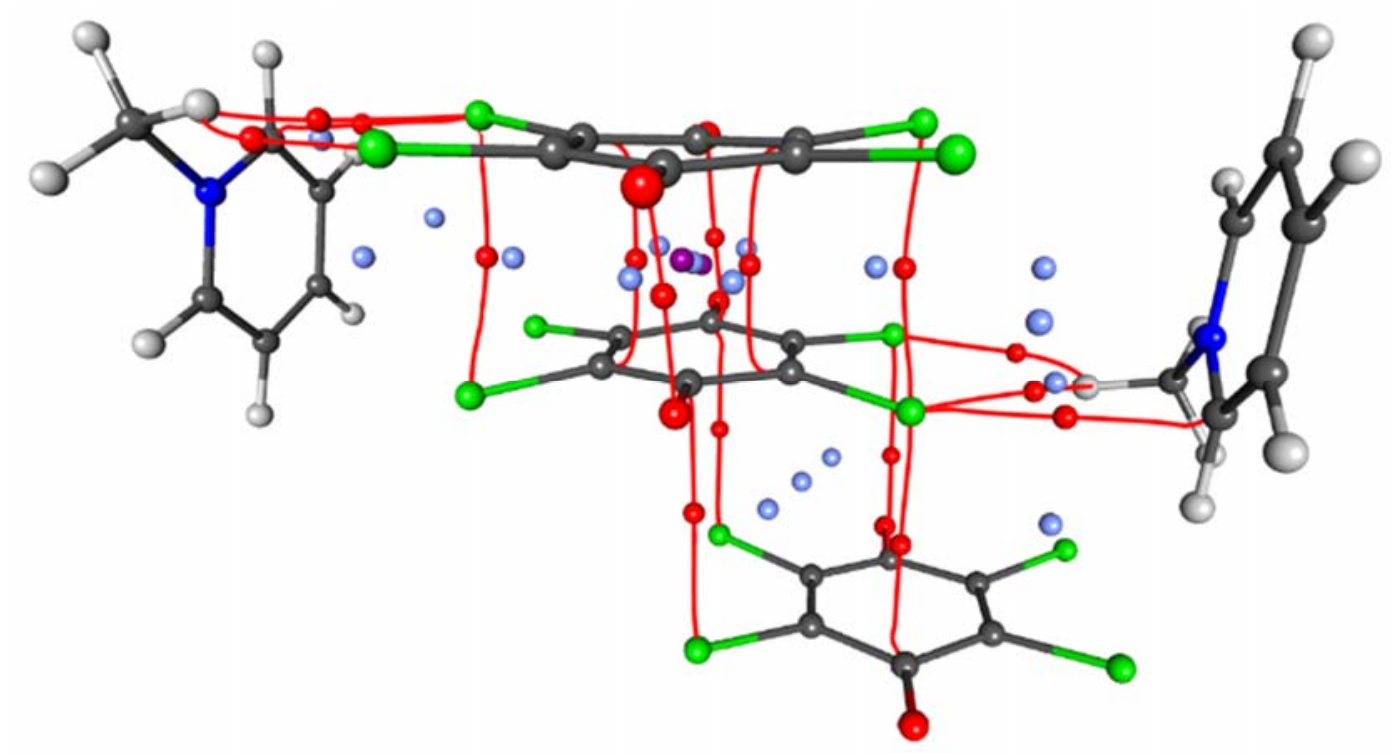

Figure 4 Critical points in triclinic polymorph of $2 \cdot N$-MePy. Close intra-dimer contact is on the top, and the longer inter-dimer contact is at the bottom; additional interactions between anions and cations are also shown. Critical points of $(3,-1)$ type, representing bonding contacts, are shown as red spheres, those of $(3,+1)$ type, representing ring centroids are light blue and those of $(3,+3)$ type, representing cage centroids are violet. Bond paths are shown as red lines.

Further insights into the nature of the $2 \mathrm{e} / \mathrm{mc}$ bonding within the triclinic $2 \cdot N$-MePy crystal are provided by quantum chemical calculations. The di-radical feature of this system can be observed in the spin density iso-surfaces (Figure 5) where it is noticed that $\alpha$ and $\beta$ spin populations are different for each semiquinone moiety. The two degenerate HOMOs and LUMOs of the dimer (Figures 6a and 7a), obtained from the Kohn-Sham orbitals, show strong characteristics of a 2e/mc bonding. ${ }^{[45]}$ In order to quantify the degree of electrons shared in the $2 \mathrm{e} / \mathrm{mc}$ bond, two 
intermolecular bond orders ( $I B O$ and $I B O^{\prime}$, respectively) were proposed. The former considers all the atoms of the semiquinone molecule and the latter only the carbon skeleton. Further details are described in the section Details and protocols of theoretical calculations. From the $I B O$ and $I B O^{\prime}$ values (Table 4) it can be concluded that only the intra-dimer contact exhibits properties distinctive of a $2 \mathrm{e} / \mathrm{mc}$ bond, i.e., interplanar distances shorter than $3.4 \AA$ and a non-negligible intermolecular electron delocalization. It is also inferred from the comparison of $I B O$ and $I B O^{\prime}$ that pancake bonding cannot be attributed only to carbon-carbon interactions since the contribution of the rest of the atoms is also relevant.

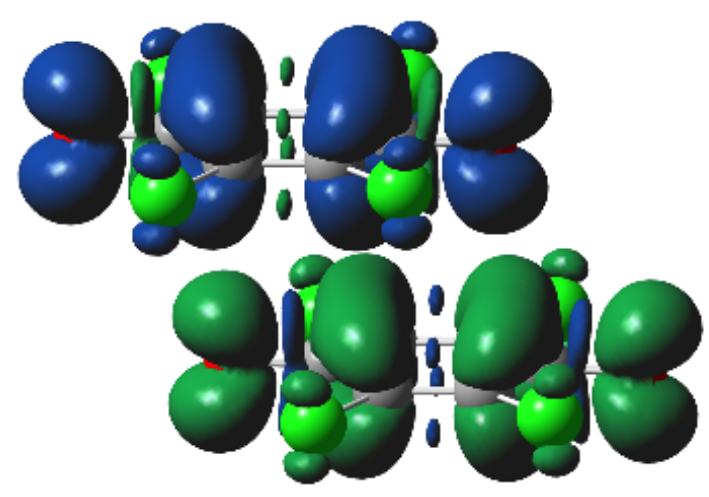

a)

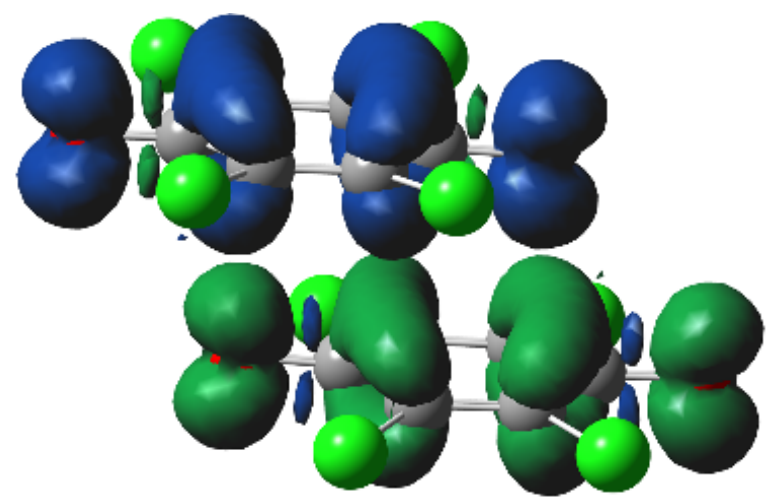

b)

Figure 5 Spin density maps of the semiquinone exhibiting pancake bonding in the a) orthorhombic $\mathbf{2} \cdot N$-MePy and b) triclinic $2 \cdot N$-MePy (isosurface $=0.001$ a.u.). 

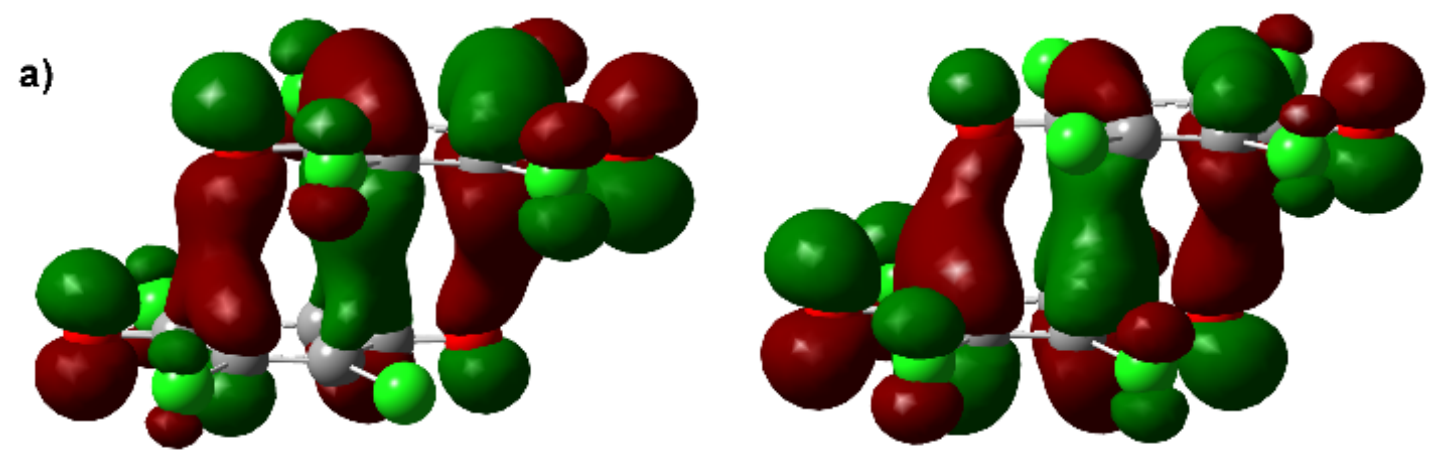

b)
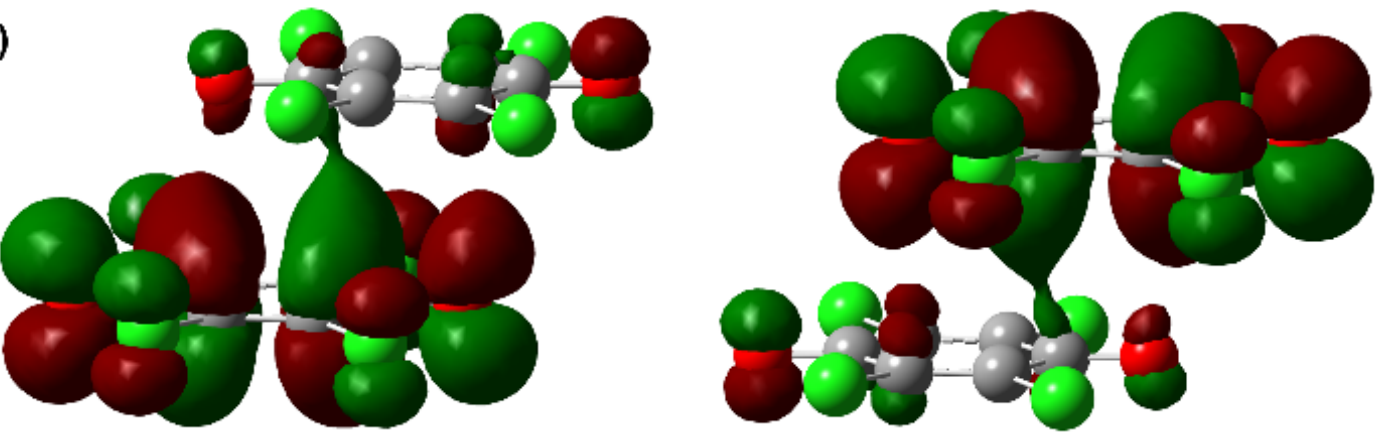

Figure 6 HOMOs of semiquinone in a) triclinic $2 \cdot N-\mathrm{MePy}$ and b) orthorhombic $2 \cdot N$-MePy. A lower degree of pancake bonding is observed for the latter system.

a)
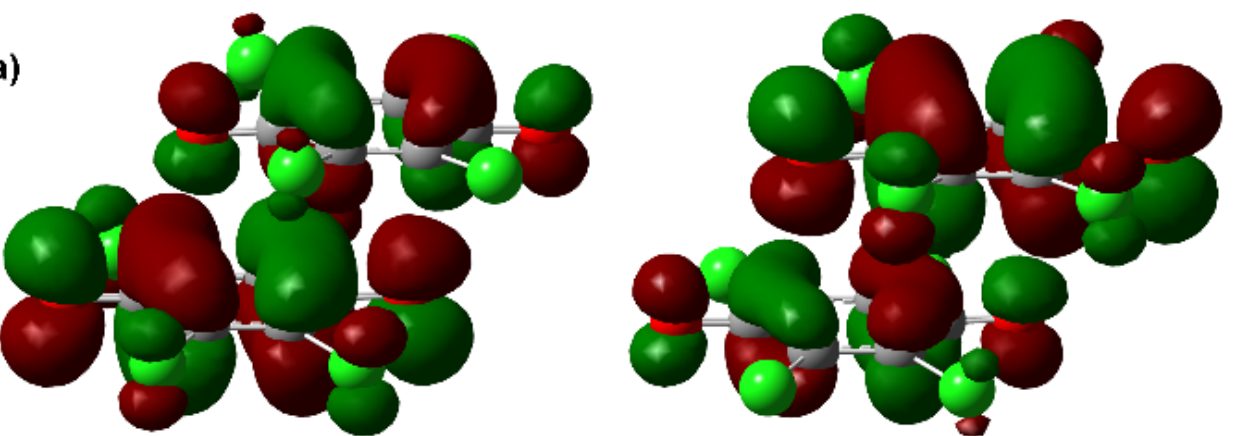

b)
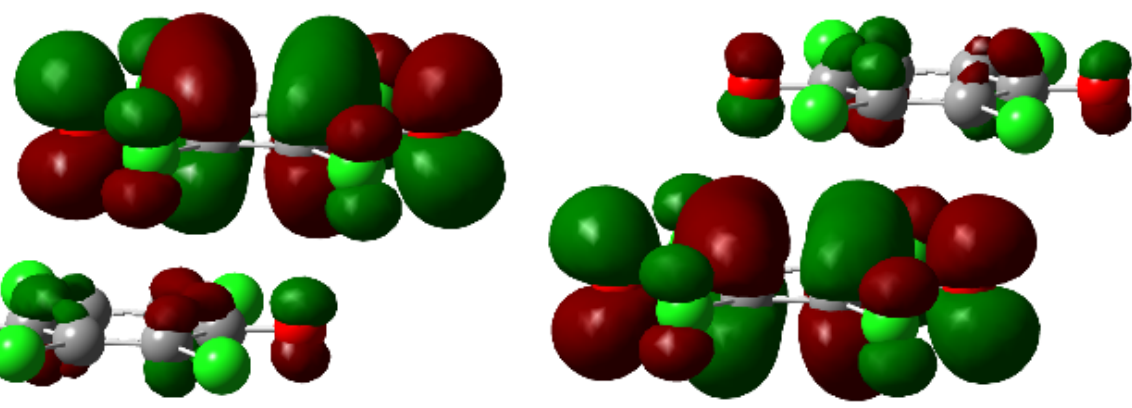
Figure 7 LUMOs of semiquinone in a) triclinic $2 \cdot N$-MePy and b) orthorhombic $2 \cdot N$-MePy. A lower degree of pancake bonding is observed for the latter system.

Table $4 I B O$ (top row) and $I B O^{\prime}$ (bottom row, italic) values for different contacts between the tetrachlorosemiquinone radicals.

\begin{tabular}{lll}
\hline interaction & $\begin{array}{l}\text { Delocalisation } \\
\text { index }\end{array}$ & Wiberg (NBO) \\
\hline $\mathbf{2} \cdot N$-MePy, orthorhombic & 0.89 & 0.26 \\
& 0.18 & 0.09 \\
$\mathbf{2} \cdot N$-MePy, triclinic & 1.61 & 0.80 \\
intra-dimer & 0.42 & 0.27 \\
$\mathbf{2} \cdot N$-MePy, triclinic & 0.43 & 0.04 \\
inter-dimer & 0.04 & 0.01 \\
\hline
\end{tabular}

Electrostatic potential (Fig. 8a) shows a good matching between electron-rich and electron-poor areas of two radicals in the intra dimer: the closest contacts $(2.86 \AA)$ are between the electron-rich oxygen and the electron-depleted carbonyl $\mathrm{C}$ atoms. Therefore, we can conclude that the "longitudinal" offset ${ }^{[37]}$ of $2.06 \AA$ which is commonly observed in stacked semiquinones, ${ }^{[24,28,30,34,36,37]}$ occurs because of electrostatic reasons (minimization of repulsion between the two charged anions), rather than steric ones. The short distance between the radicals is due to covalent $2 \mathrm{e} / \mathrm{mc}$ bonding. However, electron-rich and electron-poor areas of contiguous rings do not match in the long-distance contact between the dimers (Fig. 8b). We can conclude that the long distance and "lateral" offset ${ }^{[37]}$ are there to minimize both, electrostatic and steric repulsion. 
To quantify the effects of the geometrical arrays discussed above, the electrostatic interaction energy was calculated using the experimental electron density, along with an estimation based on the theoretical values of the PIXEL method, ${ }^{[51]}$ providing other intermolecular contributions including the polarization energy (Table 5). DFT calculated dimerization energies (DEs) support the PIXEL analysis. The electrostatic energies obtained from the experimental and theoretical sources differ from each other in part because in the former the fragment electron densities are perturbed by the rest of the system. Therefore, a fair comparison of the experimental values should be carried out with the sum of the theoretical electrostatic plus the polarization PIXEL energies. Such a comparison has been performed theoretically for highly polarized benzene-cation complexes $^{[52]}$ and it is supported by the data in Table 5. Even though the semiquinone radicals are closer in the intra-dimer contact and exchange repulsion is larger due to their proximity, the PIXEL electrostatic repulsion is $4 \mathrm{kcal} \mathrm{mol}^{-1}$ higher for the inter-dimer contact, which may be partially explained by the differences in the electrostatic potential complementarity discussed above. Moreover, the former array has stronger polarization and dispersion components which are of an attractive nature. Accordingly, the experimental electrostatic energy is $16 \mathrm{kcal} \mathrm{mol}^{-1}$ larger for the latter. Nevertheless, as mentioned before, the net interaction in both dimers is repulsive because of the predominance of electrostatic forces between charged moieties. In the actual crystal, the large Madelung energy keeps the radicals together.

To understand the stability of the triclinic $2 \cdot N-\mathrm{MePy}$ system, it has to be considered that these repulsions are balanced by the attractions with neighbouring cations. The total interaction energies for tetramers comprising a pair of stacked semiquinones and a pair of adjacent cations are decidedly attractive $\left(E_{\text {tot }}<-150 \mathrm{kcal} \mathrm{mol}^{-1}\right.$, see Supplement for details). These results are consistent with the lattice energy computed with PIXEL for this system, which is $-70.4 \mathrm{kcal} \mathrm{mol}^{-1}$ (Table S30 
in the Supplement). More than $50 \%$ of the attractive contributions to the lattice energy are of electrostatic nature, in contrast with the crystals of $\mathbf{1}$ and $\mathbf{3}$, where dispersion is the driving stabilizing component (See Figure S28 in the Supplement). The strong negative electrostatic lattice energy computed from the experimental electron density corroborates this conclusion (Table 5). In addition, a pancake bonding contribution to the interaction energy can be approximated as the

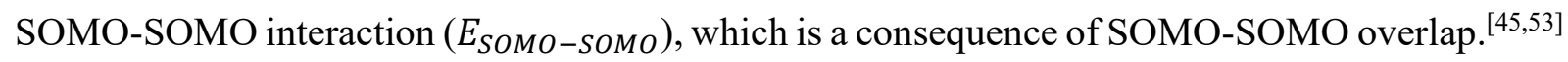
This component is evaluated to be $E_{\text {SOMO-SOMO }}=E_{D E}^{L}-E_{D E}^{H}$, where $E_{D E}^{L}$ and $E_{D E}^{H}$ stand for the dimerization energies calculated with low and high spin, respectively, which correspond to singlet and triplet states. This contributes with $-9.4 \mathrm{kcal} \mathrm{mol}^{-1}$ to the intra-dimer stabilization. Interestingly, if this value is added to the PIXEL dimerization energy, the outcome is closer to the DFT interaction energy ( -46.2 and $-45.1 \mathrm{kcal} \mathrm{mol}^{-1}$, correspondingly). These results suggest that the interaction energies for the stacked semiquinone radicals can be approximated as $E_{\text {int }}=$

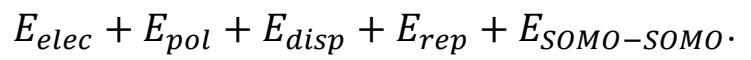

Table 5 Experimental electrostatic dimerization (Elec,exp) and lattice energies (Elec,lattice) calculated from the multipole refinement, B3LYP-D3(BJ)/def2-QZVP and PIXEL dimerization energies of the intra- and inter-dimer contacts of the triclinic $2 \cdot N-\mathrm{MePy}$ and of the antiferromagnetic dimer of the orthorhombic $\mathbf{2} \cdot N$-MePy. PIXEL contributions to the DEs correspond to electrostatic (Elec), polarization $(\mathrm{Pol})$, dispersion (Disp) and repulsion (Rep) terms. All values in $\mathrm{kcal} \mathrm{mol}^{-1}$.

\begin{tabular}{lllllllll}
\hline & Elec & $\begin{array}{l}\text { Elec } \\
\text { lattice }\end{array}$ & DFT & PIXEL & & & & \\
& total & Elec & Pol & Disp & Rep \\
\hline intra-dimer & $\mathbf{+ 2 8 . 0}$ & $\mathbf{- 2 6 6}$ & $\mathbf{+ 4 5 . 1}$ & $\mathbf{+ 5 5 . 6}$ & +50.4 & -15.5 & -23.0 & +43.7
\end{tabular}




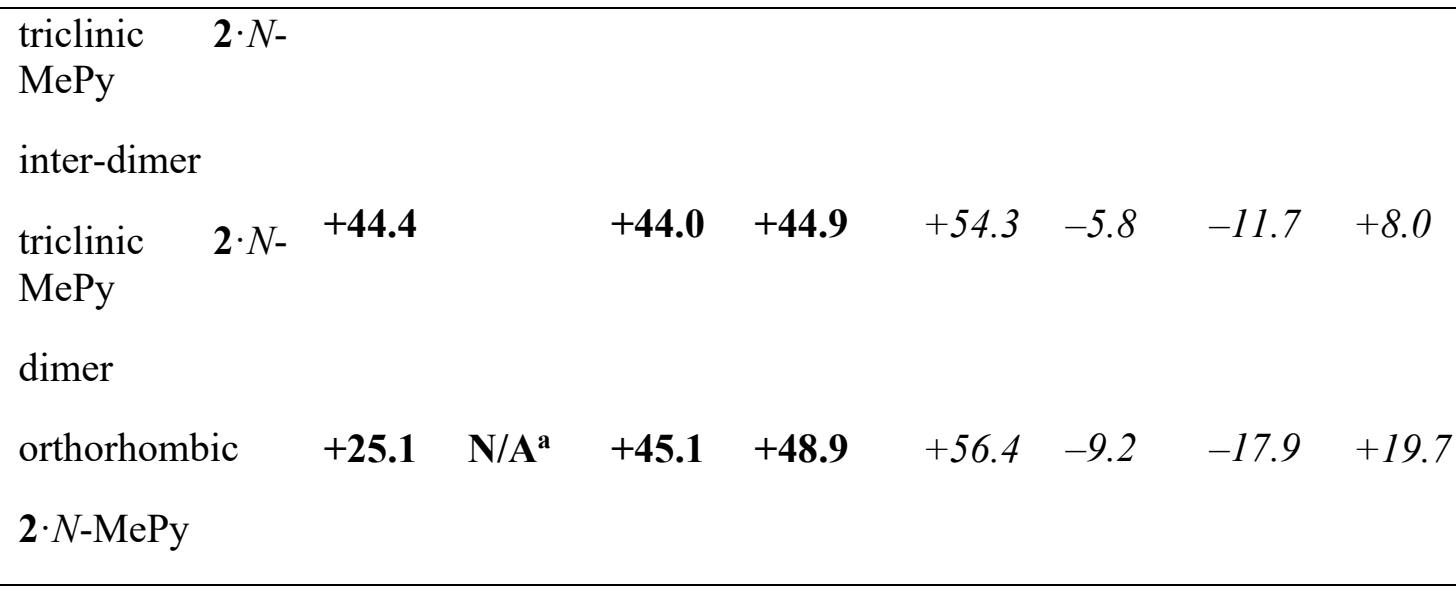

${ }^{a}$ Difficult to compute, due to a half of an anion and a half of a cation in asymmetric unit.
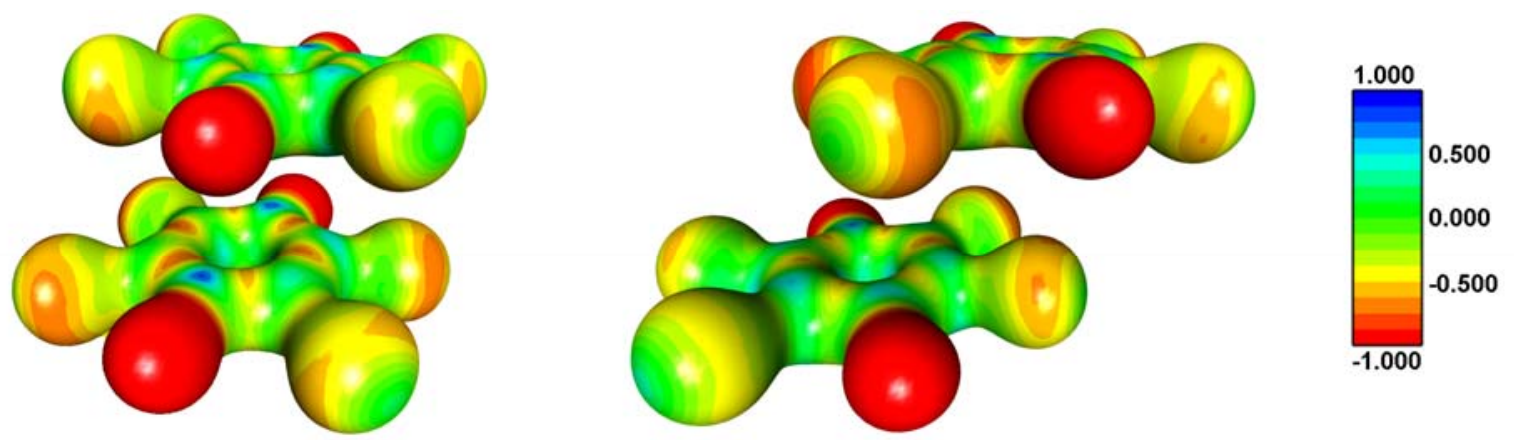

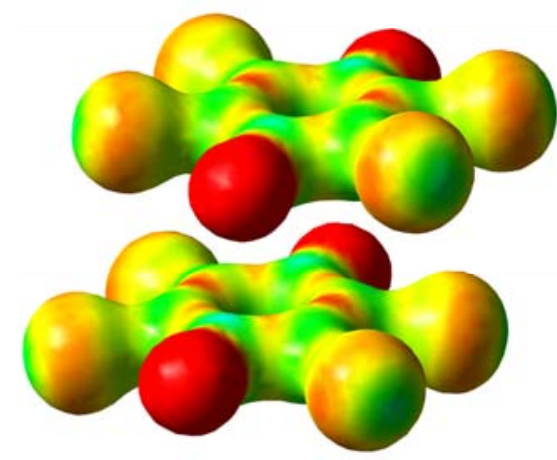

a)

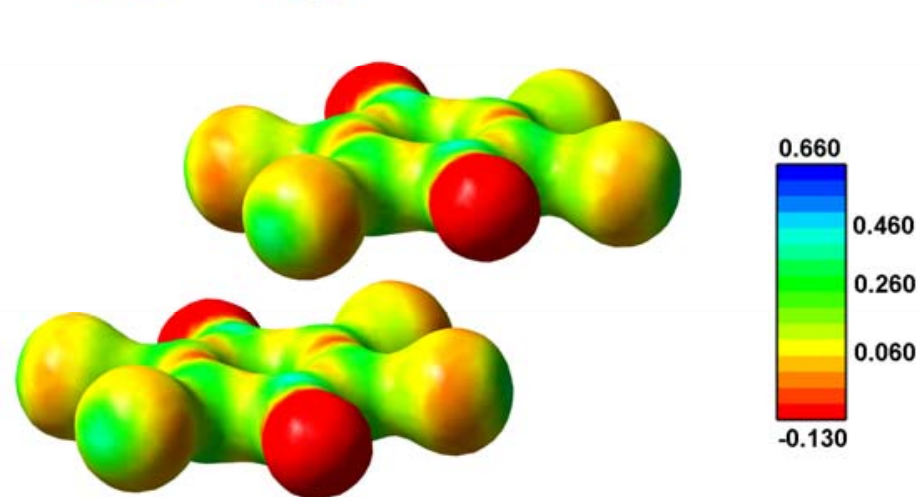

b)

Figure 8 Electrostatic potential between two tetrachlorosemiquinone radical anions in triclinic polymorph of $2 \cdot N$-MePy on an electron density iso-surface of 0.5 e $\AA^{-3}$ in a) close contact (intradimer) and b) long distance (inter-dimer); orientations of the rings are approximately the same as 
in the Fig. 4. Top row: experimental data (red: -0.1 , blue: +1.0 ), bottom row: DFT-calculated structures (red: -0.13 , blue: +0.66 e $\left.\AA^{-1}\right)$.

\section{Interactions between semiquinone rings in antiferromagnetic stacks of equidistant radicals}

Geometry of the stacking interactions in the orthorhombic $2 \cdot N$-MePy (Table 3 ) shows larger inter-planar distance than the intra-dimer contact in the triclinic polymorph, but nearly identical "longitudinal" offset (2.057 $\AA$ ). Electrostatic potential between two rings in the orthorhombic polymorph (Fig. 9) is also similar. The DFT DE and experimental electrostatic energies calculated for these systems are very similar to those of the intra-dimer contact of the triclinic crystal, although the PIXEL electrostatic contribution is smaller in the latter. (Table 5). However, there is considerably less electron density at the CPs between the rings than in the triclinic intra-dimer contact (Fig. 10 and Table S15 in the Supporting Information), and the maximum electron density does not exceed 0.048 e $\AA^{-3}$. Consequently, Pauli (steric) repulsion is likewise reduced. Also, there are five symmetry-independent $(3,-1)$ critical points (two $\mathrm{C} \cdots \mathrm{C}$, two $\mathrm{C} \cdots \mathrm{O}$ and one $\mathrm{C} \cdots \mathrm{Cl}$ ) and eight $(3,+1)$ critical points between two rings. A $(3,+3)$ local minimum is also present. This indicates that interactions between radicals in the antiferromagnetic stacks are considerably weaker than in diamagnetic dimer, in agreement with a less covalent $2 \mathrm{e} / \mathrm{mc}$ bonding, as can be seen in the HOMOs and LUMOS (Figures $6 \mathrm{~b}$ and $7 \mathrm{~b}$ ) and from the lower $I B O$ and $I B O^{\prime}$ values (Table 4).

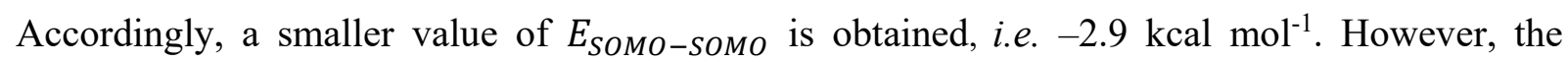
interactions are also much stronger than those between two diamagnetic dimers (along with a higher electron density), which explains the semiconductive properties of the antiferromagnetic crystals. ${ }^{[27]}$ As in the case of the model tetramers of the triclinic crystal, the interaction energies of some relevant tetramers for these systems $\left(E_{\mathrm{tot}}<-150 \mathrm{kcal} \mathrm{mol}^{-1}\right.$, see Supplement for details $)$ and 
the electrostatic lattice energies computed with the experimental electron density also yield favourable interactions.

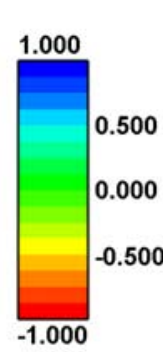

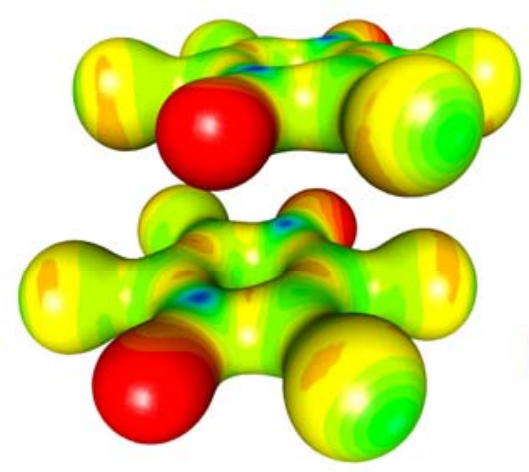

a)

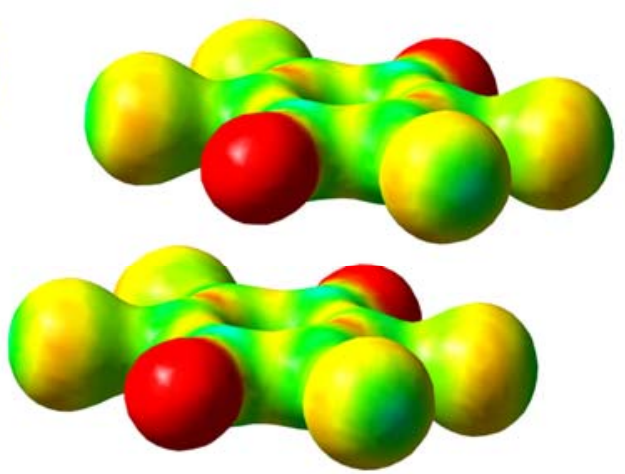

b)

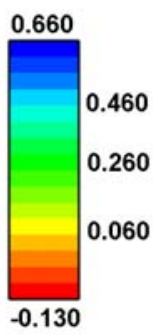

Figure 9 Electrostatic potential between two tetrachlorosemiquinone radical anions in the orthorhombic polymorph of $\mathbf{2} \cdot N-\mathrm{MePy}$ on an electron density iso-surface of $0.5 \mathrm{e} \AA^{-3}$ (0.074 a.u.). Orientations of the rings are approximately the same as in the Figs. 4 and 8. a) Experimental data (red: -0.1 , blue: +1.0$)$, b) DFT-calculated structures (red: -0.19 , blue: $+0.66 \mathrm{e} \AA^{-1}$ ). 


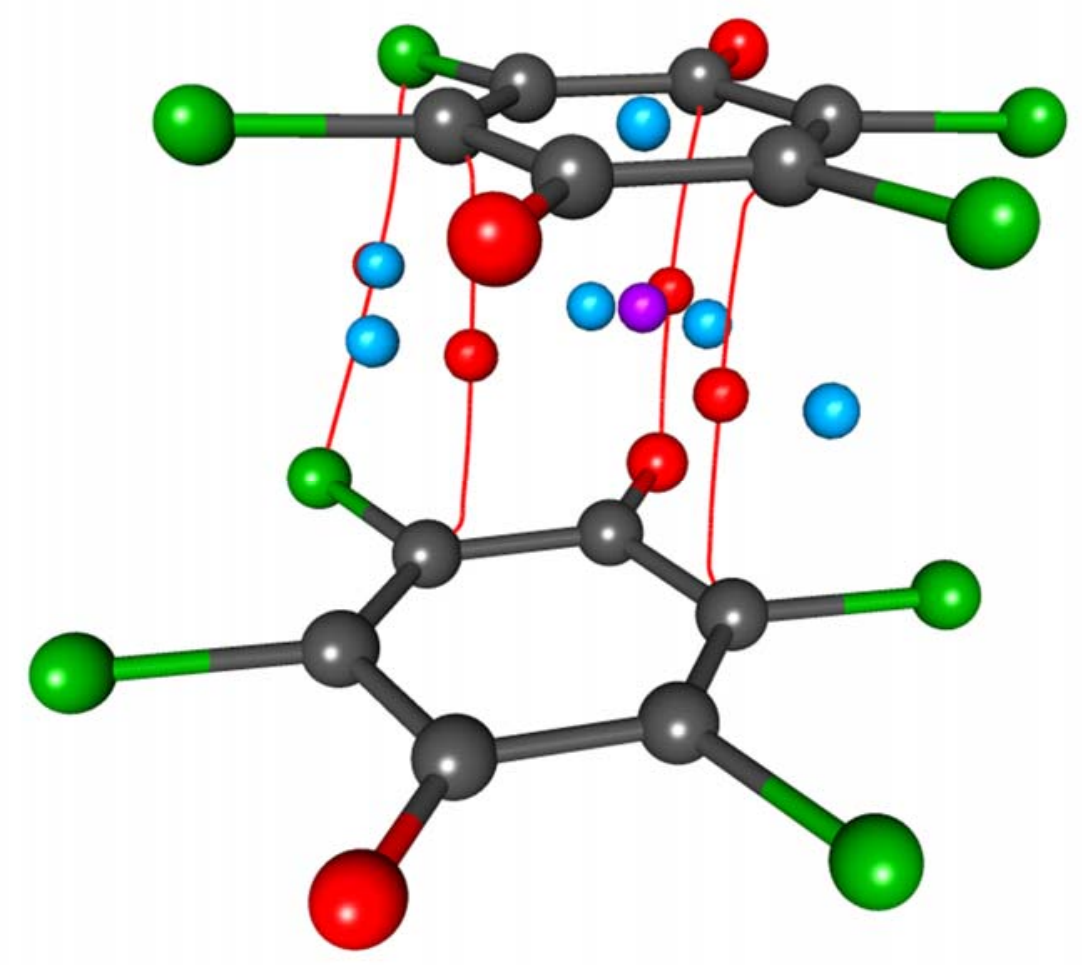

Figure 10 Critical points in orthorhombic polymorph of $\mathbf{2} \cdot N$-MePy. Critical points of $(3,-1)$ type, representing bonding contacts, are shown as red spheres, those of $(3,+1)$ type, representing ring centroids are light blue and those of $(3,+3)$ type, representing cage centroids are violet. Bond paths are shown as red lines.

In the diamagnetic dimers, the inter-planar distance is the shortest due to the covalent $2 \mathrm{e} / \mathrm{mc}$ bonding; apparently the interaction is significant enough to deform the molecule (Fig. 3). The C$\mathrm{Cl}$ bonds are bent outward in the dimer resulting in more distant chlorine atoms (angles between $\mathrm{C}_{6}$ plane and $\mathrm{C}-\mathrm{Cl}$ bonds are between 173.87 and $\left.176.14^{\circ}\right)$. The two $\mathrm{C}=\mathrm{O}$ bonds are less offplane with $\angle\left(\mathrm{C}_{6}\right.$ plane, $\left.\mathrm{C}=\mathrm{O}\right)=177.9$ and $179.6^{\circ}$. The stack of equidistant radicals has a minor intermolecular covalent component, so the inter-planar separations are larger. 
Conductivity of the radical stacks therefore also depends on spin coupling, since a substantial accumulation of electron density in contiguous rings is required for electron transfer. Our previous study of two polymorphs of $\mathbf{2} \cdot \mathrm{N}-\mathrm{MePy}{ }^{[27]}$ clearly illustrates this. In the case of antiferromagnetic stacks in orthorhombic $2 \cdot N-\mathrm{MePy}$, the electron clouds overlap throughout the entire complex so the crystals are decent semiconductors $\left(\sigma \approx 10^{-6} \mathrm{~S} \mathrm{~cm}^{-1}\right) \cdot{ }^{[27]}$ In the triclinic $2 \cdot N$ MePy crystal, there is negligible overlap between the dimers, leading to very poor conductivity beyond the instruments' measurement range (i.e. they are insulators with $\sigma<10^{-12} \mathrm{~S} \mathrm{~cm}^{-1}$ ). ${ }^{[27]}$

\section{CONCLUSIONS}

Parallel X-ray and quantum chemical charge density studies of analogous tetrachloro-substituted quinoid (1), semiquinoid (2) and aromatic hydroquinone (3) rings revealed the nature of delocalization of $\pi$-electrons and the negative charge in the semiquinone radical. The electronic structure of the radical is approximately half way between the quinoid and aromatic with partially delocalized $\pi$-electrons and $\mathrm{C}-\mathrm{O}$ bond orders of $c a .1 .5$ (theoretical values are 1.25). Induction effect of the chlorine substituents, enhancing delocalization of the negative charge and thus stabilizing the radical anion has been quantitatively assessed: in the radical $\mathbf{2}$ the chlorine atoms are more negatively charged than those in the neutral tetrachloroquinone $\mathbf{1}$ and hydroquinone $\mathbf{3}$ by approximately -0.1 e.

Subtle differences in intermolecular stacking interactions between the radicals leading to different electrical and magnetic properties have also been determined. In the case of spin coupling, close contacts and significant accumulation of electron density between contiguous rings have been observed: intra-dimer electron density in the triclinic $2 \cdot N-\mathrm{MePy}$ (diamagnetic) exceeds 0.095 e $\AA^{-3}$, and the interaction can be considered as covalent $2 \mathrm{e} / \mathrm{mc}$ "pancake bonding", with a bond 
order of 0.80 . In the antiferromagnetic stacks of orthorhombic $2 \cdot N$-MePy crystal, the $\rho_{\mathrm{BCP}}$ electron density between the rings is close to 0.05 e $\AA^{-3}$ and $(3,-1)$ critical points are found between the rings. This interaction, with a bond order of 0.26 can still be considered as a weak "pancake bond". In both cases, nearly identical "longitudinal" offset (i.e. along the $\mathrm{O}=\mathrm{C} \cdots \mathrm{C}=\mathrm{O}$ axis ${ }^{[29,37]}$ ) of about $2.06 \AA$ was found, and such arrangement decreases the electrostatic repulsion between the rings. In the case of long-distance inter-dimer contacts in triclinic $\mathbf{2} \cdot \mathrm{N}$-MePy crystal, very low electron density between the rings was found (the bond order of 0.04 is negligible) and the "lateral" offset (i.e. normal to the $\mathrm{O}=\mathrm{C} \cdots \mathrm{C}=\mathrm{O}$ axis ${ }^{[29,37]}$ ) of $2.84 \AA$ minimizes electrostatic and steric repulsion.

Considering all these findings, we conclude that besides dispersion and polarization, the weak covalent contribution is an important factor determining the inter-planar separation in the semiquinone radical stacks, particularly for the bent diamagnetic dimers. However, the offset (shift normal to the inter-planar separation) is determined by intermolecular electrostatic potential, in such a way to minimize electrostatic repulsion by allowing contacts between electron-rich and electron-poor areas of the molecules and, at the same time, lower steric repulsion. The net stacking interaction is repulsive in all cases because of the anionic nature of the semiquinone radicals. With regard to the lattice energies of the studied systems, polarization has only a small contribution and, contrary to what is obtained for other molecular solids like those of $\mathbf{1}$ and $\mathbf{3}$, dispersion, although not negligible, has a minor stabilizing role in the semiquinoid polymorphs. The most relevant attractive forces in these crystals are those between the semiquinone anions and the pyridinium cations.

The partial covalent character of the interaction, extending infinitely in the direction of cycle stacking can also explain the semiconductivity of the polymorph comprising the equidistant stacks of 2. $^{[27,54]}$ 


\section{EXPERIMENTAL}

Tetrachloroquinone and tetrachlorohydroquinone were purchased form commercial sources (Sigma-Aldrich, p.a. purity) and were recrystallized from acetone and ethanol, respectively (Kemika, Zagreb, p.a. purity). $\mathrm{N}-\mathrm{MePy} \cdot \mathrm{Cl} 4 \mathrm{Q}$ was prepared according to a previously reported procedure. $^{[27]}$

\section{$X$-ray diffraction and multipolar refinement}

X-ray diffraction measurements for $\mathbf{3}$ was performed on a Bruker D8 Venture diffractometer at $100(2) \mathrm{K}$ using $\mathrm{MoK \alpha}$ radiation, to the maximum resolution of $0.50 \AA$. The frames were integrated with the Bruker SAINT ${ }^{[55]}$ software package using a narrow-frame algorithm. Data were corrected for absorption effects using the multi-scan method (SADABS). ${ }^{[56]}$ The multiple integrated reflections were averaged for the space group $P 2{ }_{1} / c$ using SORTAV ${ }^{[57]}$ adapted to area detector data.

Single crystals of $\mathbf{1}$ and orthorhombic $\mathbf{2} \cdot N$-MePy were measured on an Oxford Rigaku XtaLAB Synergy diffractometer with a HyPix 6000HE detector at 104(2) and 100.01(11) K, respectively, using MoKa radiation, to the maximum resolution of $0.45 \AA$. Data reduction and absorption correction were done by CrysAlis PRO program package. ${ }^{[58]}$

Single crystal of triclinic $2 \cdot \mathrm{N}-\mathrm{MePy}$ was measured on a Rigaku MHF007 rotating anode diffractometer with a Pilatus 200K hybrid pixel detector at 100(2) K using MoKa radiation, to the maximum resolution of $0.45 \AA$. Data reduction and absorption correction were done by CrysAlis PRO program package. ${ }^{[58]}$ 
Spherical-atom model was refined using SHELXL-97;[59] atomic coordinates were taken from the room-temperature structures. ${ }^{[27,60,61]}$ Multipolar refinements were carried out $v s$. all reflections $F^{2}$ with program package MoPro; ${ }^{[62]}$ for triclinic and orthorhombic $2 \cdot N$-MePy up to $s=1.1 \AA^{-1}$ and for $\mathbf{1}$ and $\mathbf{3}$ up to $s=1.0 \AA^{-1}$. Chlorine atoms were modelled as hexadecapoles, $\mathrm{O}, \mathrm{N}$ and $\mathrm{C}$ as octupoles and hydrogens as dipoles; loose restraints were used for multipoles and kappas of chemically equivalent atoms. In 1 Kappa 2 values for $\mathrm{Cl}$ and $\mathrm{O}$ atoms were restrained to $0.90(5)$ and 1.00(1), respectively. Vibrations of chlorine atoms were refined as anharmonic using thirdorder Gram-Charlier coefficients. Anisotropic parameters for hydrogen atoms were calculated by the SHADE3 server ${ }^{[63]}$ and kept fixed in the multipolar atom refinement; O-H distances were restrained to $1.083(2) \AA$, aromatic C-H to $1.077(2) \AA$ and methyl C-H to $1.083(2) \AA$. Geometry and charge-density calculations were performed by MoPro; ${ }^{[62]}$ molecular graphic were prepared using MoProViewer ${ }^{[64]}$ and ORTEP-3. ${ }^{[65]}$ Crystallographic and refinement data are shown in Table 6.

Topological bond orders were calculated using the fitted formula ${ }^{[66]}$

$$
n_{\mathrm{topo}}=a+b \lambda_{3}+c\left(\lambda_{1}+\lambda_{2}\right)+d \rho_{\mathrm{cp}}
$$

Coefficients $a, b, c$ and $d$ were taken from the literature: for C-C bonds $a=-0.522, b=-1.695, c$ $=0.00, d=8.473 ;{ }^{[38]}$ for C-O bonds $a=-0.427, b=-0.240, c=0.280, d=6,464 ;{ }^{[67]}$ for C-N bonds $a=-0.284, b=0.331, c=0.559, d=6.569 ;^{[38]}$ for C-H bonds $a=-0.153, b=0.481, c=0.983, d=$ 8.087. ${ }^{[68]}$

Atomic charges are often unreliable to be calculated and depend moreover on the charge definition. ${ }^{[69]}$ An estimation of atomic charges uncertainty can be computed according to the sample standard deviation method described in Fournier et al. ${ }^{[70]}$ 
Table 6 Crystallographic, data collection and charge-density refinement details.

\begin{tabular}{|c|c|c|c|c|}
\hline Compound & 1 & $\begin{array}{l}\mathbf{2} \cdot N \text {-MePy, } \\
\text { orthorhombic }\end{array}$ & $\begin{array}{l}2 \cdot N-\mathrm{MePy} \\
\text { triclinic }\end{array}$ & 3 \\
\hline Empirical formula & $\mathrm{C}_{6} \mathrm{Cl}_{4} \mathrm{O}_{2}$ & $\mathrm{C}_{12} \mathrm{H}_{8} \mathrm{Cl}_{4} \mathrm{NO}_{2}$ & $\mathrm{C}_{12} \mathrm{H}_{8} \mathrm{Cl}_{4} \mathrm{NO}_{2}$ & $\mathrm{C}_{6} \mathrm{H}_{2} \mathrm{Cl}_{4} \mathrm{O}_{2}$ \\
\hline Formula wt. / $\mathrm{g} \mathrm{mol}^{-}$ & 245.87 & 339.99 & 339.99 & 247.88 \\
\hline $\begin{array}{l}\text { Crystal dimensions / } \\
\mathrm{mm}\end{array}$ & $\begin{array}{l}0.235 \mathrm{x} 0.152 \mathrm{x} \\
0.020\end{array}$ & $\begin{array}{llll}0.15 & \mathrm{x} & 0.05 & \mathrm{x} \\
0.05 & & & \end{array}$ & $\begin{array}{llll}0.20 & \mathrm{x} & 0.20 & \mathrm{x} \\
0.15 & & & \end{array}$ & $\begin{array}{l}0.270 \mathrm{x} 0.162 \mathrm{x} \\
0.078\end{array}$ \\
\hline Space group & $P 2{ }_{1} / c$ & P bnm & $P \overline{1}$ & $P 2{ }_{1} / n$ \\
\hline$a / \AA$ & $8.5324(1)$ & $3.77667(2)$ & $7.28708(7)$ & $8.23940(10)$ \\
\hline$b / \AA$ & $5.6636(1)$ & $18.07885(13)$ & $9.22296(8)$ & $4.7740(8)$ \\
\hline$c / \AA$ & $8.6598(1)$ & $18.60034(12)$ & $10.37403(11)$ & $10.366(2)$ \\
\hline$\alpha /{ }^{\circ}$ & 90 & 90 & $73.4641(8)$ & 90 \\
\hline$\beta /{ }^{\circ}$ & $105.909(1)$ & 90 & $72.9593(9)$ & $97.803(8)$ \\
\hline$\gamma /{ }^{\circ}$ & 90 & 90 & $75.6428(8)$ & 90 \\
\hline Z & 2 & 4 & 2 & 4 \\
\hline$V / \AA^{3}$ & $402.449(7)$ & $1269.990(15)$ & $628.660(14)$ & $403.97(10)$ \\
\hline$D_{\text {calc }} / \mathrm{g} \mathrm{cm}^{-3}$ & 2.030 & 1.779 & 1.797 & 2.039 \\
\hline$\mu / \mathrm{mm}^{-1}$ & 1.414 & 0.924 & 0.935 & 1.410 \\
\hline$\Theta$ range $/{ }^{\circ}$ & $4.35-45.36$ & $2.25-59.88$ & $2.34-51.43$ & $2.97-45.29$ \\
\hline$T / \mathrm{K}$ & $104(5)$ & $100.01(11)$ & $90(2)$ & $100(2)$ \\
\hline $\begin{array}{l}\text { Radiation } \\
\text { wavelength }\end{array}$ & $0.71073(\mathrm{MoK} \alpha)$ & $0.71073(\mathrm{MoK \alpha})$ & $0.71073(\mathrm{MoK} \alpha)$ & $0.71073(\operatorname{MoK} \alpha)$ \\
\hline Diffractometer type & XtaLAB Synergy & $\begin{array}{l}\text { XtaLAB } \\
\text { Synergy }\end{array}$ & Rigaku MHF007 & $\begin{array}{l}\text { Bruker } \\
\text { Venture }\end{array}$ \\
\hline Range of $h, k, l$ & $\begin{array}{l}-17<h<16 \\
-11<k<10\end{array}$ & $\begin{array}{l}-9<h<9 \\
-45<k<45\end{array}$ & $\begin{array}{l}-15<h<16 \\
-19<k<20\end{array}$ & $\begin{array}{l}-14<h<16 \\
-9<k<9\end{array}$ \\
\hline
\end{tabular}




$\begin{array}{lllll} & -16<l<17 & -46<l<46 & 0<l<22 & -20<l<19 \\ \begin{array}{l}\text { Reflections } \\ \text { collected }\end{array} & 29532 & 167330 & 18843 & 42112 \\ \begin{array}{l}\text { Independent } \\ \text { reflections }\end{array} & 3367 & 5290 & 13587 & 9408 \\ \begin{array}{l}\text { Reflections with } I \geq \\ 2 \sigma\end{array} & 3215 & 4787 & 12572 & 7838 \\ \begin{array}{l}\text { Absorption } \\ \text { correction }\end{array} & \text { Analytical } & \text { Analytical } & \text { Analytical } & \text { Analytical } \\ T_{\min , T_{\max }} & 0.424,1.000 & 0.774,1.212 & 0.967,1.000 & 0.702,0.898 \\ R_{\text {int }} & 0.0166 & 0.0365 & 0.0199 & 0.0446\end{array}$

Spherical

refinement

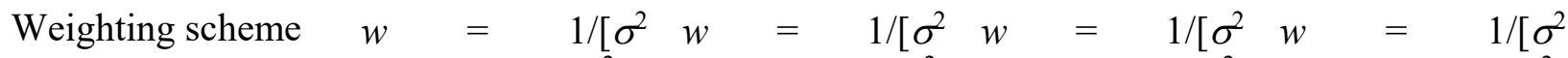
$\begin{array}{llll}\left(F_{o} 2\right)+(0.032 P)^{2}+ & \left(F_{o}\right)+(0.059 P)^{2} & \left(F_{o} 2\right)+(1.000 P)^{2} & \left(F_{o} 2\right)+(0.0265 P)^{2}\end{array}$ $0.1825 P]$ where $P+0.205 P]$ where $+0.6731 P]+0.0915 P]$ where $=\left(F_{o}^{2}+2 F_{c}^{2}\right) / 3 \quad P=\left(F_{o}^{2}+2 F_{c}^{2}\right) / 3$ where $P=P=\left(F_{o}^{2}+2 F_{c}^{2}\right) / 3$

$\begin{array}{lllll}R(F) & 0.0423 & 0.0279 & 0.0191 & 0.0267\end{array}$

$\begin{array}{lllll}R_{w}\left(F^{2}\right) & 0.983 & 0.0923 & 0.0697 & 0.0619\end{array}$

$\begin{array}{lllll}\text { Goodness of fit } & 1.050 & 0.861 & 0.369 & 1.049\end{array}$

$\mathrm{H}$ atom treatment none restrained, mixed, isotropic restrained, isotropic isotropic

$\begin{array}{llll}\text { No. of parameters } & 55 & 104 & 204\end{array}$

$\begin{array}{lllll}\text { No. of restraints } & 0 & 0 & 0 & 0\end{array}$

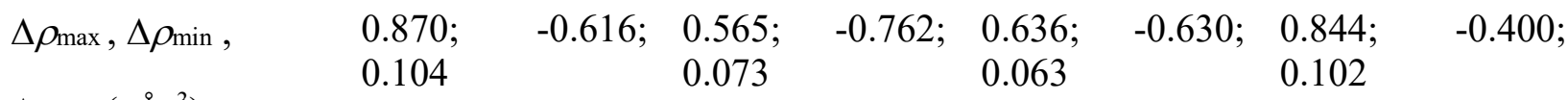

$\Delta \rho_{\mathrm{rms}}\left(\mathrm{e} \AA^{-3}\right)$

Multipolar

refinement

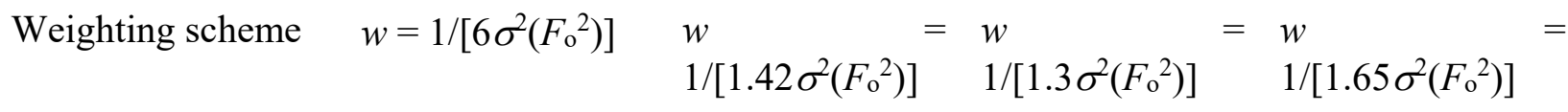

$\begin{array}{lllll}R(F) & 0.0174 & 0.0164 & 0.0101 & 0.0195\end{array}$ 


\begin{tabular}{|c|c|c|c|c|c|c|c|c|}
\hline$R_{w}\left(F^{2}\right)$ & 0.0289 & & \multicolumn{2}{|l|}{0.0175} & \multicolumn{2}{|l|}{0.0216} & \multicolumn{2}{|l|}{0.0246} \\
\hline Goodness of fit & 0.981 & & \multicolumn{2}{|l|}{0.918} & \multicolumn{2}{|l|}{0.986} & \multicolumn{2}{|l|}{0.928} \\
\hline $\mathrm{H}$ atom treatment & none & & \multicolumn{2}{|c|}{$\begin{array}{l}\text { restrained, } \\
\text { anisotropic }\end{array}$} & \multicolumn{2}{|c|}{$\begin{array}{l}\text { restrained, } \\
\text { anisotropic }\end{array}$} & \multicolumn{2}{|c|}{$\begin{array}{l}\text { restrained, } \\
\text { anisotropic }\end{array}$} \\
\hline No. of parameters & 232 & & 463 & & 830 & & 254 & \\
\hline No. of restraints & 64 & & 53 & & 144 & & 100 & \\
\hline $\begin{array}{l}\Delta \rho_{\max }, \Delta \rho_{\min } \\
\Delta \rho_{\mathrm{rms}}\left(\mathrm{e}^{-3}\right)\end{array}$ & $\begin{array}{l}0.451 \\
0.045\end{array}$ & -0.241 & $\begin{array}{l}0.202 \\
0.030\end{array}$ & -0.314 & $\begin{array}{l}0.228 \\
0.028\end{array}$ & -0.219 & $\begin{array}{l}0.576 \\
0.107\end{array}$ & -0.565 \\
\hline
\end{tabular}

\section{Details and protocols of quantum chemical computation}

Single point calculations on the experimental geometry of the monomers and some representative arrays taken from both polymorphs were performed at the B3LYP-D3(BJ)/def2QZVPP level of theory with Gaussian $09 .{ }^{[71]}$ Dimerization energies (DEs) were computed as the energy difference between the dimer (homo or hetero) and two monomers. The advantage of using this basis set is that BSSE error is minimized, hence this correction was not included in the DFT DE values. The same methodology was applied for the calculation of interaction energies of some relevant tetramers. The semiquinone dimers behave as open-shell di-radicals and thus require a broken symmetry treatment for an appropriate description at this level of approximation. The complexes in the triplet excited state dimers were also calculated to guarantee that the lowest energy electronic state was studied; furthermore, the stability test for the open shell diradical calculation was also carried out. The multi-configurational character of the open-shell diradicals was also corroborated by CASPT2 computations for the closest contact dimers of the orthorhombic and triclinic systems using an active space of $10 \pi$-electrons in 10 orbitals and a CASSCF wavefunction as reference, along with the Cholesky decomposition for the evaluation of the two- 
electron integrals. ${ }^{[72]}$ The CASPT2 calculations were done using Molcas. ${ }^{[73]}$ See the Supplement for further details. In the orthorhombic and triclinic polymorphs of $2 \cdot N-\mathrm{MePy}$, tetrachlorosemiquinone and $\mathrm{N}$-methylpyridium moieties were treated as anions and cations, respectively, because of the ionic character of these molecular crystals.

The bond orders (BO) of all non-equivalent pairs of atoms in each molecule in the $\mathrm{Cl}_{4} \mathrm{Q}(\mathbf{1})$, the orthorhombic and triclinic polymorphs of $\mathrm{N}$-MePy $\cdot \mathrm{Cl}_{4} \mathrm{Q}(\mathbf{2} \cdot \mathrm{N}-\mathrm{MePy})$ and $\mathrm{H}_{2} \mathrm{Cl}_{4} \mathrm{Q}$ (3) were calculated using: $i$ ) the delocalization indices defined by the Bader space partition (QTAIM) ${ }^{[39]}$ and $i$ ) the Wiberg indices based on the Natural Atomic Orbitals (NAO) analysis. ${ }^{[0,41]}$ Delocalization and Wiberg indices were calculated with AIMALL ${ }^{[74]}$ and Gaussian 09, ${ }^{[71]}$ respectively. In addition, the Mayer ${ }^{[75]}$ and Fuzzy ${ }^{[76]}$ bond orders calculated with Multiwfn ${ }^{[77]}$ (provided as Supporting Information) were also used, yielding in most cases a similar description of the chemical bond as with the delocalization and Wiberg indices. Intermolecular bond orders $(I B O)$ were computed as:

$$
I B O=\sum_{i \in A}^{N} \sum_{j \in B}^{N} B O_{i j}
$$

where $B O_{i j}$ are the bond orders between the $i^{\text {th }}$ and the $j^{\text {th }}$ atoms, belonging to $A$ and $B$ molecules, respectively. In the current case, $N=12$, i.e., all the atoms of the semiquinone monomers are considered. Analogously, we define

$$
I B O^{\prime}=\sum_{i \in A}^{M} \sum_{j \in B}^{M} B O_{i j}
$$

where the sums run over bonded carbon atoms only $(M=6)$. Delocalization index and Wiberg bond order in the Natural Atomic Orbitals (NAO) basis were used for the computations of $B O_{i j}$. 
The PIXEL method, ${ }^{[51]}$ which allows the evaluation of interaction energies from isolated molecular electron densities of two or more systems, was employed to determine the dissociation energies (DEs) as well as lattice energies (LEs) of three crystalline structures with the PIXEL-CLP program package ${ }^{[78]}$ (this requires complete molecules in order to obtain meaningful results). While the crystalline symmetry of the $\mathrm{Cl}_{4} \mathrm{Q}(\mathbf{1})$ and $\mathrm{H}_{2} \mathrm{Cl}_{4} \mathrm{Q}$ (3) systems can be reduced so as to get complete molecules, this procedure was not affordable for orthorhombic $\mathbf{2} \cdot N$-MePy because tetrachlorosemiquinone radical and $\mathrm{N}$-methylpiridinium ions are located at different special positions - i.e., an inversion centre and a mirror plane, respectively). DE and LE can be decomposed into electrostatic, polarization, dispersion and repulsion (Pauli) terms (Table S30 in Supporting Information). Since Pauli repulsion is modelled in PIXEL as proportional to the intermolecular overlap, it could be related to steric repulsion. Molecular electron densities were obtained from MP2/6-31G** calculations for this approximation, employing Gaussian 09. ${ }^{[71]}$

Atomic charges of the quinone, semiquionones and hydroquinone molecules obtained from the multipole refinement and QTAIM using the DFT molecular orbitals of the monomers are reported in Tables S8 - S11 in the Supporting Information. To analyse the effect of intermolecular interactions, the QTAIM atomic charges were also analysed for the heterodimers. Discrepancies are found between the DFT monomer and the dimeric atomic charges because of the difference in chemical environments.

\section{ASSOCIATED CONTENT}

(Word Style “TE_Supporting_Information”). Supporting Information. Details on refinement and residual density (residual density plots, XDRK plots), details on molecular structure (deformation density maps and electrostatic potentials, details on topology of electron density, atomic charges, 
topology of intermolecular interactions), details on quantum chemical calculations. This material is available free of charge via the Internet at http://pubs.acs.org.

\section{AUTHOR INFORMATION}

\section{Corresponding Author}

*(Word Style "FA_Corresponding_Author_Footnote"). * (Word Style

"FA_Corresponding_Author_Footnote"). KM: Department of Physical Chemistry, Rudjer Bošković Institute, Bijenička 54, HR-10000 Zagreb, Croatia, e-mail: kmolcano@irb.hr ; CJ: Cristallographie, Résonance Magnetique et Modélisations, UMR 7036, Institut Jean Barriol, CNRS and Université de Lorraine BP 70239, F54506 Vandoeuvre-les-Nancy CEDEX, France, email: christian.jelsch@univ-lorraine.fr.

\section{Present Addresses}

$\dagger$ If an author's address is different than the one given in the affiliation line, this information may be included here.

\section{Author Contributions}

The manuscript was written through contributions of all authors. All authors have given approval to the final version of the manuscript.

\section{Funding Sources}

The work was financed by the Croatian Science Foundation, grant no. IP-2014-09-4079 and French-Croatian bilateral - Hubert Curien grant for years 2015-2016. We thank Gobierno de España MINECO (CTQ2014-56295-R and Severo Ochoa Excellence Accreditation 2014-2018 SEV-2013-031), FEDER funds (Project CTQ2014-56295-R) and the CERCA Programme/Generalitat de Catalunya are acknowledge for funding. B. Landeros-Rivera and J. 
Hernández-Trujillo thank DGTIC-UNAM for supercomputer resources (project LANCAD-

UNAM-DGTIC-103) and financial support from PAIP Facultad de Química UNAM (grant 50009004).

\section{Notes}

Any additional relevant notes should be placed here.

\section{ACKNOWLEDGMENT}

The work was financed by the Croatian Science Foundation, grant no. IP-2014-09-4079 and French-Croatian bilateral - Hubert Curien grant for years 2015-2016. We thank Gobierno de España MINECO (CTQ2014-56295-R and Severo Ochoa Excellence Accreditation 2014-2018 SEV-2013-031), FEDER funds (Project CTQ2014-56295-R) and the CERCA Programme/Generalitat de Catalunya are acknowledge for funding. B. Landeros-Rivera and J. Hernández-Trujillo thank DGTIC-UNAM for supercomputer resources (project LANCADUNAM-DGTIC-103) and financial support from PAIP Facultad de Química UNAM (grant 5000-9004). Dr. Fraser White and dr. Jakub Wojciehowski from Rigaku Oxford Diffraction Ltd. are gratefully acknowledged for diffraction measurements on the state-of-the-art diffractometer XtaLAB Synergy-S.

\section{ABBREVIATIONS}

$\mathrm{Cl}_{4} \mathrm{Q}$, tetrachloroquinone (chloranil); $\mathrm{Cl}_{4} \mathrm{Q}^{-}$, tetrachlorosemiquinone radical anion; $\mathrm{H}_{2} \mathrm{Cl}_{4} \mathrm{Q}$, tetrachlorohydroquinone, $N$-MePy, $N$-methylpyridinium cation; HOMA, harmonic oscillator model of aromaticity; NICS, nucleus-independent chemical shift; QTAIM, quantum theory of atoms-in-molecules; $\mathrm{BO}$, bond order; IBO, intermolecular bond order. 


\section{REFERENCES}

(Word Style “TF_References_Section"). References are placed at the end of the manuscript. Authors are responsible for the accuracy and completeness of all references. Examples of the recommended format for the various reference types can be found at http://pubs.acs.org/page/4authors/index.html. Detailed information on reference style can be found in The ACS Style Guide, available from Oxford Press.

[1] Sies, H.; Packer, L. Eds., Methods in Enzymology: Quinones and Quinone Enzymes, Part B, Vol. 382, Academic Press, London, 2004.

[2] Price, E. R.; Johnson, S. C. Eds., Quinones: Occurence, medicinal uses and physiological importance, Nova Science Publishers, New York, 2013.

[3] Chapman, H. N. ; Fromme, P.; Barty, A.; White, T. A.; Kirian, R. A.; Aquila, A.; Hunter, M. Femtosecond X-ray protein nanocrystallography, Nature, 2011, 470, 73-77.

[4] Buryanovsky, Y. Fu.; Zhang, L. Crystal structure of quinone reductase 2 in complex with cancer prodrug CB1954, Biochem. Biophys. Res. Commun., 2005, 336, 332-338.

[5] Bottow, J. L.; Dunlop, T. Formation and Biological Targets of Quinones: Cytotoxic versus Cytoprotective Effects, Chem. Res. Toxicol., 2017, 30, 13-37.

[6] Dias, G. G.; King, A.; de Moliner, F.; Vendrell, M.; da Silva Junior, E. N. Quinone-based fluorophores for imaging biological processes, Chem. Soc. Rev., 2018, 47, $12-27$.

[7] Ganesan, V.; Rosokha, S. V.; Kochi, J. K. J. Am. Chem. Soc., 2003 125, 2559-2571. 
[8] Ramnial, T.; Taylor, S. A.; Clyburne, J. A. C.; Walsby, C. J. Isolation of the Latent Precursor Complex in Electron-Transfer Dynamics. Intermolecular Association and SelfExchange with Acceptor Anion Radicals, Chem. Commun., 2007, 2066-2068.

[9] Alemany, P.; Canadell, E.; Geng, Y.; Hauser, J.; Macchi, P.; Krämer, K.; Decurtins, S.; Liu, S.-X. Exploring the Electronic Structure of an Organic Semiconductor Based on a Compactly Fused Electron Donor-Acceptor Molecule, ChemPhysChem, 2015, 16, 1361-1365.

[10] Yu, X.; Mailman, A.; Dube, P. A.; Assoud, A.; Oakley, R. T. The first semiquinonebridged bisdithiazolyl radical conductor: a canted antiferromagnet displaying a spin-flop transition, Chem. Commun., 2011, 47, 4655-4657.

[11] Yu, X.; Mailman, A.; Lekin, K.; Assoud, A.; Robertson, C. M.; Noll, B. C.; Campana, C. F.; Howard, J. A. K.; Dube, P. A.; Oakley, R. T. Semiquinone-Bridged Bisdithiazolyl Radicals as Neutral Radical Conductors, J. Am. Chem. Soc., 2012, 134, 2264-2275.

[12] Horiuchi, S.; Kumai, R.; Tokura, Y. Hydrogen-bonded donor-acceptor compounds for organic ferroelectric materials, Chem. Commun., 2007, 2321-2329.

[13] Giovannetti, G.; Kumar, S.; Stroppa, A.; van den Brink, J.; Picozzi, S. Multiferroicity in TTF-CA Organic Molecular Crystals Predicted through Ab Initio Calculations, Phys. Rev. Lett., 2009, 103, 266401.

[14] Ding, Y.; Yu, G. A Bio-Inspired, Heavy-Metal-Free, Dual-Electrolyte Liquid Battery towards Sustainable Energy Storage, Angew. Chem., Int. Ed., 2016, 55, 4772-4776.

[15] Kim, K. C. Design Strategies for Promising Organic Positive Electrodes in Lithium-Ion Batteries: Quinones and Carbon Materials, Ind. Eng. Chem. Res., 2017, 56, 12009-12023. 
[16] Guo, Q.; Corbett, J. T.; Yue, G.; Fann, Y. C.; Qian, S. Y.; Tomer, K. B.; Mason, R. P. Electron Spin Resonance Investigation of Semiquinone Radicals Formed from the Reaction of Ubiquinone 0 with Human Oxyhemoglobin, J. Biol. Chem., 2002, 277, 6104-6110.

[17] Reece, S. Y. ; Nocera, D. G. Proton-Coupled Electron Transfer in Biology: Results from Synergistic Studies in Natural and Model Systems, Annu. Rev. Biochem., 2009, 78, 673-699.

[18] Kopka, B.; Magerl, K.; Savitsky, A.; Davari, M. D.; Röllen, K.; Bocola, M.; Dick, B.; Schwaneberg, B.; Jaeger, K.-E.; Krauss, U. Electron transfer pathways in a light, oxygen, voltage (LOV) protein devoid of the photoactive cysteine, Sci. Reports, 2017, 7, 13346.

[19] Postila, P. A.; Kaszuba, K.; Kuleta, P.; Vattulainen, I.; Sarewicz, M.; Osyczka, A.; Róg, T. Atomistic determinants of co-enzyme Q reduction at the $\mathrm{Q}_{\mathrm{i}}$-site of the cytochrome $b c_{1}$ complex, Sci. Reports, 2016, 6, 33607.

[20] Boesch, S. E.; Wheeler, R. A. $\pi$-Donor Substituent Effects on Calculated Structures and Vibrational Frequencies of $p$-Benzoquinone, $p$-Fluoranil, and $p$-Chloranil, J. Phys. Chem., 1995, 99, 8125-8134.

[21] Katan, C.; Blöchl, P. E.; Margl, P.; Koenig, C. First-principles molecular-dynamics simulations for neutral $p$-chloranil and its radical anion, Phys. Rev. B, 1996, 53, 12112-12120.

[22] Boesch, S. E.; Wheeler, R. A. $\pi$-Donor Substituent Effects on Calculated Structures, Spin Properties, and Vibrations of Radical Anions of $p$-Chloranil, $p$-Fluoranil, and $p$-Benzoquinone, $J$. Phys. Chem. A, 1997, 101, 8351-8359. 
[23] O'Malley, P. J. Electronic Structure Studies of Quinones and Semiquinones: Accurate Calculation of Spin Densities and Electron Paramagnetic Resonance Parameters, Antioxidants \& Redox Signaling, 2001, 3, 825-838.

[24] Molčanov, K.; Kojić-Prodić, B.; Babić, D.; Žilić, B.; Rakvin, D. Stabilisation of tetrabromo- and tetrachlorosemiquinone (bromanil and chloranil) anion radicals in crystals, CrystEngComm, 2011, 13, 5170-5178.

[25] a) Kruszewski, J.; Krygowski, T. M. Definition of aromaticity basing on the harmonic oscillator model, Tetrahedron Lett., 1972, 13, 3839-3842; b) Ostrowski, S.; Dobrowolski, J. Cz. What does HOMA index really measure? RSCAdv, 2014, 4, 44158-44161.

[26] Schleyer, P. v. R.; Maerker, C.; Dransfeld, A.; Jiao, H.; Hommes, N. J. R. v. E. NucleusIndependent Chemical Shifts: A Simple and Efficient Aromaticity Probe, J. Am. Chem. Soc. 1996, $118,6317$.

[27] Molčanov, K.; Stilinović, V.; Šantić, A.; Maltar-Strmečki, N.; Pajić, D.; Kojić-Prodić, B. Fine tuning of $\pi$-stack separation distances of semiquinone radicals affects their magnetic and electric properties, Cryst. Growth Des., 2016, 16, 4777-4782.

[28] Molčanov, K.; Babić, D.; Kojić-Prodić, B.; Stare, J.; Maltar-Strmečki, N.; Androš, L. Spincoupling in dimer of 2,3-dicyano-5,6-dichlorosemiquinone radical anions characterised by ring separation distance of $2.81 \AA$, Acta Crystallogr. B, 2014, 70, 181-190.

[29] Molčanov, K.; Kojić-Prodić, B. Spin pairing, electrostatic and dipolar interactions shape stacking of radical anions in alkali salts of 4,5-dichloro-3,6-dioxocyclohexa-1,4-diene-1,2dicarbonitrile (DDQ), CrystEngComm, 2017, 19, 1801-1808. 
[30] Molčanov, K.; Kojić-Prodić, B.; Babić, D.; Pajić, D.; Novosel, N.; Zadro, K. Temperature induced magnetic bistability in a crystal of tetrachlorosemiquinone anion radical, CrystEngComm, 2012, 14, 7958-7964.

[31] Bader, S. D.; Parkin, S. S. P. Spintronics, Annu. Rev. Condens. Matter Phys., 2010, 1, 7188.

[32] Podzorov, V. Buliding molecules for a function, Nature Mater., 2010, 10, 616-617.

[33] Hicks, R. G. Switchable materials: A new spin on bistability, Nature Chem., 2011, 3, 189191.

[34] Lü, J.-M.; Rosokha, S. V.; Kochi, J. K. Stable (Long-Bonded) Dimers via the Quantitative Self-Association of Different Cationic, Anionic, and Uncharged $\pi$-Radicals: Structures, Energetics, and Optical Transitions, J. Am. Chem. Soc., 2003, 125, 12161-12171.

[35] Devic, T.; Yuan, M.; Adams, J.; Frederickson, D. C.; Lee, S.; Venkataraman, The Maximin Principle of $\pi$-Radical Packings, J. Am. Chem. Soc., 2005, 127, 14616-14627.

[36] Rosokha, S. V.; Kochi, J. K. Continuum of Outer- and Inner-Sphere Mechanisms for Organic Electron Transfer. Steric Modulation of the Precursor Complex in Paramagnetic (IonRadical) Self-Exchanges, J. Am. Chem. Soc., 2007, 129, 3683-3697.

[37] Rosokha, S. V.; Lu, J.; Rosokha, T. Y.; Kochi, J. K. Counter-ion modulation of longdistance $\pi$-bonding of the open-shell p-benzoquinone anions, Phys. Chem. Chem. Phys., 2009, 11, $324-332$.

[38] Howard, S. T.; Lamarche, O. Description of covalent bond orders using the charge density topology, J. Phys. Org. Chem., 2003, 16, 133-141. 
[39] Bader, R. F. W.; Stephens, M. E. Spatial localization of the electronic pair and number distributions in molecules, J. Am. Chem. Soc., 1975, 97, 7391-7399.

[40] Wiberg, K. B. Application of the pople-santry-segal CNDO method to the cyclopropylcarbinyl and cyclobutyl cation and to bicyclobutane, Tetrahedron, 1968, 24, 10831096.

[41] Foster, J. P.; Weinhold, F. Natural hybrid orbitals, J. Am. Chem. Soc., 1980, 102, 72117218.

[42] a) Chua, Z.; Zarychta, B.; Gianopoulos, C. G.; Zhurov, V. V.; Pinkerton, A. A. Revisiting the Charge Density Analysis of 2,5-Dichloro-1,4-Benzoquinone at $20 \mathrm{~K}$, Acta Cryst. B, 2017, B73, 654-659; b) Molčanov, K.; Mou, Z.; Kertesz, M.; Kojić-Prodić, B.; Stalke, D.; Demeshko, S.; Šantić, A.; Stilinović, V. Two-electron / multicentre - pancake bonding in $\boldsymbol{\pi}$-stacked trimers in a salt of tetrachloroquinone anion, Chem. Eur. J., 2018, 24, 8292-8297; c) Vuković, V.; Molčanov, K.; Jelsch, C.; Wenger, E.; Jurić, M.; Androš Dubraja, L.; Kojić-Prodić, B. Malleable electronic structure of chloranilic acid and its species determined by X-ray charge density studies, manuscript about to be submitted to Cryst. Growth Des.; d) Molčanov, K.; Jelsch, C.; Wenger, E.; Stare, J.; Madsen, A. Ø.; Kojić-Prodić, B. Experimental evidence of 3-centre, 2-electron covalent bond character of the central O-H-O fragment on the Zundel cation in crystals of Zundel nitranilate tetrahydrate, CrystEngComm, 2017, 19, 3898-3901.

[43] Estévez-Fregoso, M.; Hernández-Trujillo, J. Electron delocalization and electron density of small polycyclic aromatic hydrocarbons in singlet excited states, Phys. Chem. Chem. Phys., 2016, 18, 11792-11799. 
[44] Cremer, D.; Pople, J. A. General definition of ring puckering coordinates, J. Am. Chem. Soc., 1975, 97, 1354-1358.

[45] Cui, Z.-H.; Lischka, H.; Beneberu, H. T.; Kertesz, M. Double pancake bonds, J. Am. Chem. Soc., 2014, 136, 12958-12965.

[46] Mou, Z.; Uchida, K.; Kubo, T.; Kertesz, M. Evidence of $\sigma$ - and $\pi$-Dimerization in a Series of Phenalenyls, J. Am. Chem. Soc., 2014, 136, 18009-18022.

[47] Mou, Z.; Kertesz, M. Pancake Bond Orders of a Series of $\pi$-Stacked Triangulene Radicals, Angew. Chem. Int. Ed., 2017, 56, $10188-10191$.

[48] Cui, Z.-H.; Gupta, A.; Lischka, H.; Kertesz, M. Concave or convex $\pi$-dimers: the role of the pancake bond in substituted phenalenyl radical dimers, Phys. Chem. Chem. Phys., 2015, 17, 23963-23969.

[49] Beneberu, H. Z.; Tian, Y.-H.; Kertesz, M. Bonds or not bonds? Pancake bonding in 1,2,3,5dithiadiazolyl and 1,2,3,5-diselenadiazolyl radical dimers and their derivatives, Phys. Chem. Chem. Phys., 2012, 14, 10713-10725.

[50] Preuss, K. E. Pancake bonds: $\pi$-Stacked dimers of organic and light-atom radicals, Polyhedron, 2014, 79, 1-15.

[51] Gavezzotti, A. Non-conventional bonding between organic molecules. The 'halogen bond' in crystalline systems, Mol. Phys., 2008, 106, 1473-1485.

[52] Rocha-Rinza, T.; Hernández-Trujillo, J. The nature of benzene-cation interactions from the topology of the electron distribution, Chem. Phys. Lett., 2006, 422, 36-40. 
[53] Mota, F.; Miller, J. S.; Novoa, J. J. Study of the Diradicaloid Character in a Prototypical Pancake-Bonded Dimer: The Stacked Tetracyanoethylene (TCNE) Anion Dimer and the Neutral $\mathrm{K}_{2} \mathrm{TCNE}_{2}$ Complex, Chem. Phys. Chem., 2014, 15, 165-176.

[54] Molčanov, K.; Stalke, D.; Šantić, A.; Demeshko, S.; Stilinović, V.; Kojić-Prodić, B. Probing semiconductivity in crystals of stable semiquinone radicals: organic salts of 5,6-dichloro2,3-dicyanosemiquinone (DDQ) radical anion, CrystEngComm, 2018, 20, 1862-1873.

[55] Bruker, 2012, SAINT. Bruker AXS Inc., Madison, Wisconsin, USA.

[56] Bruker, 2001, SADABS. Bruker AXS Inc., Madison, Wisconsin, USA.

[57] Blessing, R. H. Data Reduction and Error Analysis for Accurate Single Crystal Diffraction Intensities, Crystallogr. Rev., 1987, 1, 3-58.

[58] CrysAlis ${ }^{\text {Pro }}$, Rigaku Oxford Diffraction, 2017, version: 1.171.39.13a, Rigaku Corporation, Oxford, UK.

[59] Sheldrick, G. M. A short history of SHELX, Acta Crystallogr. A, 2008, 64, 112-122.

[60] van Weperen, K. J.; Visser, G. J. Refinement of the crystal structure of tetrachloro-pbenzoquinone (chloranil) at $110 \mathrm{~K}$, Acta Cryst. B, 1972, B28, 338-342.

[61] Sakurai, T. A nuclear quadrupole resonance and X-ray study of the crystal structure of tetrachlorohydroquinone, Acta Cryst., 1962, 15, 443-447.

[62] Jelsch, C.; Guillot, B.; Lagoutte, A.; Lecomte, C. Advances in protein and small-molecule charge-density refinement methods using MoPro, J. Appl. Crystallogr., 2005, 38, 38-54. 
[63] Madsen, A. Ø. SHADE web server for estimation of hydrogen anisotropic displacement parameters, J. Appl. Cryst., 2006, 39, 757-758.

[64] Guillot, B. Molecular recognition enrichment rules in crystals and protein/ligand complexes, Acta Crystallogr. A, 2012, 68, s204.

[65] Farrugia, L. J. ORTEP-3 for Windows - a version of ORTEP-III with a Graphical User Interface (GUI), J. Appl. Crystallogr., 1997, 30, 565.

[66] Zarychta, B.; Zaleski, Z.; Kyzioł, J.; Dazskiewicz, Z.; Jelsch, C. Charge-density analysis of 1-nitroindoline: refinement quality using free $R$ factors and restraints, Acta Cryst. B, 2011, B67, 250-262.

[67] Tsirelson, V. G.; Bartashevich, E. V.; Stash, A. I.; Potemkin, V. A. Determination of covalent bond orders and atomic valence indices using topological features of the experimental electron density, Acta Crystallogr. B, 2007, B63, 142-150.

[68] Zhurova, E. A.; Zhurov, V. V.; Pinkerton, A. A. Structure and Bonding in $\beta$-HMXCharacterization of a Trans-Annular N $\cdots \mathrm{N}$ Interaction, J. Am. Chem. Soc., 2007, 129, 1388713893.

[69] R. Kamiński, S. Domagała, K. N. Jarzembska, A. A. Hoser, W. F. Sanjuan-Szklarz, M. J. Gutmann, A. Makal, M. Malińska, J. M. Bąk, K. Woźniak, Statistical analysis of multipole-modelderived structural parameters and charge-density properties from high-resolution X-ray diffraction experiments Acta Crystalloogr. A, 2013, A70, 72-91. 
[70] B. Fournier, B. Guillot, C. Lecomte, C. Lecomte, E. Escudero-Adán, C. Jelsch, A method to estimate statistical errors of properties derived from charge-density modelling, Acta Crystallogr. $A$, 2018, $A 74,170-183$.

[71] Gaussian 09, Revision E.01, Frisch, M. J.; Trucks, G. W.; Schlegel, H. B.; Scuseria, G. E.; Robb, M. A.; Cheeseman, J. R.; Scalmani, G.; Barone, V.; Mennucci, B.; Petersson, G. A.; Nakatsuji, H.; Caricato, M.; Li, X.; Hratchian, H. P.; Izmaylov, A. F.; Bloino, J.; Zheng, G.; Sonnenberg, J. L.; Hada, M.; Ehara, M.; Toyota, K.; Fukuda, R.; Hasegawa, J.; Ishida, M.; Nakajima, T.; Honda, Y.; Kitao, O.; Nakai, H.; Vreven, T.; Montgomery, Jr., J. A.; Peralta, J. E.; Ogliaro, F.; Bearpark, M.; Heyd, J. J.; Brothers, E.; Kudin, K. N.; Staroverov, V. N.; Kobayashi, R.; Normand, J.; Raghavachari, K.; Rendell, A.; Burant, J. C.; Iyengar, S. S.; Tomasi, J.; Cossi, M.; Rega, N.; Millam, J. M.; Klene, M.; Knox, J. E.; Cross, J. B.; Bakken, V.; Adamo, C.; Jaramillo, J.; Gomperts, R.; Stratmann, R. E.; Yazyev, O.; Austin, A. J.; Cammi, R.; Pomelli, C.; Ochterski, J. W.; Martin, R. L.; Morokuma, K.; Zakrzewski, V. G.; Voth, G. A.; Salvador, P.; Dannenberg, J. J.; Dapprich, S.; Daniels, A. D.; Farkas, Ö.; Foresman, J. B.; Ortiz, J. V.; Cioslowski, J.; Fox, D. J., Gaussian, Inc., Wallingford CT, 2009.

[72] Beebe, N. H. F.; Linderberg, J. Simplifications in the generation and transformation of twoelectron integrals in molecular calculations, Int. J. Quantum Chem., 1977, 12, 683-705.

[73] Aquilante, F.; Autschbach, J.; Carlson, R. K.; Chibotaru, L. F.; Delcey, M. G.; De Vico, L.; Fdez. Galván, I.; Ferré, N.; Frutos, L. M.; Gagliardi, L.; Garavelli, M.; Giussani, A.; Hoyer, C. E.; Li Manni, G.; Lischka, H.; Ma, D.; Malmqvist, P. Å.; Müller, T.; Nenov, A.; Olivucci, M.: Pedersen, T. B.; Peng, D.; Plasser, F.; Pritchard, B.; Reiher, M.; Rivalta, I.; Schapiro, I.; SegarraMartí, J.; Stenrup, M.; Truhlar, D. G.; Ungur, L.; Valentini, A.;Vancoillie, S.; Veryazov, V.; 
Vysotskiy, V. P.; Weingart, O.; Zapata, F.; Lindh, R. Molcas 8: New capabilities for multiconfigurational quantum chemical calculations across the periodic table, J. Comput. Chem., 2016, 37, 506-541.

[74] AIMAll (Version 17.01.25), Todd, A.; Keith, T. K. Hristmill Software, Overland Park KS, USA, 2017 (aim.tkgristmill.com)

[75] Mayer, I. Charge, bond order and valence in the AB initio SCF theory, Chem. Phys. Lett., 1983, 97, 270-274.

[76] Mayer, I.; Salvador, P. Overlap populations, bond orders and valences for 'fuzzy' atoms, Chem. Phys. Lett., 2004, 383, 368-375.

[77] Lu, T.; Chen, F. Multiwfn: A multifunctional wavefunction analyzer, J. Comp. Chem., 2012, 33, 580-592.

[78] Gavezzotti, A. Calculation of Intermolecular Interaction Energies by Direct Numerical Integration over Electron Densities. 2. An Improved Polarization Model and the Evaluation of Dispersion and Repulsion Energies, J. Phys.Chem. B 2003, 107, 2344-2353. 
Table of Contents Graphic and Synopsis
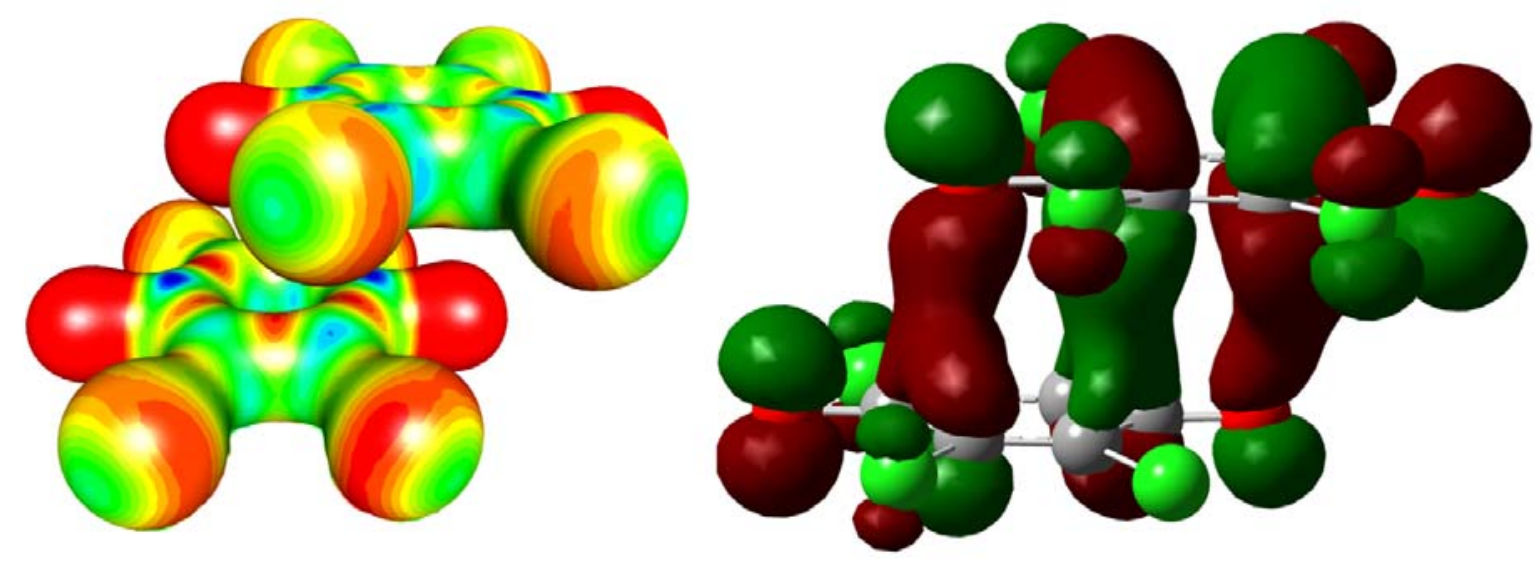

A combination of experimental X-ray charge density and quantum chemical computation

confirms covalent character ('pancake bonding') of $\pi$-interactions between semiquinone radical anions, which are responsible for magnetic and electrical properties of their crystals. 


\section{Supporting Information}

S1 Details on refinement and residual density

S2 Details on molecular structure

S3 Details on intermolecular interactions

S4 Details on quantum chemical calculations 


\section{S1 Details on refinement and residual density}
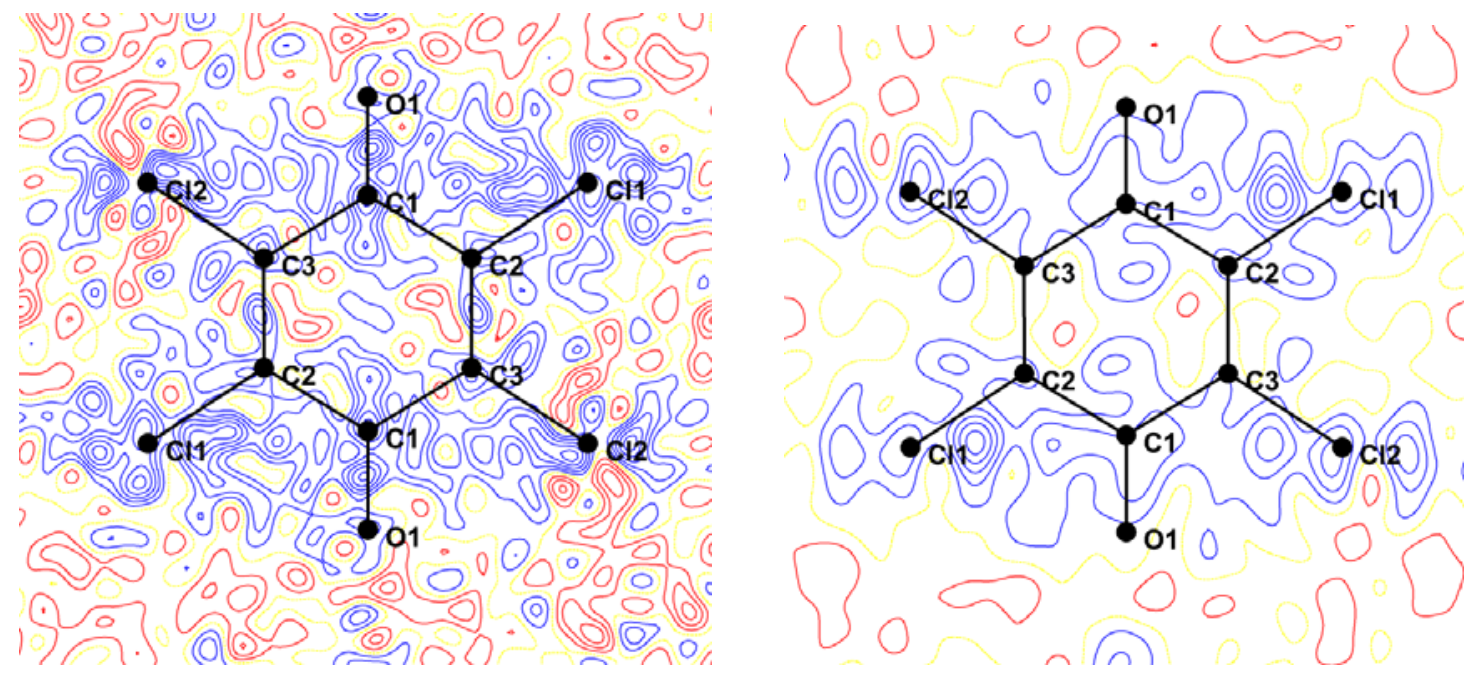

Figure S1 Residual electron density at the tetracloroquinone 1 in ring plane, with a) all reflections used and b) only low-angle reflections $\left(\mathrm{s}<0.7 \AA^{-1}\right)$ used. Positive density is shown in blue and negative in red; yellow dotted lines represent zero density. Contours are drawn for $0.05 \mathrm{e}^{-1}$.

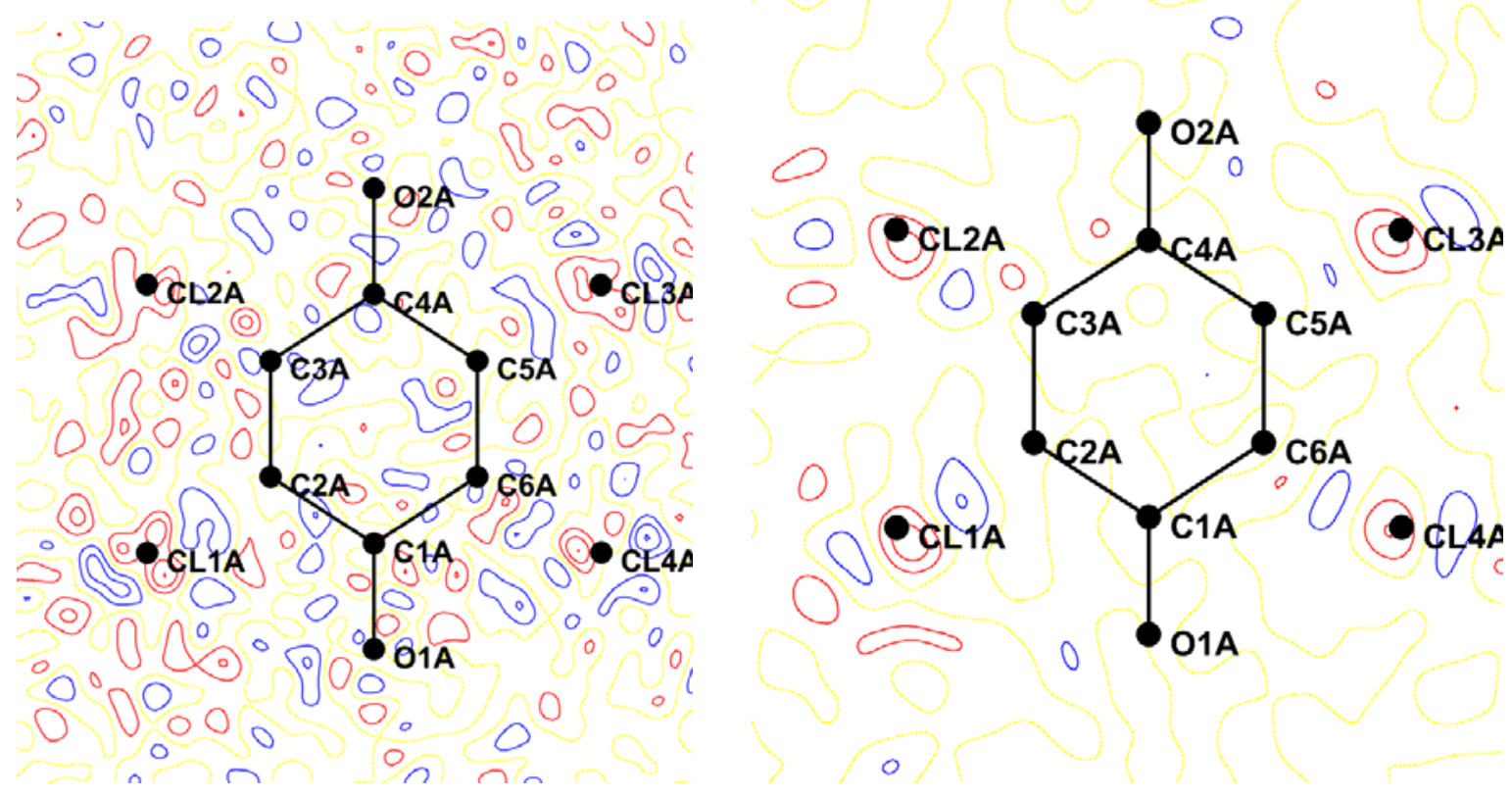

Figure S2 Residual electron density at the tetraclorosemiquinone radical anion in triclinic $\mathbf{2}$ in the ring plane, with a) all reflections used and b) only low-angle reflections $\left(\mathrm{s}<0.7 \AA^{-1}\right)$ used. Contours as in Fig. S1. 


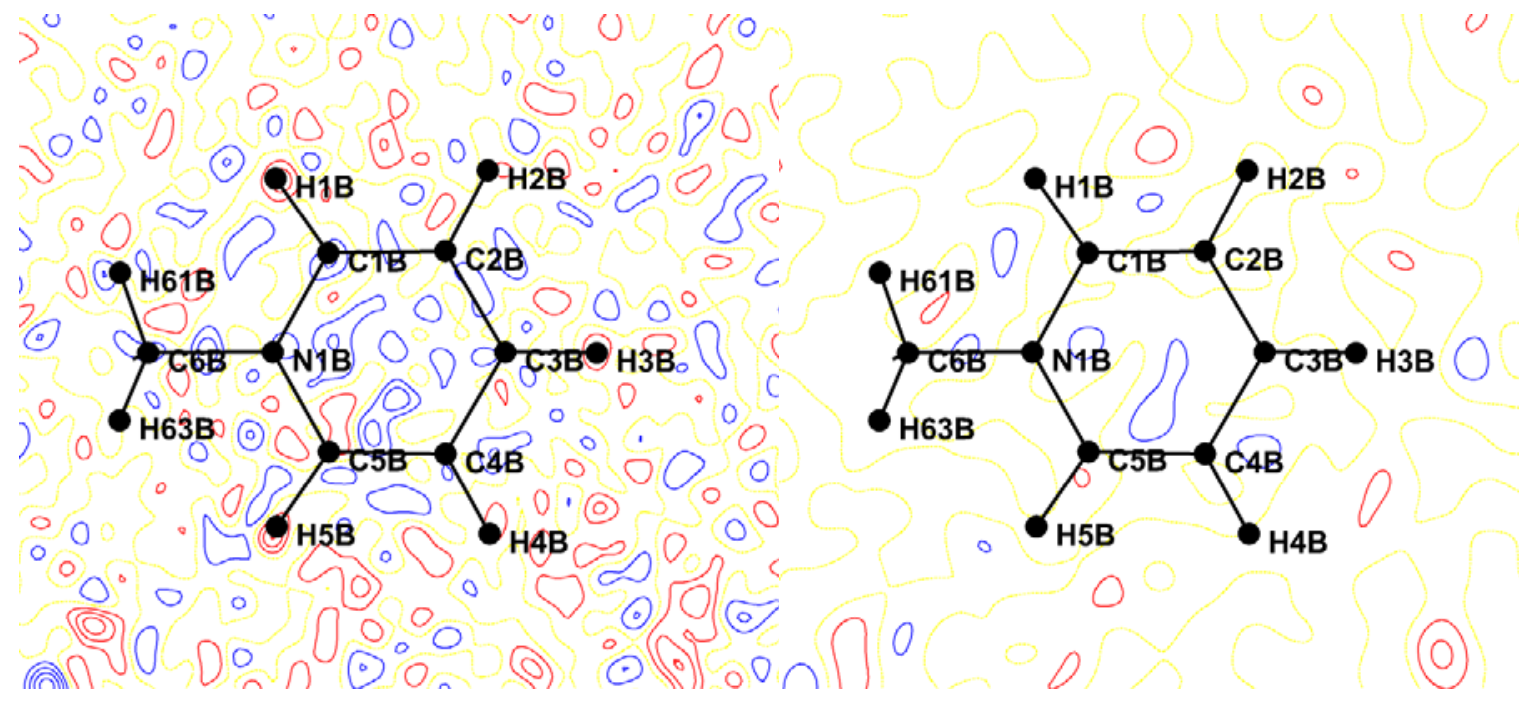

Figure S3 Residual electron density at the $N$-methylpyridinium cation in triclinic $\mathbf{2}$ in the ring plane, with a) all reflections used and b) only low-angle reflections $\left(s<0.7 \AA^{-1}\right)$ used. Contours as in Fig. S1.

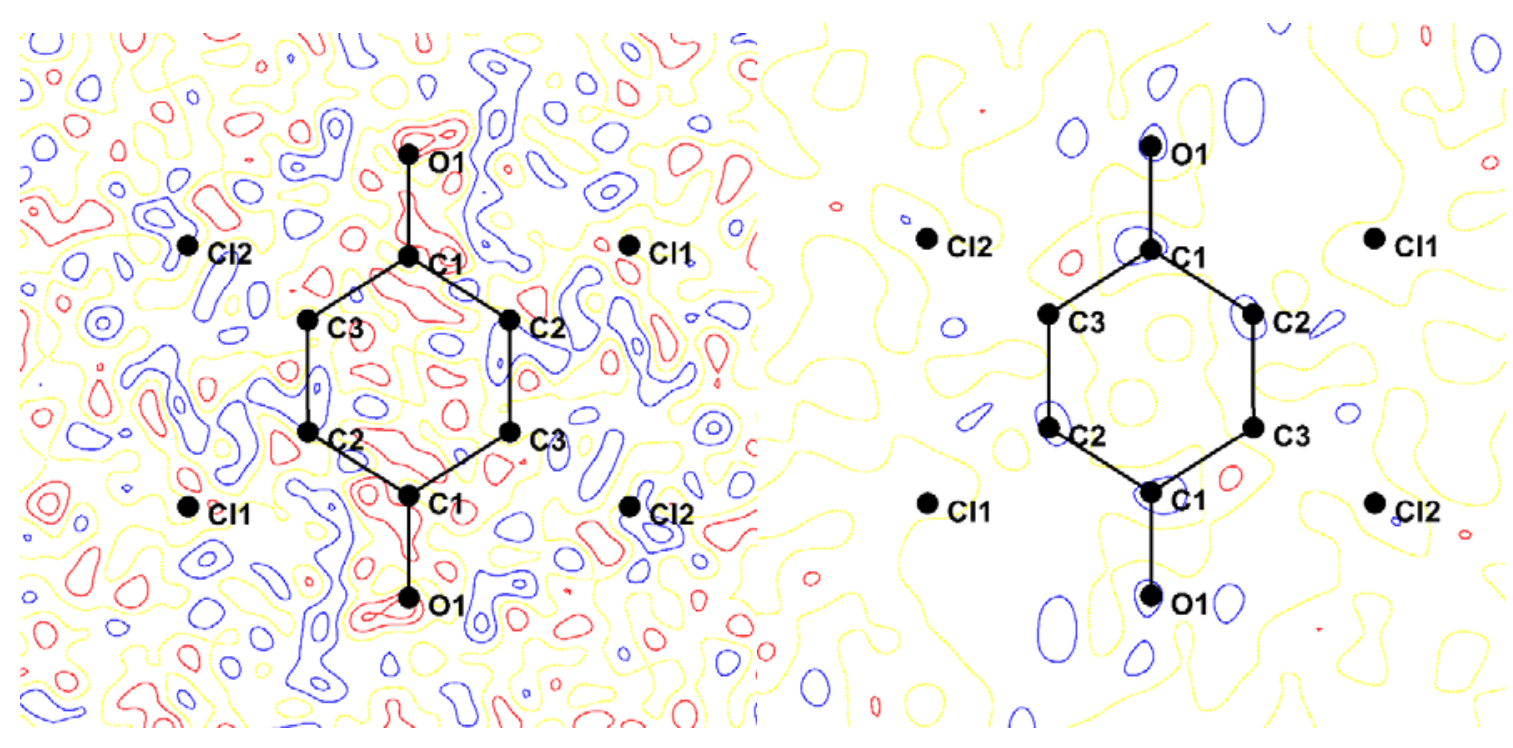

Figure S4 Residual electron density at the tetraclorosemiquinone radical anion in orthorhombic $\mathbf{2}$ in the ring plane, with a) all reflections used and b) only low-angle reflections $\left(s<0.7 \AA^{-1}\right)$ used. Contours as in Fig. S1. 


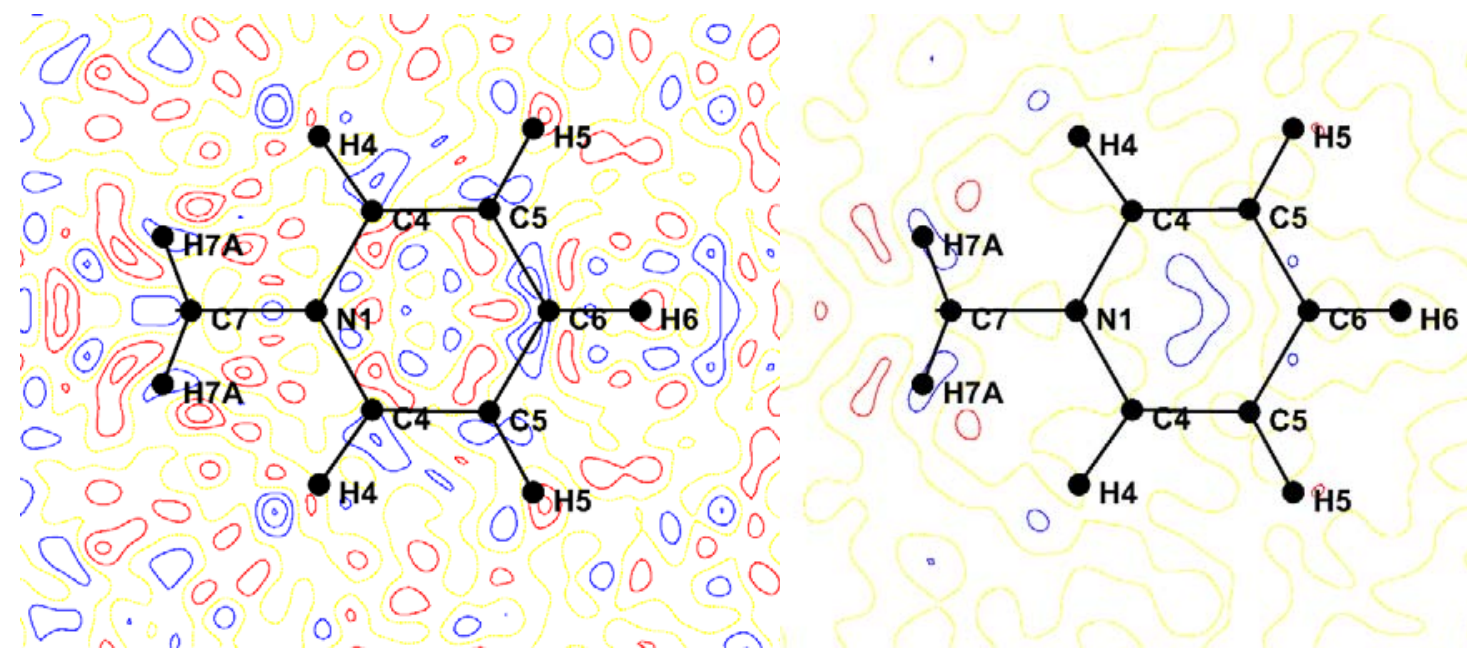

Figure S5 Residual electron density at the $N$-methylpyridinium cation in orthorhombic 2 in the ring plane, with a) all reflections used and b) only low-angle reflections $\left(s<0.7 \AA^{-1}\right)$ used. Contours as in Fig. S1.

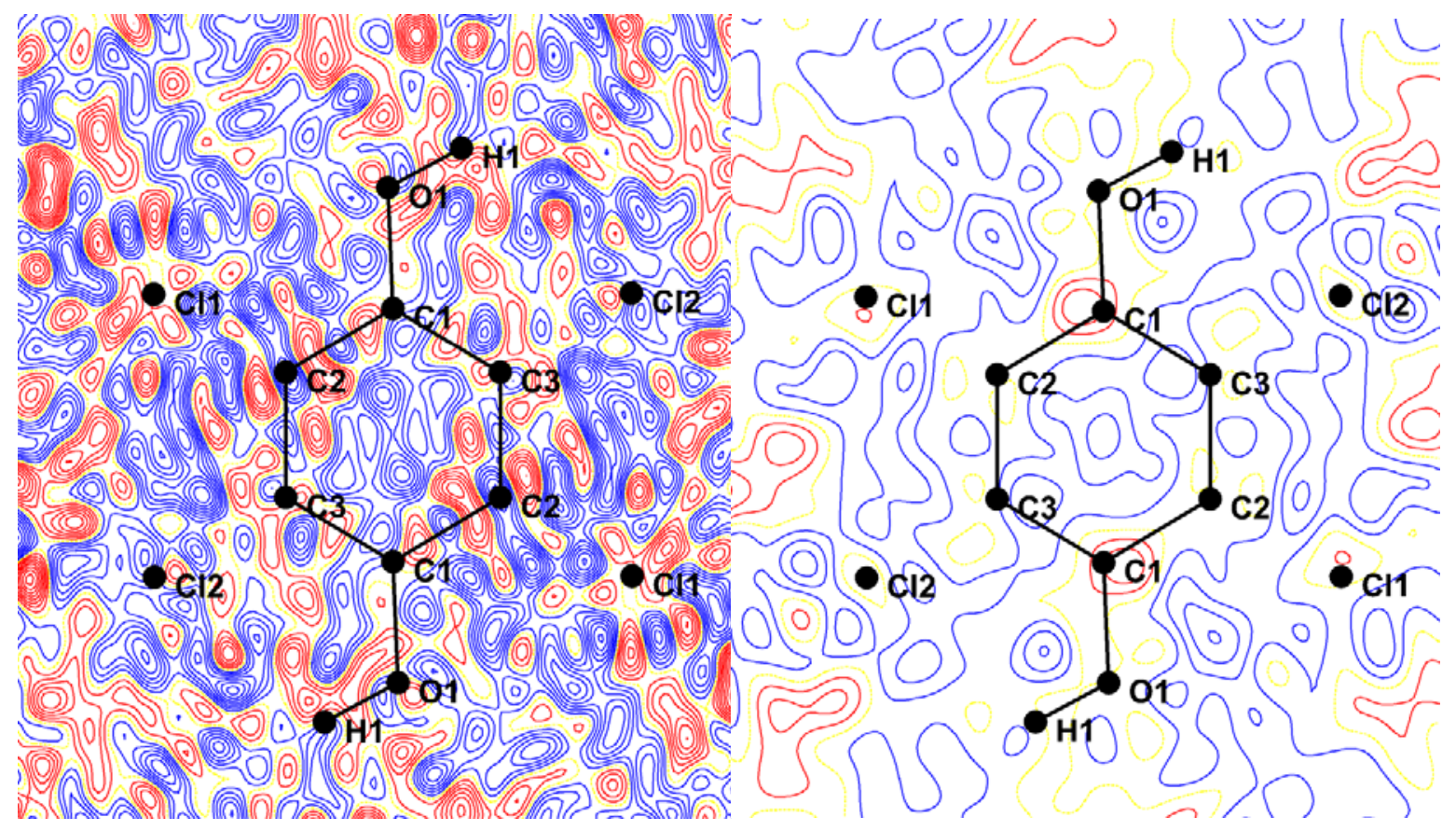

Figure S6 Residual electron density at the tetraclorohydroquinone $\mathbf{3}$ in the ring plane, with a) all reflections used and b) only low-angle reflections $\left(s<0.7 \AA^{-1}\right)$ used. Contours as in Fig. S1. 


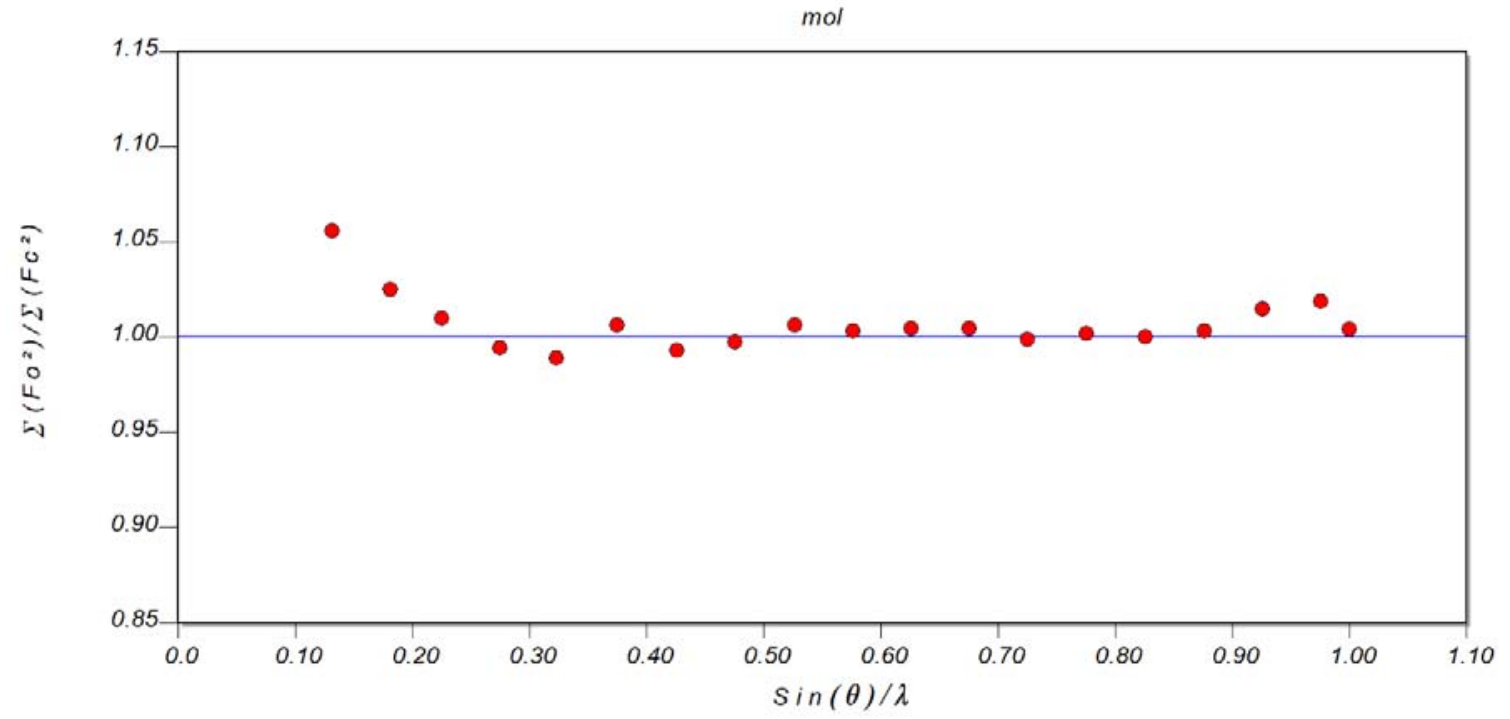

Figure S7 XDRK plot for 1 showing the fit of $<Y_{\mathrm{obs}}>v s<Y_{\text {calc }}>$ as a function of resolution.

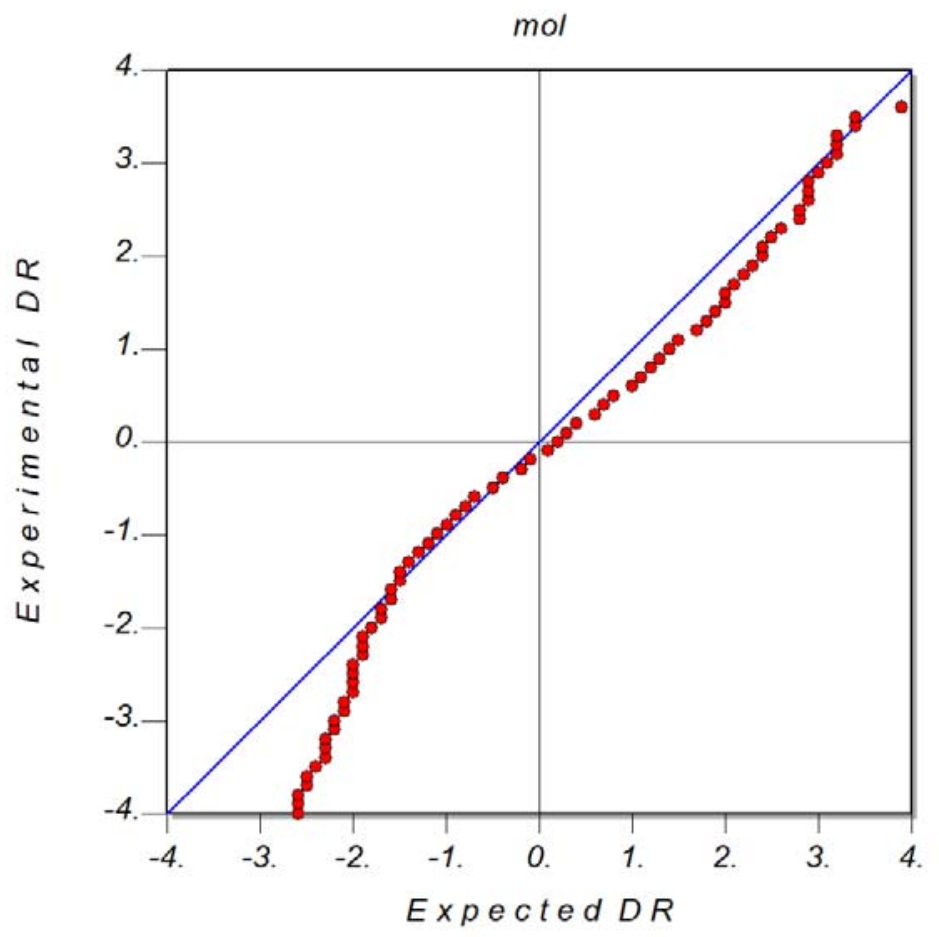

Figure S8 XDRK plot for 1 showing the expected and experimental $Y_{\text {obs- }} Y_{\text {calc }}$ data profile. 


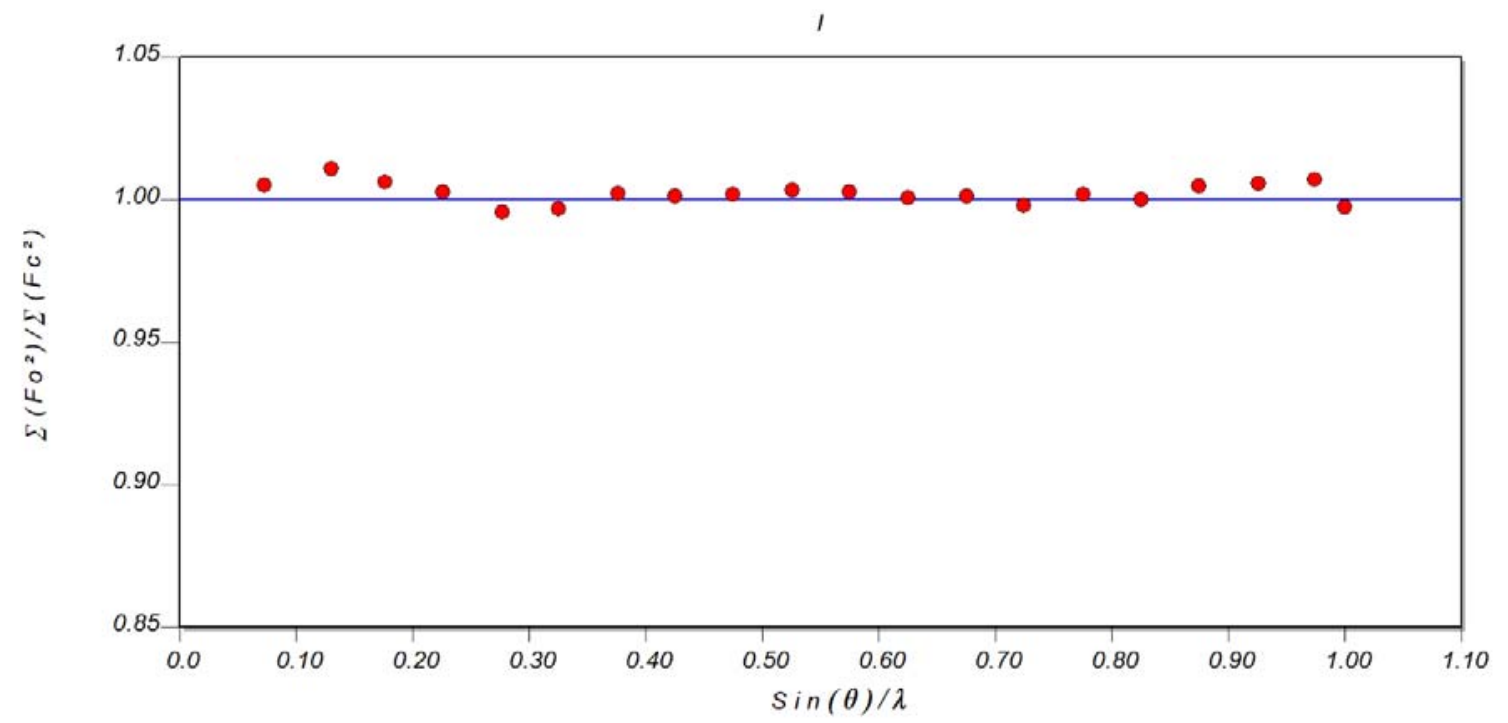

Figure S9 XDRK plot for orthorhombic 2. $N$-MePy showing the fit of $\left\langle Y_{\text {obs }}>v s<Y_{\text {calc }}>\right.$ as a function of resolution.

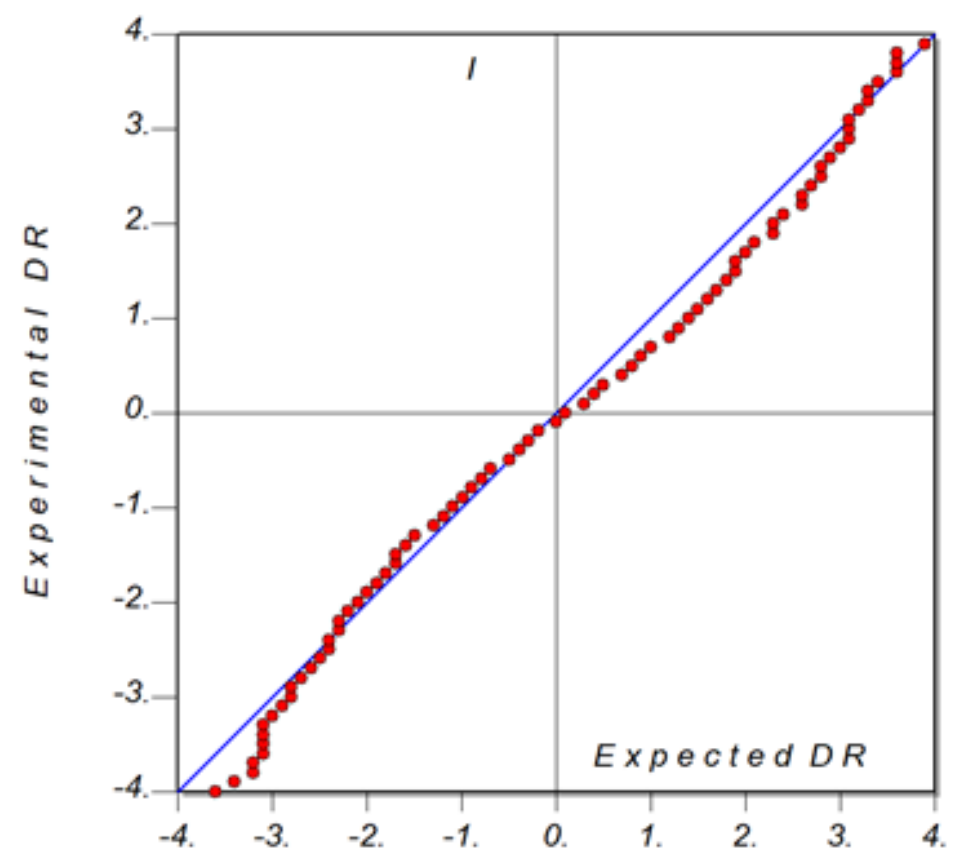

Figure S10 XDRK plot for orthorhombic $2 \cdot N$-MePy showing the expected and experimental $Y_{\text {obs- }} Y_{\text {calc }}$ data profile. 


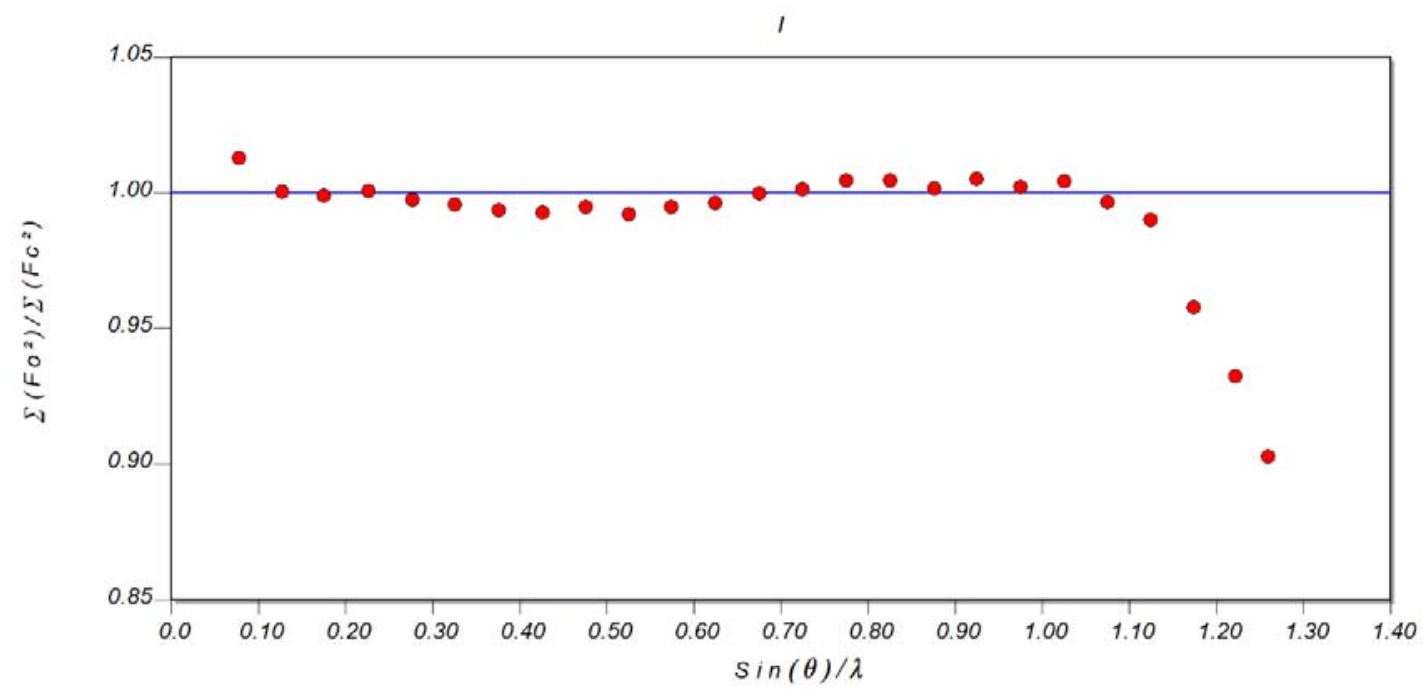

Figure S11 XDRK plot for triclinic 2. $N$-MePy showing the fit of $\left\langle Y_{\text {obs }}>v s<Y_{\text {calc }}>\right.$ as a function of resolution.

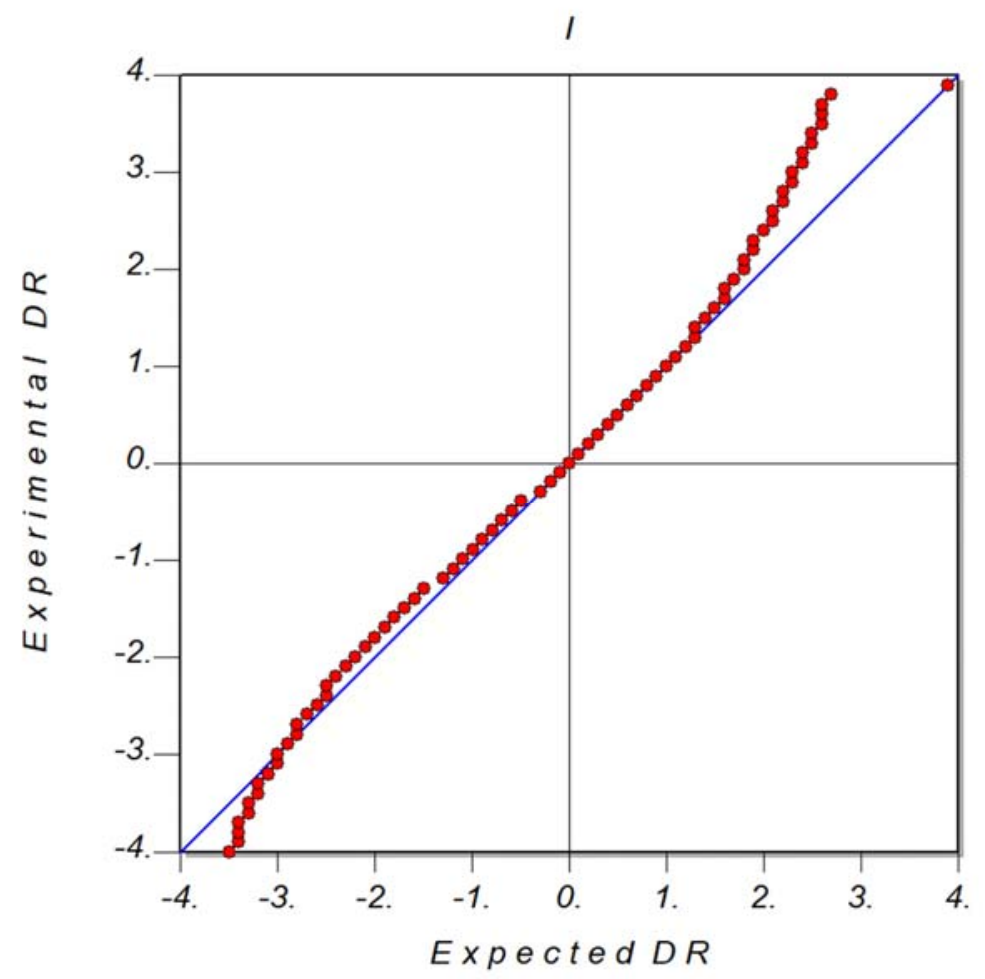

Figure S12 XDRK plot for triclinic $2 \cdot N$-MePy showing the expected and experimental $Y_{\text {obs- }} Y_{\text {calc }}$ data profile. 


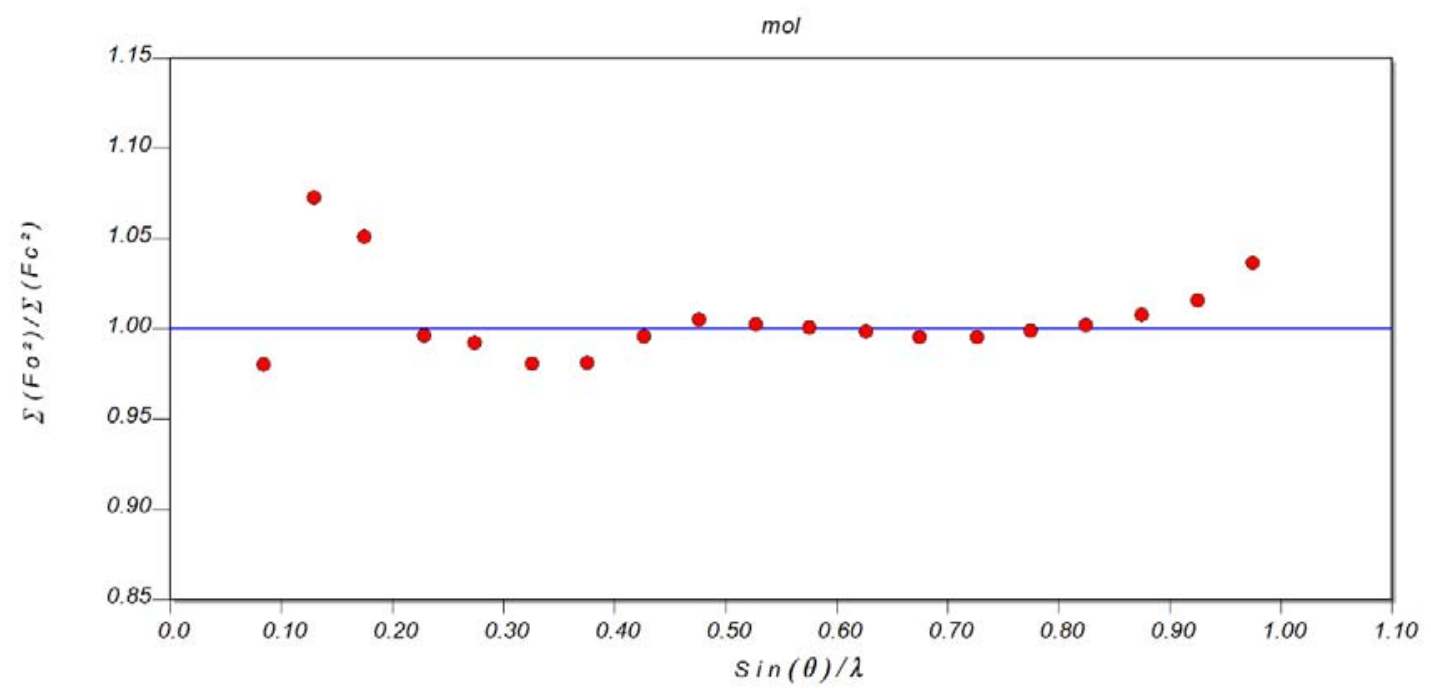

Figure S13 XDRK plot for 3 showing the fit of $<Y_{\text {obs }}>v s<Y_{\text {calc }}>$ as a function of resolution.

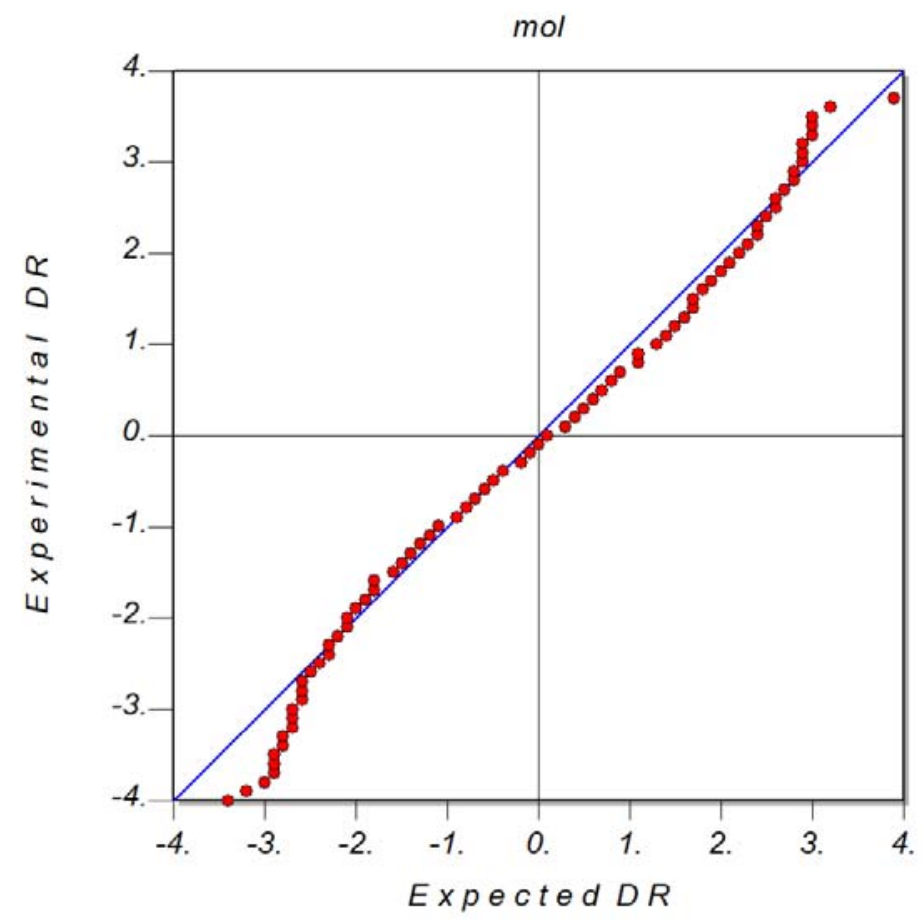

Figure S14 XDRK plot for 3 showing the expected and experimental $Y_{\text {obs- }} Y_{\text {calc }}$ data profile. 

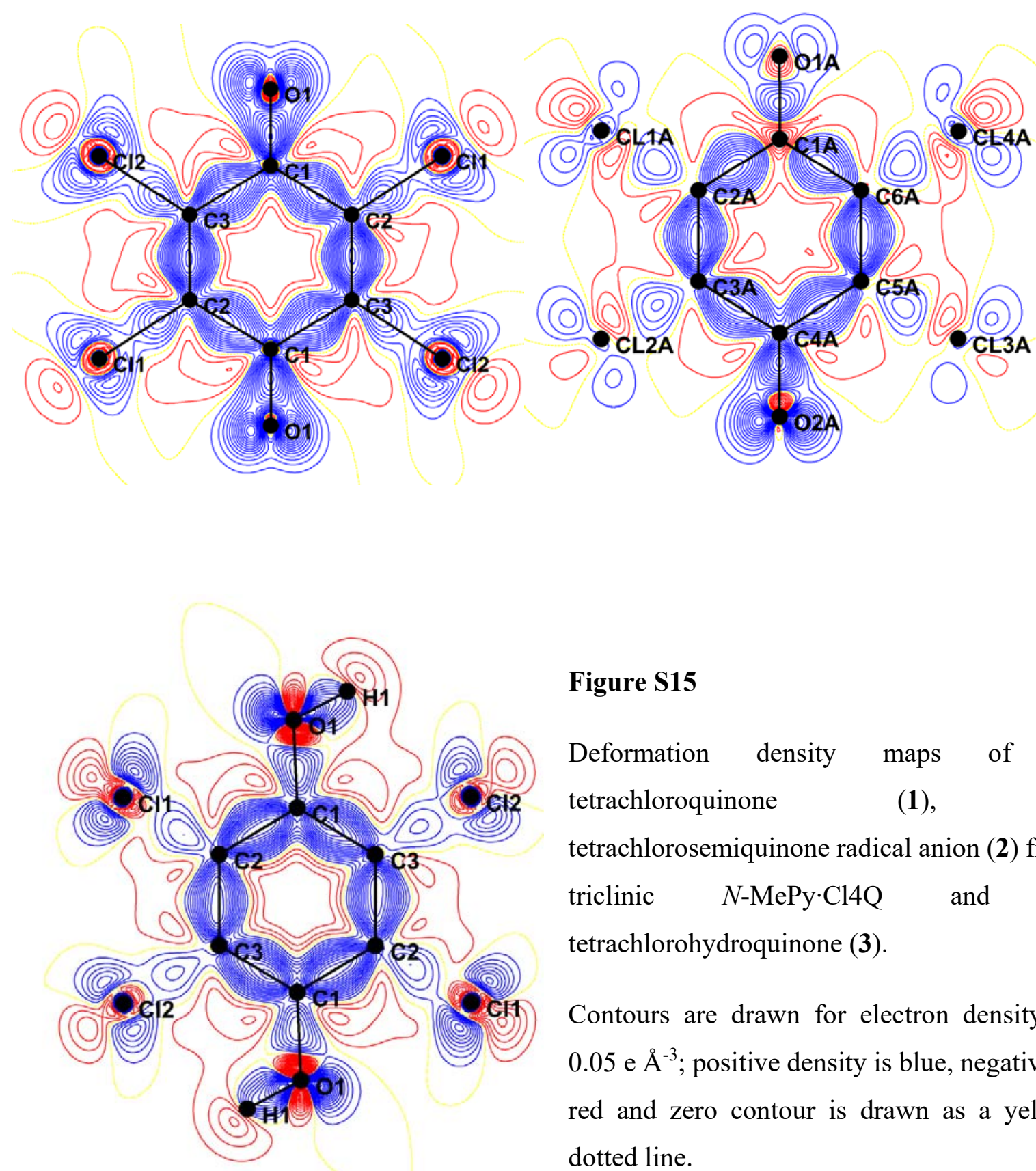

Figure S15

Deformation density maps of a) tetrachloroquinone (1), b) tetrachlorosemiquinone radical anion (2) from triclinic $\quad \mathrm{N}-\mathrm{MePy} \cdot \mathrm{Cl} 4 \mathrm{Q}$ and c) tetrachlorohydroquinone (3).

Contours are drawn for electron density of 0.05 e $\AA^{-3}$; positive density is blue, negative is red and zero contour is drawn as a yellow dotted line. 

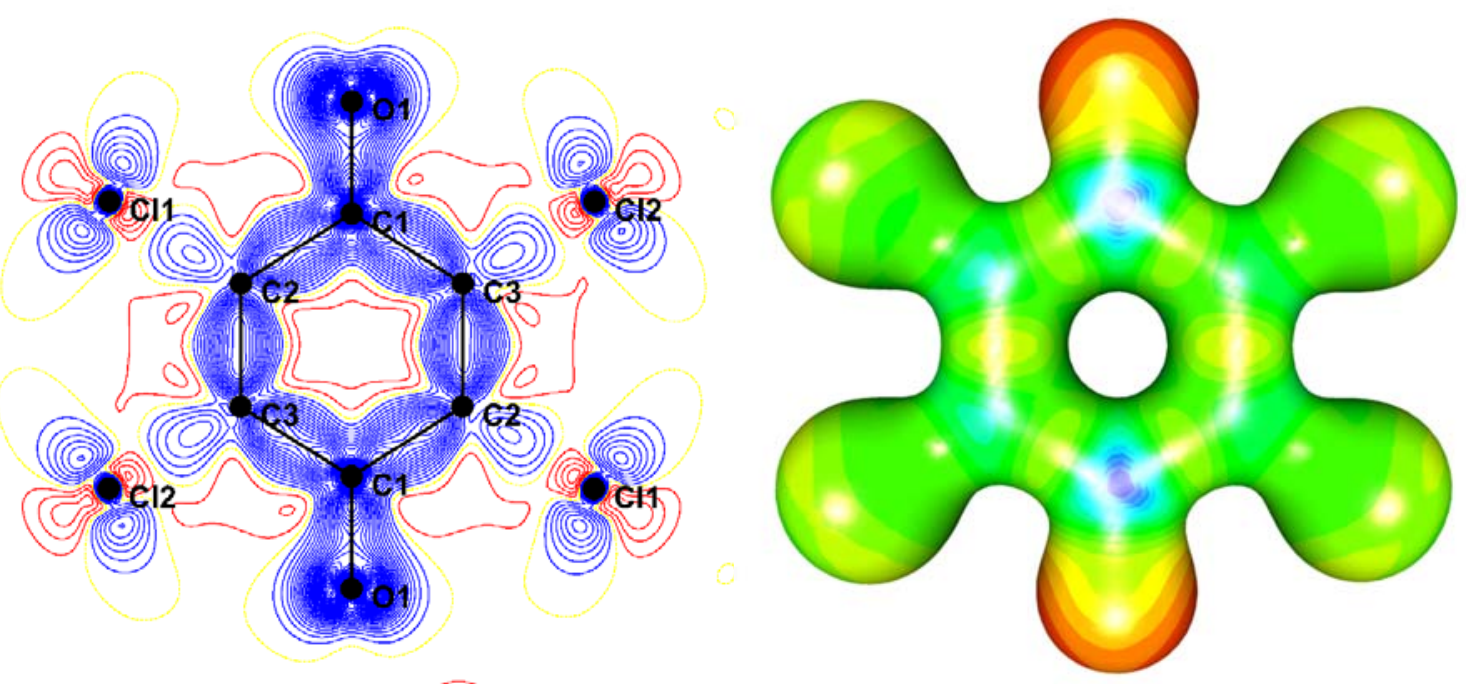

Figure S16 Deformation density of anion $\mathbf{2}$ in orthorhombic polymorph of $\mathbf{2} \cdot N$-MePy (contours at $0.05 \mathrm{e} \AA^{-3}$; positive density is blue, negative is red and zero contour is a yellow dotted line) and electrostatic potential electrostatic potential mapped onto an electron density isosurface of 0.5 (red: -0.1 , blue: +1.0 ).
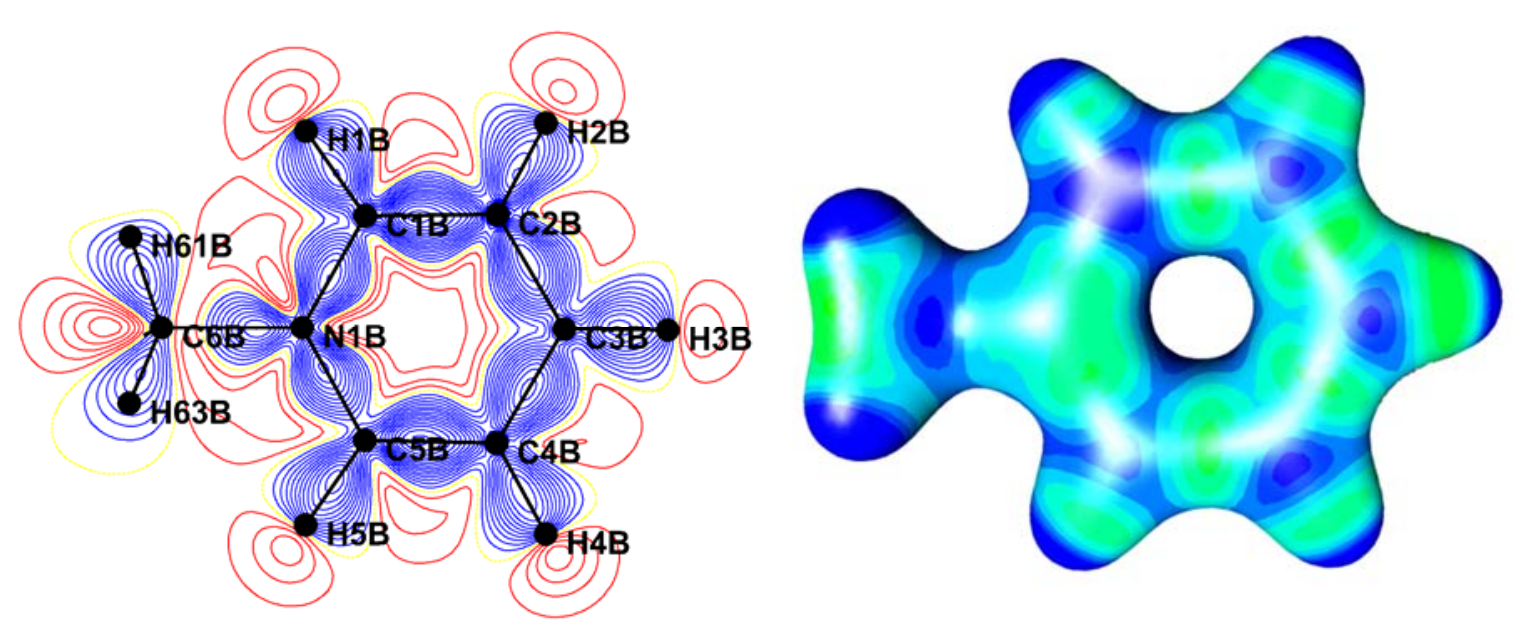

Figure S17 $N$-methylpyridinium cation in triclinic 2 $N$-MePy: a) deformation density (contours at 0.05 e $\AA^{-3}$; positive density is blue, negative is red and zero contour is a yellow dotted line), b) electrostatic potential mapped onto an electron density isosurface of 0.5 (red: -0.1 , blue: +1.0 ). 

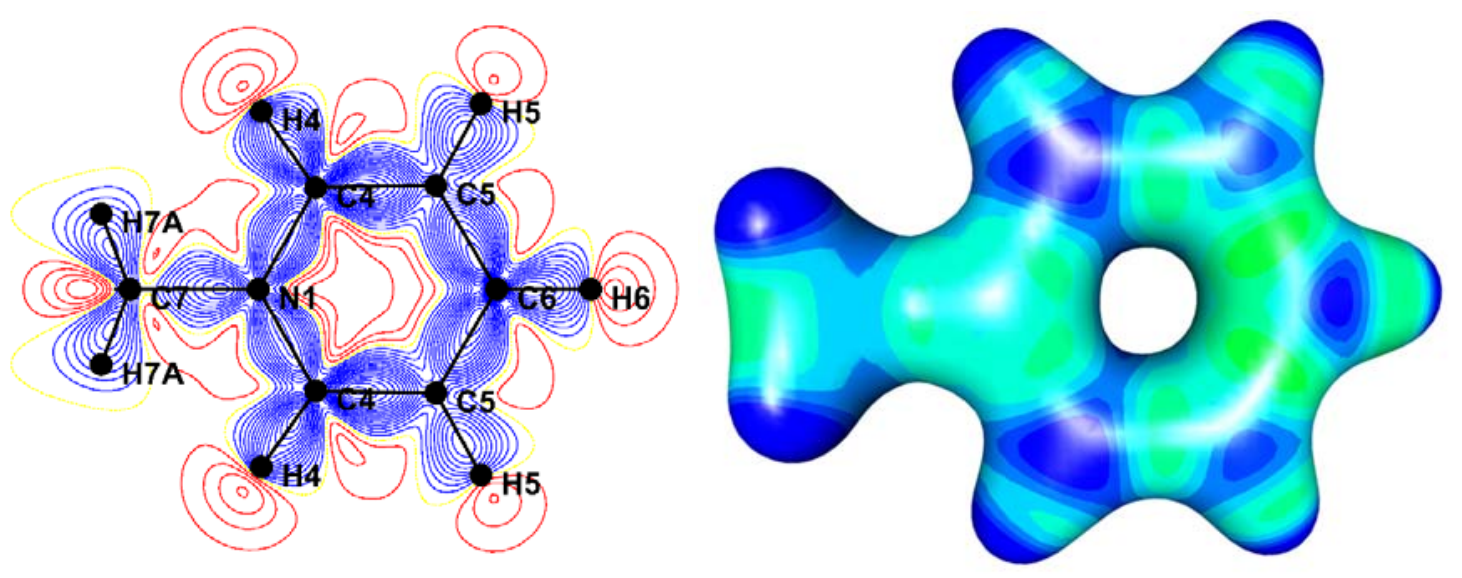

Figure S18 $N$-methylpyridinium cation in orthorhombic $2 \cdot N$-MePy: a) deformation density (contours at $0.05 \mathrm{e} \AA^{-3}$; positive density is blue, negative is red and zero contour is a yellow dotted line), b) electrostatic potential mapped onto an electron density isosurface of 0.5 (red: -0.1 , blue: +1.0 ).
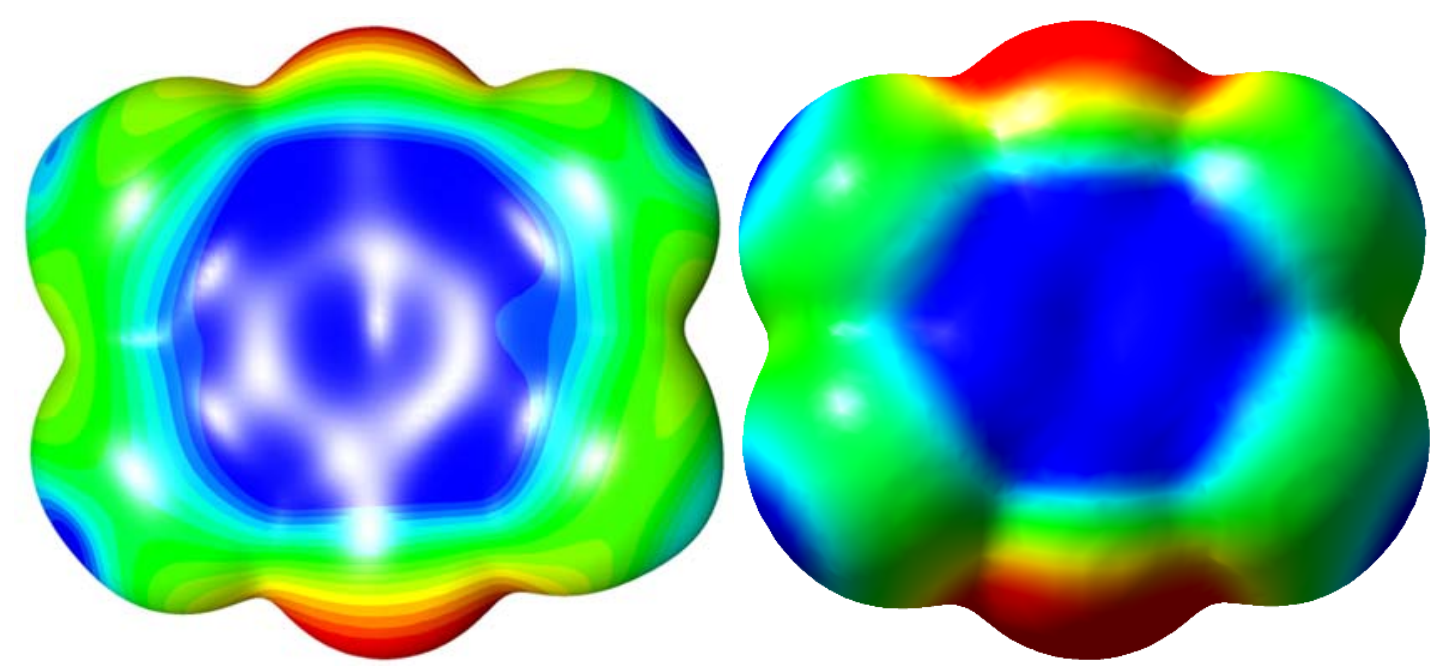

Figure S19 Electrostatic potential of $\mathrm{Cl}_{4} \mathrm{Q}$ (1) plotted onto an electron density isosurface of 0.0067 $\mathrm{e} \cdot \AA^{-3}$ : experimental (left; red; -0.05 , blue: +0.05 e $\AA^{-1}$ ) and theoretical (right; red: -0.005 , blue: +0.005 e $\left.\AA^{-1}\right)$. 

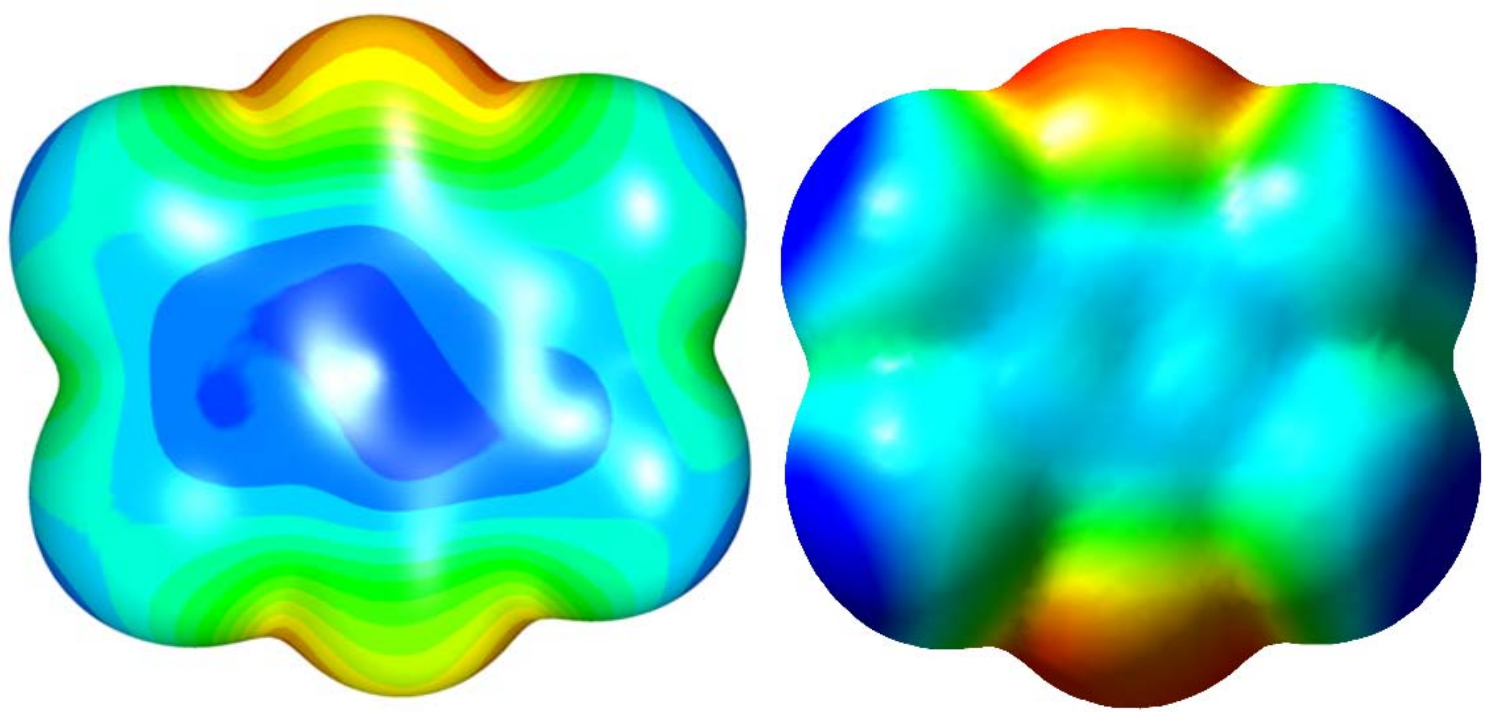

Figure S20 Electrostatic potential of tetrachlorosemiquinone radical anion (2) from triclinic polymorph plotted onto an electron density isosurface of $0.0067 \mathrm{e} \cdot \AA^{-3}$ : experimental (left; red; 0.30, blue: $+0.18 \mathrm{e} \AA^{-1}$ ) and theoretical (right; red: -0.33 , blue: $+0.20 \mathrm{e} \AA^{-1}$ ).
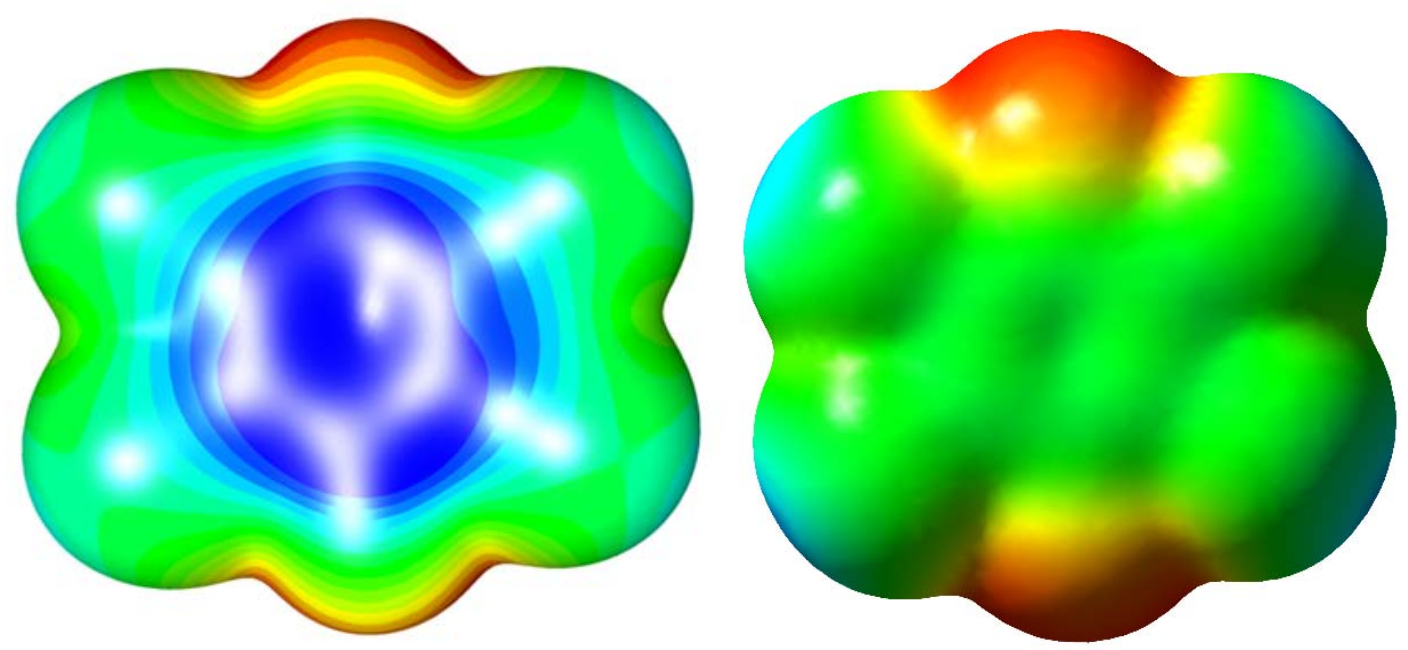

Figure S21 Electrostatic potential of tetrachlorosemiquinone radical anion (2) from orthorhombic polymorph plotted onto an electron density isosurface of $0.0067 \mathrm{e} \cdot \AA^{-3}$ : experimental (left; red; 0.20 , blue: +0.10 e $\AA^{-1}$ ) and theoretical (right; red: -0.33 , blue: +0.14 e $\AA^{-1}$ ). 

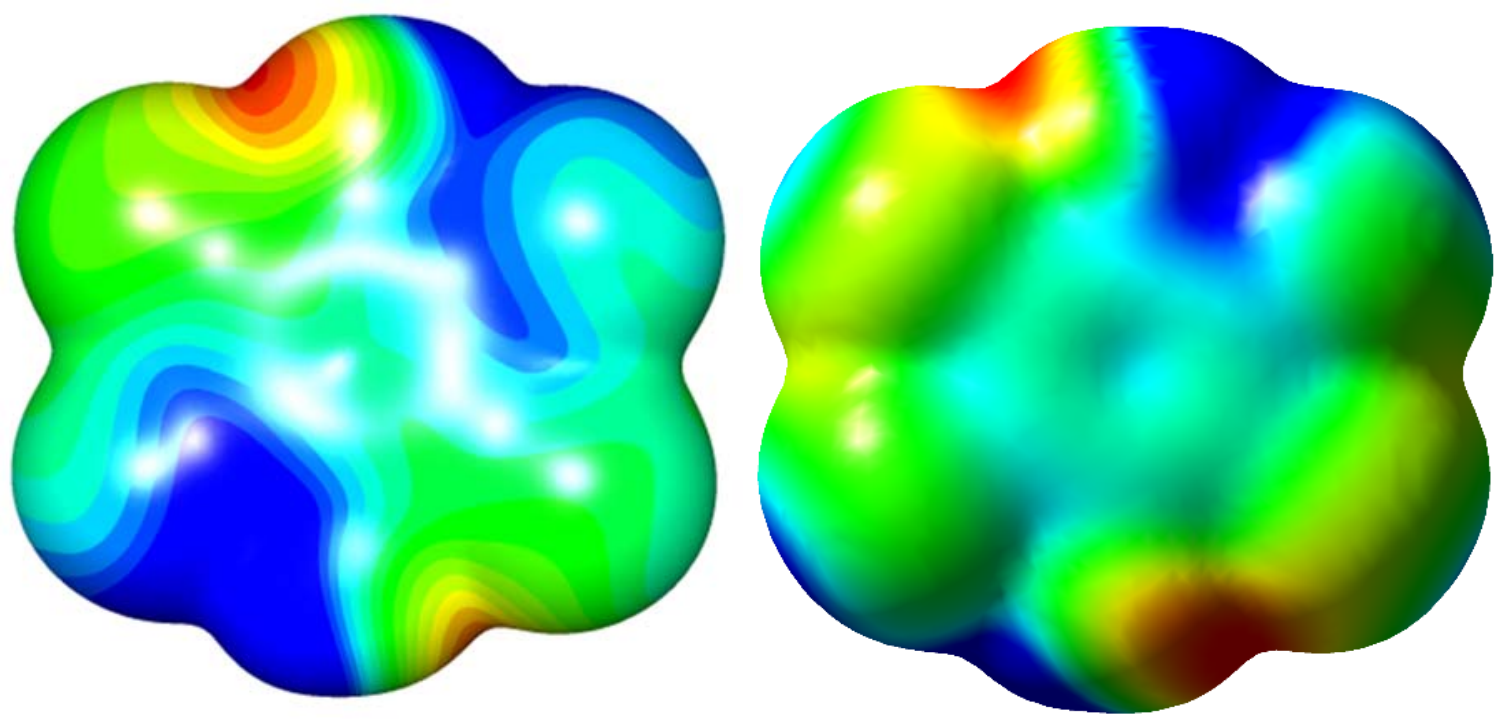

Figure S22 Electrostatic potential of tetrachlorohydroquinone (3) plotted onto an electron density isosurface of $0.0067 \mathrm{e} \cdot \AA^{-3}$ : experimental (left; red; -0.10 , blue: +0.05 e $\AA^{-1}$ ) and theoretical (right; red: -0.60 , blue: +0.50 e $\left.\AA^{-1}\right)$.

Table S1 Topology of electron density in the compound 1, derived from electron-density after multipole refinement.

\begin{tabular}{llllll}
\hline Bond & Length $(\AA)$ & $\begin{array}{l}\text { Electron Density } \\
\left(\mathrm{e} \AA^{-3}\right) \rho_{\text {cp }}\end{array}$ & $\begin{array}{l}\text { Laplacian } \\
\left(\mathrm{e}^{-3}\right)\end{array}$ & Ellipticity & $\begin{array}{l}\text { Bond order } \\
n_{\text {topo }}\end{array}$ \\
\hline C1-O1 & $1.2125(8)$ & 2.862 & -22.0 & 0.10 & 1.35 \\
$\mathrm{C} 1-\mathrm{C} 3$ & $1.4897(6)$ & 1.822 & -14.1 & 0.21 & 0.94 \\
$\mathrm{C} 3-\mathrm{C} 2$ & $1.3467(5)$ & 2.368 & -24.4 & 0.38 & 1.78 \\
$\mathrm{C} 2-\mathrm{C} 1$ & $1.4901(6)$ & 1.831 & -14.6 & 0.20 & 1.00 \\
$\mathrm{C} 2-\mathrm{C} 11$ & $1.6984(5)$ & 1.481 & -4.2 & 0.14 & \\
$\mathrm{C} 3-\mathrm{C} 2$ & $1.7000(5)$ & 1.466 & -3.5 & 0.08 & \\
\hline
\end{tabular}


Table S2 Topology of electron density in the compound 3, derived from electron-density after multipole refinement. Symmetry operator: $i)-x, 1-y, 1-z$.

\begin{tabular}{llllll}
\hline Bond & Length $(\AA)$ & $\begin{array}{l}\text { Electron Density } \\
\left(\mathrm{e} \AA^{-3}\right) \rho_{\mathrm{cp}}\end{array}$ & $\begin{array}{l}\text { Laplacian } \\
\left(\mathrm{e} \AA^{-3}\right)\end{array}$ & Ellipticity & $\begin{array}{l}\text { Bond order } \\
n_{\text {topo }}\end{array}$ \\
\hline $\mathrm{C} 1-\mathrm{O} 1$ & $1.3545(8)$ & 2.100 & -17.8 & 0.10 & 1.06 \\
$\mathrm{C} 1-\mathrm{C} 2$ & $1.3982(6)$ & 2.212 & -19.6 & 0.32 & 1.43 \\
$\mathrm{C} 2-\mathrm{C} 3$ & $1.3988(5)$ & 2.108 & -17.7 & 0.25 & 1.31 \\
$\mathrm{C} 3-\mathrm{C} 1^{i}$ & $1.3996(6)$ & 2.164 & -19.3 & 0.26 & 1.42 \\
$\mathrm{C} 2-\mathrm{Cl1}$ & $1.7188(5)$ & 1.379 & -3.6 & 0.07 & \\
$\mathrm{C} 3-\mathrm{Cl} 2$ & $1.7179(5)$ & 1.357 & -3.5 & 0.09 & \\
$\mathrm{O} 1-\mathrm{H} 1$ & $0.980(2)$ & 0.343 & -27.7 & 0.023 & 0.51 \\
\hline
\end{tabular}

Table S3 Topology of electron density of the tetrachlorosemiquinone radical anion in triclinic 2, derived from electron-density after multipole refinement.

\begin{tabular}{llllll}
\hline Bond & Length $(\AA)$ & $\begin{array}{l}\text { Electron Density } \\
\left(\mathrm{e}^{-3}\right) \rho_{\mathrm{cp}}\end{array}$ & $\begin{array}{l}\text { Laplacian } \\
\left(\mathrm{e}^{-3}\right)\end{array}$ & Ellipticity & $\begin{array}{l}\text { Bond order } \\
n_{\text {topo }}\end{array}$ \\
\hline $\mathrm{C} 1-\mathrm{O} 1$ & $1.2483(3)$ & 2.717 & -34.1 & 0.08 & 1.50 \\
$\mathrm{C} 4-\mathrm{O} 2$ & $1.2510(3)$ & 2.689 & -32.2 & 0.10 & 1.47 \\
$\mathrm{C} 1-\mathrm{C} 2$ & $1.4564(4)$ & 1.939 & -16.2 & 0.20 & 1.16 \\
$\mathrm{C} 2-\mathrm{C} 3$ & $1.3702(3)$ & 2.191 & -20.2 & 0.29 & 1.50 \\
$\mathrm{C} 3-\mathrm{C} 4$ & $1.4563(4)$ & 1.902 & -14.8 & 0.26 & 1.08 \\
$\mathrm{C} 4-\mathrm{C} 5$ & $1.4571(3)$ & 1.897 & -15.0 & 0.22 & 1.07 \\
$\mathrm{C} 5-\mathrm{C} 6$ & $1.3701(3)$ & 2.192 & -19.6 & 0.32 & 1.45 \\
$\mathrm{C} 6-\mathrm{C} 1$ & $1.4552(4)$ & 1.926 & -15.5 & 0.24 & 1.12 \\
$\mathrm{C} 2-\mathrm{Cl} 1$ & $1.7222(3)$ & 1.394 & -4.0 & 0.14 & \\
$\mathrm{C} 3-\mathrm{Cl} 2$ & $1.7243(2)$ & 1.403 & -4.4 & 0.09 & \\
$\mathrm{C} 5-\mathrm{Cl} 3$ & $1.7215(3)$ & 1.380 & -3.9 & 0.15 & \\
$\mathrm{C} 6-\mathrm{C} 14$ & $1.7230(3)$ & 1.381 & -3.8 & 0.11 & \\
\hline
\end{tabular}


Table S4 Topology of electron density of the tetrachlorosemiquinone radical anion in orthorhombic $\mathbf{2}$, derived from electron-density after multipole refinement.

\begin{tabular}{llllll}
\hline Bond & Length $(\AA)$ & $\begin{array}{l}\text { Electron Density } \\
\left(\mathrm{e}^{-3}\right) \rho_{\mathrm{cp}}\end{array}$ & $\begin{array}{l}\text { Laplacian } \\
\left(\mathrm{e} \AA^{-3}\right)\end{array}$ & $\begin{array}{l}\text { Ellipticity } \\
n_{\text {topo }}\end{array}$ \\
\hline $\mathrm{C} 1-\mathrm{O} 1$ & $1.2480(3)$ & 2.868 & -29.6 & 0.01 & 1.47 \\
$\mathrm{C} 1-\mathrm{C} 2$ & $1.4544(4)$ & 1.953 & -13.6 & 0.13 & 0.88 \\
$\mathrm{C} 2-\mathrm{C} 3$ & $1.3686(3)$ & 2.256 & -21.0 & 0.25 & 1.50 \\
$\mathrm{C} 3-\mathrm{C} 1$ & $1.4558(4)$ & 1.958 & -13.5 & 0.13 & 0.88 \\
$\mathrm{C} 2-\mathrm{Cl} 1$ & $1.7211(3)$ & 1.391 & -3.9 & 0.07 & \\
$\mathrm{C} 3-\mathrm{Cl} 2$ & $1.7214(2)$ & 1.397 & -3.9 & 0.06 & \\
\hline
\end{tabular}

Table S5 Topology of electron density of the $N$-methylpyridinium cation in triclinic 2, derived from electron-density after multipole refinement.

\begin{tabular}{llllll}
\hline Bond & Length $(\AA)$ & $\begin{array}{l}\text { Electron Density } \\
\left(\mathrm{e}^{-3}\right) \rho_{\mathrm{cp}}\end{array}$ & $\begin{array}{l}\text { Laplacian } \\
\left(\mathrm{e} \AA^{-3}\right)\end{array}$ & Ellipticity & $\begin{array}{l}\text { Bond order } \\
n_{\text {topo }}\end{array}$ \\
\hline N1B-C1B & $1.3469(4)$ & 2.27 & -27.4 & 0.17 & 1.22 \\
N1B-C5B & $1.3525(4)$ & 2.14 & -22.3 & 0.21 & 1.21 \\
N1B-C6B & $1.4752(4)$ & 1.63 & -9.6 & 0.07 & 0.97 \\
C1B-C2B & $1.3849(5)$ & 2.21 & -21.7 & 0.31 & 1.53 \\
C2B-C3B & $1.3915(5)$ & 2.13 & -20.0 & 0.20 & 1.47 \\
C3B-C4B & $1.3934(5)$ & 2.11 & -19.9 & 0.21 & 1.49 \\
C4B-C5B & $1.3792(4)$ & 2.22 & -22.5 & 0.24 & 1.62 \\
C1B-H1B & $0.949(9)$ & 1.79 & -19.7 & 0.07 & 0.85 \\
C2B-H2B & $0.945(10)$ & 1.72 & -18.6 & 0.05 & 0.84 \\
C3B-H3B & $0.969(10)$ & 1.72 & -18.4 & 0.06 & 0.86 \\
C4B-H4B & $0.939(10)$ & 1.76 & -20.4 & 0.04 & 0.83 \\
C5B-H5B & $0.935(10)$ & 1.75 & -20.1 & 0.06 & 0.82 \\
C6B-H61B & $0.989(10)$ & 1.75 & -17.5 & 0.11 & 0.93 \\
C6B-H62B & $0.937(11)$ & 1.73 & -17.2 & 0.14 & 0.96 \\
C6B-H63B & $0.973(11)$ & 1.74 & -16.8 & 0.14 & 0.96 \\
\hline
\end{tabular}


Table S6 Topology of electron density of the $N$-methylpyridinium cation in orthorhombic 2, derived from electron-density after multipole refinement.

\begin{tabular}{llllll}
\hline Bond & Length $(\AA)$ & $\begin{array}{l}\text { Electron Density } \\
\left(\mathrm{e} \AA^{-3}\right) \rho_{\mathrm{cp}}\end{array}$ & $\begin{array}{l}\text { Laplacian } \\
\left(\mathrm{e} \AA^{-3}\right)\end{array}$ & Ellipticity & $\begin{array}{l}\text { Bond order } \\
n_{\text {topo }}\end{array}$ \\
\hline N1-C7 & $1.4826(4)$ & 1.706 & -9.7 & 0.08 & 1.02 \\
N1-C4 & $1.3498(4)$ & 2.278 & -20.8 & 0.25 & 1.32 \\
C4-C5 & $1.3846(5)$ & 2.221 & -21.0 & 0.24 & 1.56 \\
C5-C6 & $1.3911(5)$ & 2.126 & -18.2 & 0.20 & 1.38 \\
C4-H4 & $1.082(9)$ & 1.793 & -19.8 & 0.02 & 0.83 \\
C5-H5 & $1.082(10)$ & 1.667 & -17.5 & 0.05 & 0.87 \\
C6-H6 & $1.082(10)$ & 1.650 & -18.8 & 0.04 & 0.76 \\
C7-H7A & $1.076(10)$ & 1.669 & -17.0 & 0.09 & 0.88 \\
C7-H7B & $1.076(10)$ & 1.545 & -19.7 & 0.08 & 0.65 \\
\hline
\end{tabular}

Table S7 Atomic charges (e) in compound $\mathbf{1}\left(\mathrm{Cl}_{4} \mathrm{Q}\right)$ derived from $P_{\text {val, }}$, topology of electron density and QTAIM/DFT. $P_{\text {val }}$ derived values are from the $Q=N_{\text {val }}-P_{\text {val }}$ difference between number of valence electrons in neutral and refined multipolar atom. Esd's were obtained after refinement vs. all variables.

\begin{tabular}{cccc}
\hline Atom & $P_{\text {val }}$ derived & Topological & DFT/Monomer \\
\hline $\mathrm{O} 1$ & $-0.16(6)$ & -1.000 & -1.071 \\
$\mathrm{C} 11$ & $+0.02(8)$ & $-0.087(4)$ & -0.121 \\
$\mathrm{C} 12$ & $+0.03(8)$ & $-0.086(4)$ & -0.121 \\
$\mathrm{C} 1$ & $+0.30(10)$ & +1.156 & 1.078 \\
$\mathrm{C} 2$ & $-0.13(8)$ & +0.019 & 0.118 \\
$\mathrm{C} 3$ & $-0.06(8)$ & +0.003 & 0.118 \\
\hline
\end{tabular}


Table S8 Atomic charges (e) in compound $3\left(\mathrm{H}_{2} \mathrm{Cl}_{4} \mathrm{Q}\right)$ derived from $P_{\text {val, }}$, topology of electron density and QTAIM/DFT. $P_{\text {val }}$ derived values are from the $Q=N_{\text {val }}-P_{\text {val }}$ difference between number of valence electrons in neutral and refined multipolar atom. Esd's were obtained after refinement vs. all variables.

\begin{tabular}{cccc}
\hline Atom & $\begin{array}{c}P_{\text {val }} \\
\text { derived }\end{array}$ & Topological & DFT/Monomer \\
\hline O1 & $-0.48(9)$ & -1.093 & -1.139 \\
C11 & $-0.04(18)$ & $-0.12(4)$ & -0.171 \\
C12 & $-0.07(18)$ & $-0.15(3)$ & -0.199 \\
C1 & $-0.04(12)$ & +0.441 & 0.637 \\
C2 & $+0.06(10)$ & +0.021 & 0.142 \\
C3 & $+0.18(9)$ & +0.287 & 0.126 \\
H1 & $+0.42(3)$ & +0.558 & 0.605 \\
\hline
\end{tabular}


Table S9 Atomic charges (e) in the semiquinone radical in triclinic $2 \cdot N$-MePy derived from $P_{\mathrm{val}}$, topology of electron density and QTAIM/DFT. $P_{\text {val }}$ derived values are from the $Q=N_{\text {val }}-P_{\text {val }}$ difference between number of valence electrons in neutral and refined multipolar atom. Esd's were obtained after refinement vs. all variables.

\begin{tabular}{ccccccc}
\hline Atom & $P_{\text {val }}$ derived & Topological & DFT/Monomer & $\begin{array}{c}\text { DFT/Dimer } \\
\text { DFT/Dimer }\end{array}$ & $\begin{array}{c}\text { DFT/Dimer } \\
6\end{array}$ \\
\hline O1 & $-0.12(3)$ & -0.97 & -1.141 & -1.088 & -1.141 & -1.082 \\
$\mathrm{O} 2$ & $-0.14(3)$ & -0.94 & -1.138 & -1.087 & -1.073 & -1.186 \\
\hline $\mathrm{Cl} 1$ & $-0.170(12)$ & $-0.243(10)$ & -0.240 & -0.224 & -0.199 & -0.191 \\
$\mathrm{C} 12$ & $-0.174(12)$ & $-0.249(15)$ & -0.240 & -0.228 & -0.183 & -0.246 \\
$\mathrm{Cl} 3$ & $-0.171(12)$ & $-0.232(9)$ & -0.239 & -0.179 & -0.184 & -0.207 \\
$\mathrm{C} 14$ & $-0.173(5)$ & $-0.236(13)$ & -0.240 & -0.180 & -0.216 & -0.187 \\
\hline $\mathrm{C} 1$ & $-0.15(6)$ & +0.77 & 0.968 & 0.987 & 0.972 & 0.982 \\
$\mathrm{C} 2$ & $+0.05(5)$ & +0.08 & 0.077 & 0.085 & 0.089 & 0.094 \\
$\mathrm{C} 3$ & $+0.05(5)$ & +0.09 & 0.077 & 0.085 & 0.095 & 0.075 \\
$\mathrm{C} 4$ & $-0.10(6)$ & +0.75 & 0.962 & 0.980 & 0.981 & 0.951 \\
$\mathrm{C} 5$ & $+0.12(5)$ & +0.17 & 0.078 & 0.095 & 0.095 & 0.088 \\
$\mathrm{C} 6$ & $+0.07(4)$ & +0.11 & 0.076 & 0.094 & 0.084 & 0.094 \\
\hline Total & -0.91 & -0.91 & -1.000 & -0.660 & -0.680 & -0.815 \\
\hline
\end{tabular}


Table S10 Atomic charges (e) in the semiquinone radical in orthorhombic $2 \cdot N$-MePy derived from $P_{\text {val, }}$ topology of electron density and QTAIM/DFT. $P_{\text {val }}$ derived values are from the $Q=$ $N_{\text {val }}-P_{\text {val }}$ difference between number of valence electrons in neutral and refined multipolar atom. Esd's were obtained after refinement vs. all variables.

\begin{tabular}{cccccc}
\hline Atom & $\begin{array}{c}P_{\text {val }} \\
\text { derived }\end{array}$ & Topological & DFT/Monomer & $\begin{array}{c}\text { DFT/Dimer } \\
1\end{array}$ & $\begin{array}{c}\text { DFT/Dimer } \\
4\end{array}$ \\
\hline O1 & $-0.22(5)$ & -0.97 & -1.141 & -1.205 & -1.159 \\
C11 & $-0.12(4)$ & $-0.25(4)$ & -0.239 & -0.228 & -0.220 \\
C12 & $-0.12(4)$ & $-0.25(9)$ & -0.238 & -0.188 & -0.186 \\
C1 & $+0.30(7)$ & +0.77 & 0.964 & 0.953 & 0.947 \\
C2 & $-0.07(5)$ & +0.08 & 0.077 & 0.083 & 0.074 \\
C3 & $-0.07(5)$ & +0.09 & 0.078 & 0.096 & 0.092 \\
\hline Total & -0.96 & -1.06 & -0.998 & -0.978 & -0.904 \\
\hline
\end{tabular}

Table S11 Atomic charges (e) of $N$-methylpyridinium cation in orthorhombic $2 \cdot N$-MePy derived from $P_{\text {val }}$ and topology of experimental electron density. $P_{\text {val }}$ derived values are from the $Q=N_{\text {val }}$ - $P_{\text {val }}$ difference between number of valence electrons in neutral and refined multipolar atom. Esd's were obtained after refinement vs. all variables.

\begin{tabular}{ccc}
\hline Atom & $P_{\text {val }}$ derived & Topological \\
\hline $\mathrm{N} 1$ & $+0.01(8)$ & -0.251 \\
$\mathrm{C} 4$ & $+0.02(8)$ & -0.056 \\
$\mathrm{H} 4$ & $+0.22(9)$ & +0.293 \\
$\mathrm{C} 5$ & $-0.20(12)$ & -0.138 \\
$\mathrm{H} 5$ & $+0.05(9)$ & +0.219 \\
$\mathrm{C} 6$ & $+0.31(7)$ & -0.165 \\
$\mathrm{H} 6$ & $+0.22(10)$ & +0.137 \\
$\mathrm{C} 7$ & $-0.03(8)$ & -0.040 \\
H7A & $+0.02(8)$ & +0.183 \\
H7B & $+0.02(8)$ & +0.187 \\
\hline Total & +0.96 & +0.870 \\
\hline
\end{tabular}


Table S12 Atomic charges (e) of $N$-methylpyridinium cation in triclinic $2 \cdot N$-MePy from $P_{\text {val }}$ and topology of electron density. $P_{\text {val }}$ derived values are from the $Q=N_{\text {val }}-P_{\text {val }}$ difference between number of valence electrons in neutral and refined multipolar atom. Esd's were obtained after refinement vs. all variables.

\begin{tabular}{lrrrrr}
\hline & \multicolumn{2}{c}{$P_{\text {val }}$} & & \multicolumn{2}{c}{$P_{\text {val }}$} \\
Atom & derived & Topological & Atom & derived & Topological \\
\hline C1B & $-0.28(7)$ & 0.074 & H1B & $0.32(4)$ & 0.039 \\
C2B & $0.25(8)$ & 0.085 & H2B & $0.04(4)$ & 0.040 \\
C3B & $-0.30(9)$ & 0.086 & H3B & $0.24(5)$ & 0.046 \\
C4B & $0.13(9)$ & 0.088 & H4B & $0.12(4)$ & 0.044 \\
C5B & $-0.15(7)$ & 0.072 & H5B & $0.21(4)$ & 0.042 \\
C6B & $-0.03(9)$ & 0.091 & H61B & $0.20(5)$ & 0.045 \\
\hline N1B & $0.06(4)$ & 0.043 & H62B & $-0.01(5)$ & 0.050 \\
\hline Total & +0.91 & +0.91 & H63B & $0.11(5)$ & 0.047 \\
\hline
\end{tabular}


Table S13 Total electron density $\rho_{\text {tot }}$ and Laplacian $\nabla^{2} \rho$ at the intermolecular contacts. Experimentally determined critical points between the tetrachlorosemiquinone radical anions in triclinic 2· $N$-MePy Symmetry operation on A: (i) $1-x, 2-y, 1-z$, (ii) $-x, 2-y, 1-z$.

\begin{tabular}{|c|c|c|c|c|}
\hline $\bar{A} \ldots \mathrm{B}$ & $\rho_{\mathrm{tot}}$ & Laplacian & CP type & Symm. \\
\hline \multicolumn{5}{|c|}{ close (intra dimer) } \\
\hline $\mathrm{C} 1 \cdots \mathrm{O} 2$ & 0.0808 & 1.04 & $(3,-1)$ & (i) \\
\hline $\mathrm{C} 3 \cdots \mathrm{C} 5$ & 0.0953 & 0.95 & $(3,-1)$ & (i) \\
\hline $\mathrm{Cl} 2 \cdots \mathrm{Cl} 3$ & 0.0624 & 0.74 & $(3,-1)$ & (i) \\
\hline $\mathrm{O} 2 \cdots \mathrm{C} 1$ & 0.0808 & 1.04 & $(3,-1)$ & (i) \\
\hline $\mathrm{C} 5 \cdots \mathrm{C} 3$ & 0.0953 & 0.95 & $(3,-1)$ & (i) \\
\hline $\mathrm{Cl} 3 \cdots \mathrm{Cl} 2$ & 0.0624 & 0.74 & $(3,-1)$ & (i) \\
\hline $\mathrm{C} 3 \cdots \mathrm{C} 3$ & 0.0902 & 0.97 & $(3,+1)$ & (i) \\
\hline $\mathrm{C} 3 \cdots \mathrm{Cl} 3$ & 0.0617 & 0.71 & $(3,+1)$ & (i) \\
\hline $\mathrm{C} 4 \cdots \mathrm{C} 2$ & 0.0634 & 0.76 & $(3,+1)$ & (i) \\
\hline $\mathrm{C} 2 \cdots \mathrm{C} 3$ & 0.0548 & 0.67 & $(3,+3)$ & (i) \\
\hline $\mathrm{C} 1 \cdots \mathrm{C} 4$ & 0.0548 & 0.67 & $(3,+3)$ & (i) \\
\hline $\mathrm{C} 4 \cdots \mathrm{C} 6$ & 0.0283 & 0.32 & $(3,+1)$ & (i) \\
\hline $\mathrm{C} 5 \cdots \mathrm{C} 5$ & 0.0294 & 0.33 & $(3,+1)$ & (i) \\
\hline $\mathrm{C} 5 \cdots \mathrm{Cl} 2$ & 0.0617 & 0.71 & $(3,+1)$ & (i) \\
\hline $\mathrm{C} 1 \cdots \mathrm{C} 5$ & 0.0634 & 0.76 & $(3,+1)$ & (i) \\
\hline $\mathrm{C} 1 \cdots \mathrm{C} 3$ & 0.0632 & 0.76 & $(3,+1)$ & (i) \\
\hline $\mathrm{C} 1 \cdots \mathrm{C} 4$ & 0.0548 & 0.67 & $(3,+3)$ & (i) \\
\hline $\mathrm{C} 1 \cdots \mathrm{C} 4$ & 0.0548 & 0.67 & $(3,+3)$ & (i) \\
\hline long (inter & dimer) & & & \\
\hline $\mathrm{C} 1 \cdots \mathrm{Cl} 3$ & 0.0453 & 0.51 & $(3,-1)$ & (ii) \\
\hline $\mathrm{C} 4 \cdots \mathrm{Cl} 4$ & 0.0356 & 0.41 & $(3,-1)$ & (ii) \\
\hline $\mathrm{C} 6 \cdots \mathrm{C} 4$ & 0.0283 & 0.32 & $(3,+1)$ & (ii) \\
\hline $\mathrm{Cl} 3 \cdots \mathrm{Cl} 1$ & 0.0129 & 0.15 & $(3,+1)$ & (ii) \\
\hline
\end{tabular}


Table S14 Total electron density $\rho$ tot and Laplacian $\nabla 2 \rho$ at the intermolecular contacts. Experimentally determined critical points between the tetrachlorosemiquinone radical anions in orthorhombic $2 \cdot N-\mathrm{MePy}$. Symm. operation on A: (i) $1+x, y, z$, (ii) $2-x, 1-y,-z$.

\begin{tabular}{lllll}
\hline $\mathrm{A} \ldots \mathrm{B}$ & $\rho_{\text {tot }}$ & Laplacian & CP type & Symm. \\
\hline $\mathrm{C} 2 \ldots \mathrm{C} 3$ & 0.0480 & 0.53 & $(3,-1)$ & $(i)$ \\
$\mathrm{C} 3 \ldots \mathrm{C} 2$ & 0.0480 & 0.53 & $(3,-1)$ & $(i)$ \\
$\mathrm{C} 1 \ldots \mathrm{O} 1$ & 0.0345 & 0.47 & $(3,-1)$ & $(i)$ \\
$\mathrm{O} 1 \ldots \mathrm{C} 1$ & 0.0345 & 0.47 & $(3,-1)$ & $(i)$ \\
$\mathrm{C} 12 \ldots \mathrm{C} 22$ & 0.0303 & 0.37 & $(3,-1)$ & $(i)$ \\
$\mathrm{C} 11 \ldots \mathrm{O} 1$ & 0.0069 & 0.18 & $(3,+1)$ & $(i)$ \\
$\mathrm{C} 11 \ldots \mathrm{C} 2$ & 0.1579 & 2.77 & $(3,+1)$ & $(i i)$ \\
$\mathrm{C} 12 \ldots \mathrm{O} 1$ & 0.0096 & 0.17 & $(3,+1)$ & $(i)$ \\
$\mathrm{C} 12 \ldots \mathrm{C} 3$ & 0.0303 & 0.37 & $(3,+1)$ & $(i)$ \\
$\mathrm{O} 1 \ldots \mathrm{O} 1$ & 0.0166 & 0.32 & $(3,+1)$ & $(i)$ \\
$\mathrm{C} 1 \ldots \mathrm{C} 2$ & 0.0332 & 0.42 & $(3,+1)$ & $(i)$ \\
$\mathrm{C} 1 \ldots \mathrm{C} 3$ & 0.0333 & 0.42 & $(3,+1)$ & $(i)$ \\
$\mathrm{C} 2 \ldots \mathrm{C} 2$ & 0.0443 & 0.50 & $(3,+1)$ & $(i)$ \\
$\mathrm{C} 2 \ldots \mathrm{C} 2$ & 0.0311 & 0.38 & $(3,+3)$ & $(i)$ \\
\hline
\end{tabular}




\section{S4 Quantum chemical calculations}

Graphical representations of the studied systems are depicted in Figures 1-9, indicating nonequivalent internuclear distances in green. Values of the Mayer, Fuzzy, Delocalization Index (DI) and Wiberg (NBO) bond orders calculated with B3LYP and M06-2X for each system are provided in Tables S18-S29.

Carbon-carbon bond orders obtained with both functionals for ethane, ethane and benzene are close to the ideal 1.5, 1.0 and 2.0 values, except for the Fuzzy BO, which is considerably larger than unity for pure single bonds in ethane.

BENZENE

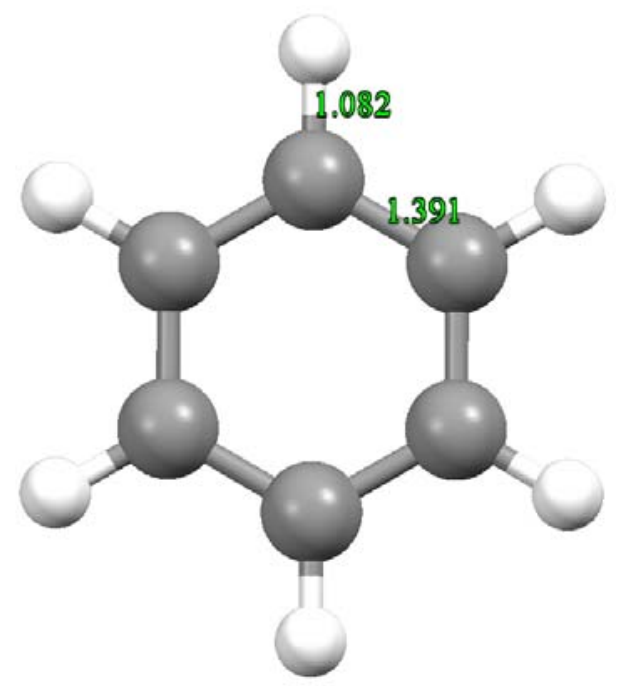

Figure S23 Optimized structure of benzene. Bond distances depicted in green $(\AA)$.

Table S15 Bond orders of benzene calculated with B3LYP.

\begin{tabular}{lcccc}
\hline Bonds & Mayer & Fuzzy & Delocalization index & Wiberg (NBO) \\
\hline C-H & 0.91 & 0.88 & 0.96 & 0.92 \\
C-C & 1.51 & 1.46 & 1.39 & 1.45 \\
\hline
\end{tabular}

Table S16 Bond orders of benzene calculated with M06-2X.

\begin{tabular}{ccccc}
\hline Bonds & Mayer & Fuzzy & Delocalization index & Wiberg (NBO) \\
\hline C-H & 0.92 & 0.88 & 0.96 & 0.92 \\
C-C & 1.53 & 1.46 & 1.39 & 1.45 \\
\hline
\end{tabular}




\section{TETRACHLOROQUINONE}

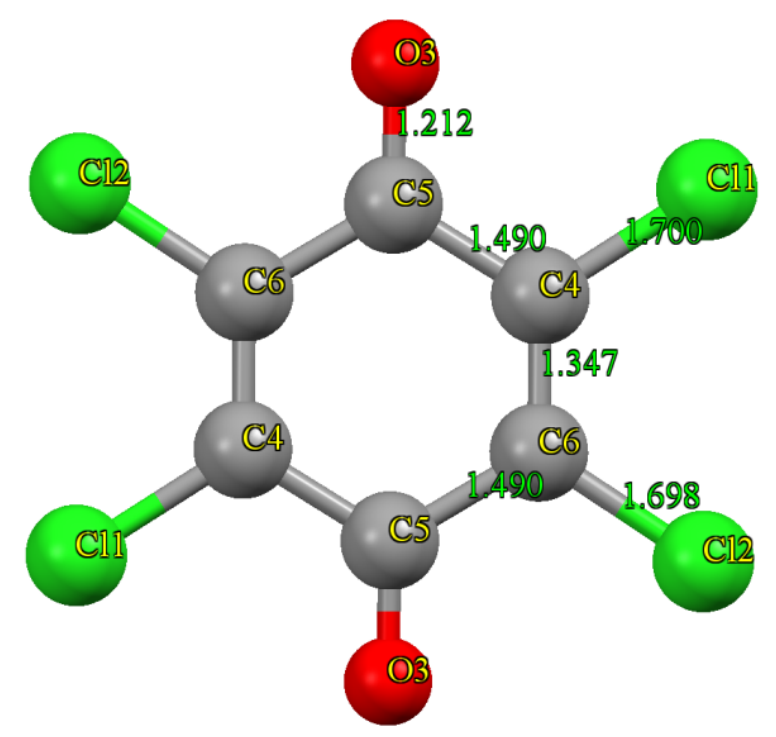

Figure S24 Crystallographic structure of chloranil in $\mathrm{Cl}_{4} \mathrm{Q}$ crystal. Bond distances depicted in green $(\AA)$.

Table S17 Bond orders of chloranil in the $\mathrm{Cl}_{4} \mathrm{Q}$ crystal calculated with B3LYP.

\begin{tabular}{ccccc}
\hline Bonds & Mayer & Fuzzy & Delocalization index & Wiberg (NBO) \\
\hline C5-C4 & 1.00 & 1.00 & 0.96 & 1.00 \\
C4-C6 & 1.59 & 1.50 & 1.55 & 1.63 \\
C6-C5 & 1.00 & 1.00 & 0.96 & 1.00 \\
C5-O3 & 2.15 & 1.97 & 1.38 & 1.79 \\
C4-C11 & 1.20 & 1.26 & 1.18 & 1.12 \\
C6-C12 & 1.21 & 1.26 & 1.18 & 1.12 \\
\hline
\end{tabular}

Table S18 Bond orders of chloranil in the $\mathrm{Cl}_{4} \mathrm{Q}$ crystal calculated with M06-2X.

\begin{tabular}{ccccc}
\hline Bonds & Mayer & Fuzzy & Delocalization index & Wiberg (NBO) \\
\hline C5-C4 & 1.06 & 0.99 & 0.95 & 0.99 \\
C4-C6 & 1.67 & 1.52 & 1.58 & 1.67 \\
C6-C5 & 1.06 & 0.99 & 0.95 & 0.99 \\
C5-O3 & 1.95 & 1.99 & 1.37 & 1.81 \\
C4-C11 & 1.33 & 1.26 & 1.17 & 1.12 \\
C6-C12 & 1.32 & 1.26 & 1.17 & 1.12 \\
\hline
\end{tabular}




\section{TETRACHLOROQYDROQUINONE}

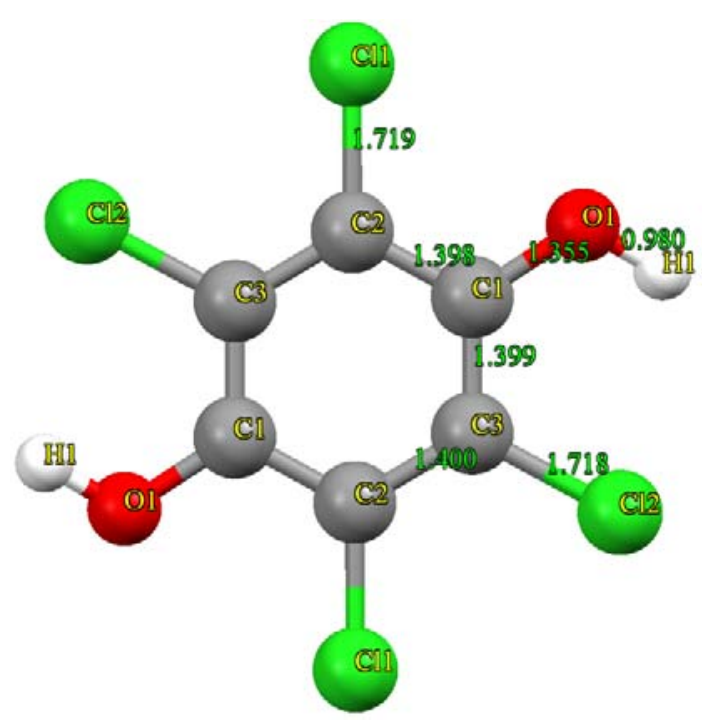

Figure S25 Crystallographic structure of tetrachlorohydroquinone in H2Cl4Q crystal. Bond distances depicted in green $(\AA)$.

Table S19 Bond orders of tetrachlorohydroquinone in the $\mathrm{H}_{2} \mathrm{Cl}_{4} \mathrm{Q}$ crystal calculated with B3LYP.

\begin{tabular}{ccccc}
\hline Bonds & Mayer & Fuzzy & Delocalization index & Wiberg (NBO) \\
\hline C2-C1 & 1.35 & 1.27 & 1.26 & 1.32 \\
C1-C3 & 1.33 & 1.27 & 1.26 & 1.32 \\
C3-C2 & 1.33 & 1.27 & 1.30 & 1.34 \\
C2-Cl1 & 1.11 & 1.23 & 1.14 & 1.09 \\
C1-O1 & 1.32 & 1.33 & 0.93 & 1.06 \\
C3-C12 & 1.05 & 1.22 & 1.13 & 1.08 \\
O1-H1 & 0.91 & 0.80 & 0.59 & 0.72 \\
\hline
\end{tabular}

Table S20 Bond orders of tetrachlorohydroquinone in the $\mathrm{H}_{2} \mathrm{Cl}_{4} \mathrm{Q}$ crystal calculated with M06$2 \mathrm{X}$.

\begin{tabular}{ccccc}
\hline Bonds & Mayer & Fuzzy & Delocalization index & Wiberg (NBO) \\
\hline C2-C1 & 1.40 & 1.27 & 1.26 & 1.32 \\
C1-C3 & 1.38 & 1.28 & 1.27 & 1.33 \\
C3-C2 & 1.37 & 1.27 & 1.30 & 1.35 \\
C2-Cl1 & 1.28 & 1.23 & 1.14 & 1.08 \\
C1-O1 & 1.14 & 1.33 & 0.91 & 1.05 \\
C3-C12 & 1.20 & 1.22 & 1.13 & 1.07 \\
O1-H1 & 0.84 & 0.80 & 0.58 & 0.72 \\
\hline
\end{tabular}




\section{$N-\mathrm{MePy} \cdot \mathrm{Cl}_{4} \mathrm{Q}$ (orthorhombic)}

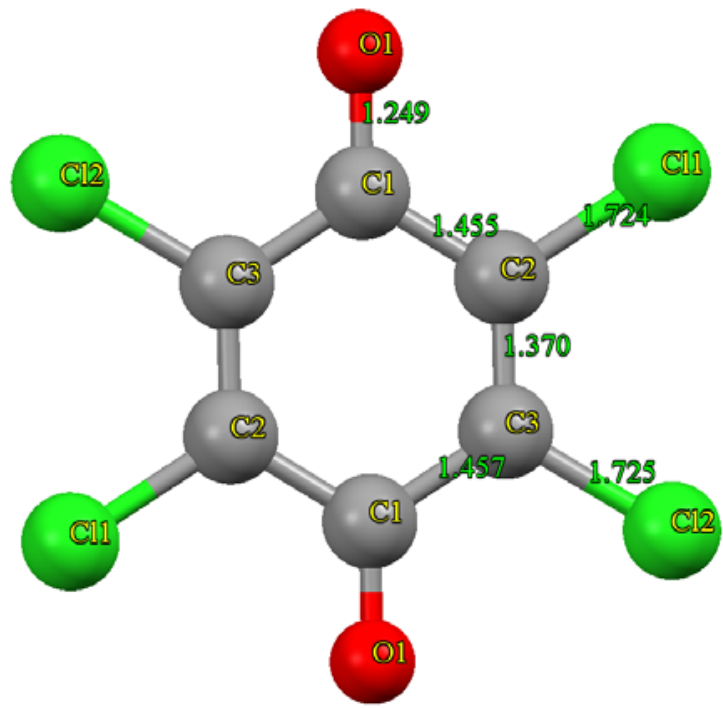

Figure S26 Crystallographic structure of tetrachlorosemiquinone radical anion in $\mathrm{N}-\mathrm{MePy} \cdot \mathrm{Cl}_{4} \mathrm{Q}$ (orthorhombic) crystal. Bond distances depicted in green $(\AA)$.

Table S21 Bond orders of tetrachlorosemiquinone radical anion in the $\mathrm{N}-\mathrm{MePy} \cdot \mathrm{Cl}_{4} \mathrm{Q}$ (orthorhombic) crystal calculated with B3LYP.

\begin{tabular}{ccccc}
\hline Bonds & Mayer & Fuzzy & Delocalization index & Wiberg (NBO) \\
\hline C1-C2 & 1.10 & 1.11 & 1.07 & 1.11 \\
C2-C3 & 1.50 & 1.41 & 1.45 & 1.51 \\
C3-C1 & 1.10 & 1.10 & 1.07 & 1.10 \\
C1-O1 & 2.10 & 1.79 & 1.26 & 1.53 \\
C2-C11 & 1.08 & 1.21 & 1.12 & 1.06 \\
C3-C12 & 1.08 & 1.21 & 1.12 & 1.06 \\
\hline
\end{tabular}

Table S22 Bond orders of tetrachloorsemiquinone radical anion in the $\mathrm{N}-\mathrm{MePy} \cdot \mathrm{Cl}_{4} \mathrm{Q}$ (orthorhombic) crystal calculated with M06-2X.

\begin{tabular}{ccccc}
\hline Bonds & Mayer & Fuzzy & Delocalization index & Wiberg (NBO) \\
\hline C1-C2 & 1.18 & 1.10 & 1.06 & 1.10 \\
C2-C3 & 1.54 & 1.42 & 1.47 & 1.53 \\
C3-C1 & 1.17 & 1.10 & 1.06 & 1.10 \\
C1-O1 & 1.80 & 1.81 & 1.25 & 1.53 \\
C2-C11 & 1.24 & 1.21 & 1.12 & 1.06 \\
C3-C12 & 1.24 & 1.21 & 1.12 & 1.06 \\
\hline
\end{tabular}




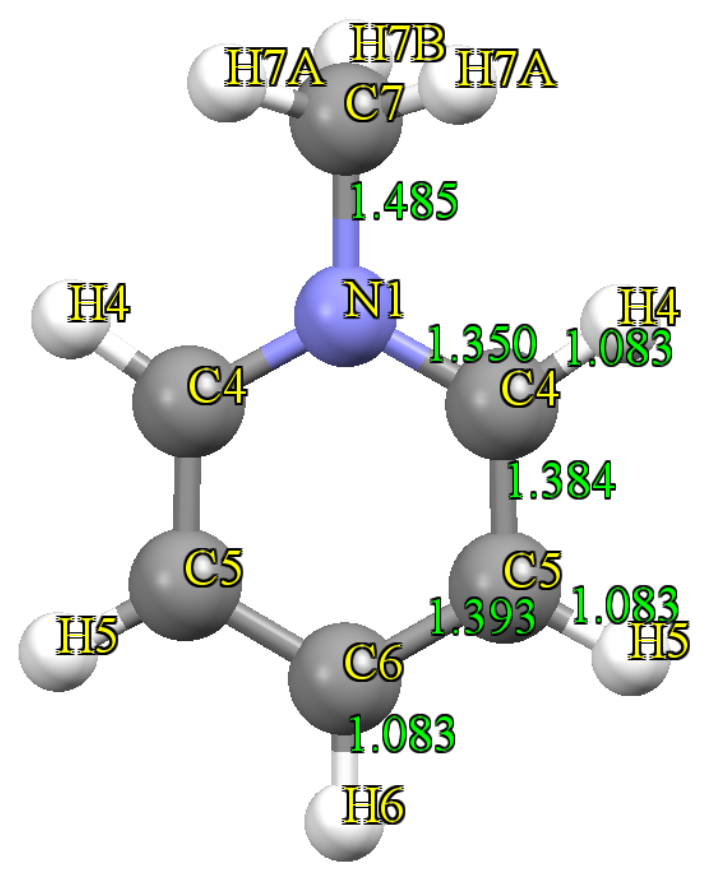

Figure S27 Crystallographic structure of $N$-methylpyridinium cation in $\mathrm{N}$-MePy$\cdot \mathrm{Cl}_{4} \mathrm{Q}$ (orthorhombic) crystal. Bond distances depicted in green $(\AA)$.

Table S23 Bond orders of $N$-methylpyridium cation in the $N$-MePy $\cdot \mathrm{Cl}_{4} \mathrm{Q}$ (orthorhombic) crystal calculated with B3LYP.

\begin{tabular}{ccccc}
\hline Bonds & Mayer & Fuzzy & Delocalization index & Wiberg (NBO) \\
\hline N1-C4 & 1.29 & 1.40 & 1.15 & 1.27 \\
C4-C5 & 1.45 & 1.46 & 1.37 & 1.47 \\
C5-C6 & 1.38 & 1.43 & 1.37 & 1.42 \\
N1-C7 & 0.85 & 1.11 & 0.88 & 0.91 \\
C4-H4 & 0.97 & 0.84 & 0.91 & 0.91 \\
C5H5 & 0.94 & 0.86 & 0.94 & 0.90 \\
C6H6 & 0.94 & 0.86 & 0.94 & 0.91 \\
C7-H7A & 0.96 & 0.87 & 0.93 & 0.93 \\
C7-H7B & 0.96 & 0.87 & 0.93 & 0.92 \\
\hline
\end{tabular}


Table S24 Bond orders of $N$-methylpyridium cation in the $N$-MePy $\cdot \mathrm{Cl}_{4} \mathrm{Q}$ (orthorhombic) crystal calculated with M06-2X.

\begin{tabular}{ccccc}
\hline Bonds & Mayer & Fuzzy & Delocalization index & Wiberg (NBO) \\
\hline N1-C4 & 1.23 & 1.40 & 1.14 & 1.27 \\
C4-C5 & 1.40 & 1.46 & 1.37 & 1.47 \\
C5-C6 & 1.37 & 1.43 & 1.37 & 1.42 \\
N1-C7 & 0.79 & 1.11 & 0.88 & 0.91 \\
C4-H4 & 0.83 & 0.84 & 0.91 & 0.91 \\
C5H5 & 0.80 & 0.86 & 0.94 & 0.90 \\
C6H6 & 0.80 & 0.85 & 0.94 & 0.90 \\
C7-H7A & 0.84 & 0.87 & 0.93 & 0.93 \\
C7-H7B & 0.80 & 0.87 & 0.93 & 0.92 \\
\hline
\end{tabular}




\section{System N-Me-Py·CI4Q (triclinic)}

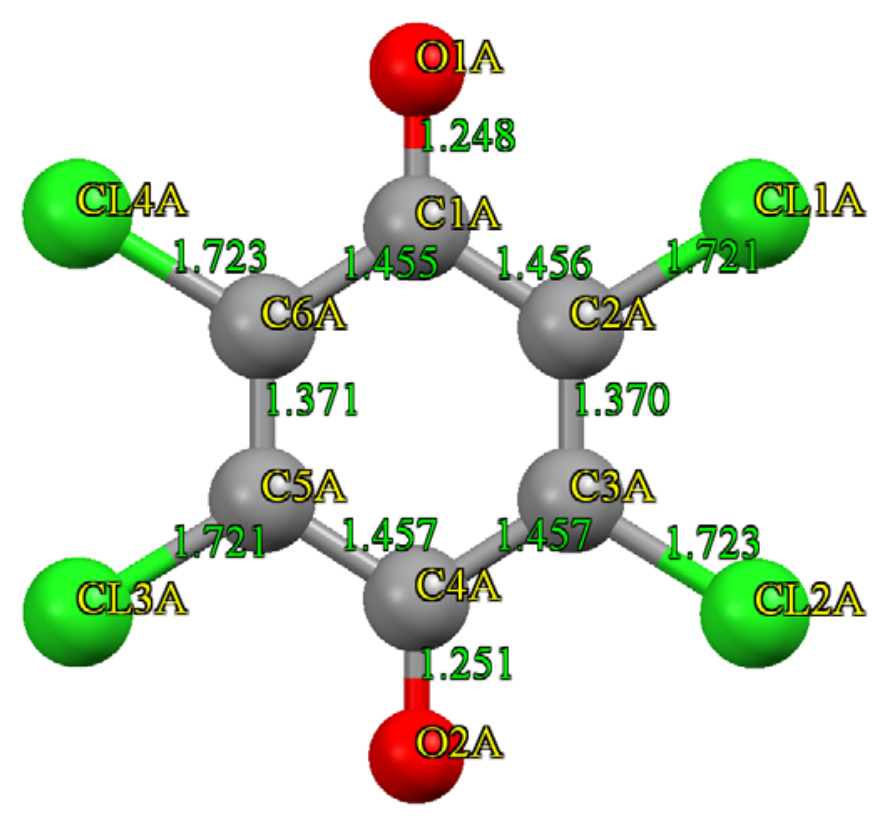

Figure S28 Crystallographic structure of tetrachlorosemiquinone radical anion in $\mathrm{N}-\mathrm{MePy} \cdot \mathrm{Cl}_{4} \mathrm{Q}$ (triclinic) crystal. Bond distances depicted in green $(\AA)$. 
Table S25 Bond orders of tetrachlorosemiquinone radical anion in the $N$-MePy $\cdot \mathrm{Cl} 4 \mathrm{Q}$ (triclinic) crystal calculated with B3LYP.

\begin{tabular}{rcccc}
\hline \multicolumn{1}{c}{ Bonds } & Mayer & Fuzzy & Delocalization index & Wiberg (NBO) \\
\hline C1A-C2A & 1.10 & 1.10 & 1.07 & 1.10 \\
C2A-C3A & 1.51 & 1.41 & 1.45 & 1.51 \\
C3A-C4A & 1.10 & 1.10 & 1.07 & 1.10 \\
C4A-C5A & 1.10 & 1.10 & 1.07 & 1.10 \\
C5A-C6A & 1.51 & 1.40 & 1.45 & 1.51 \\
C6A-C1A & 1.10 & 1.11 & 1.07 & 1.10 \\
C1A-O1A & 2.10 & 1.80 & 1.26 & 1.53 \\
C2A-C11A & 1.08 & 1.21 & 1.12 & 1.06 \\
C3A-C12A & 1.07 & 1.21 & 1.12 & 1.06 \\
C4A-O2A & 2.10 & 1.80 & 1.26 & 1.53 \\
C5A-Cl3A & 1.07 & 1.21 & 1.12 & 1.07 \\
C6A-C14A & 1.08 & 1.21 & 1.12 & 1.06 \\
\hline
\end{tabular}


Table S26 Bond orders of tetrachlorosemiquinone radical anion in the N-Me-Py·Cl4Q (triclinic) crystal calculated with M06-2X.

\begin{tabular}{|c|c|c|c|c|}
\hline Bonds & Mayer & Fuzzy & $\begin{array}{c}\text { Delocalization } \\
\text { index }\end{array}$ & Wiberg (NBO) \\
\hline $\mathrm{C} 1 \mathrm{~A}-\mathrm{C} 2 \mathrm{~A}$ & 1.17 & 1.10 & 1.06 & 1.10 \\
\hline $\mathrm{C} 2 \mathrm{~A}-\mathrm{C} 3 \mathrm{~A}$ & 1.55 & 1.42 & 1.47 & 1.53 \\
\hline $\mathrm{C} 3 \mathrm{~A}-\mathrm{C} 4 \mathrm{~A}$ & 1.16 & 1.10 & 1.06 & 1.10 \\
\hline C4A-C5A & 1.17 & 1.10 & 1.06 & 1.10 \\
\hline C5A-C6A & 1.55 & 1.42 & 1.47 & 1.53 \\
\hline C6A-C1A & 1.17 & 1.10 & 1.06 & 1.10 \\
\hline C1A-O1A & 1.80 & 1.81 & 1.25 & 1.53 \\
\hline C2A-C11A & 1.23 & 1.21 & 1.12 & 1.06 \\
\hline $\mathrm{C} 3 \mathrm{~A}-\mathrm{Cl} 2 \mathrm{~A}$ & 1.23 & 1.21 & 1.12 & 1.06 \\
\hline $\mathrm{C} 4 \mathrm{~A}-\mathrm{O} 2 \mathrm{~A}$ & 1.80 & 1.81 & 1.25 & 1.53 \\
\hline $\mathrm{C} 5 \mathrm{~A}-\mathrm{C} 13 \mathrm{~A}$ & 1.22 & 1.21 & 1.12 & 1.06 \\
\hline C6A-Cl4A & 1.23 & 1.21 & 1.12 & 1.06 \\
\hline
\end{tabular}


Figure S29 Crystallographic structure of $N$-methylpyridium cation in $\mathrm{N}$-MePy. $\mathrm{Cl}_{4} \mathrm{Q}$ (triclinic) crystal. Bond distances depicted in green $(\AA)$.

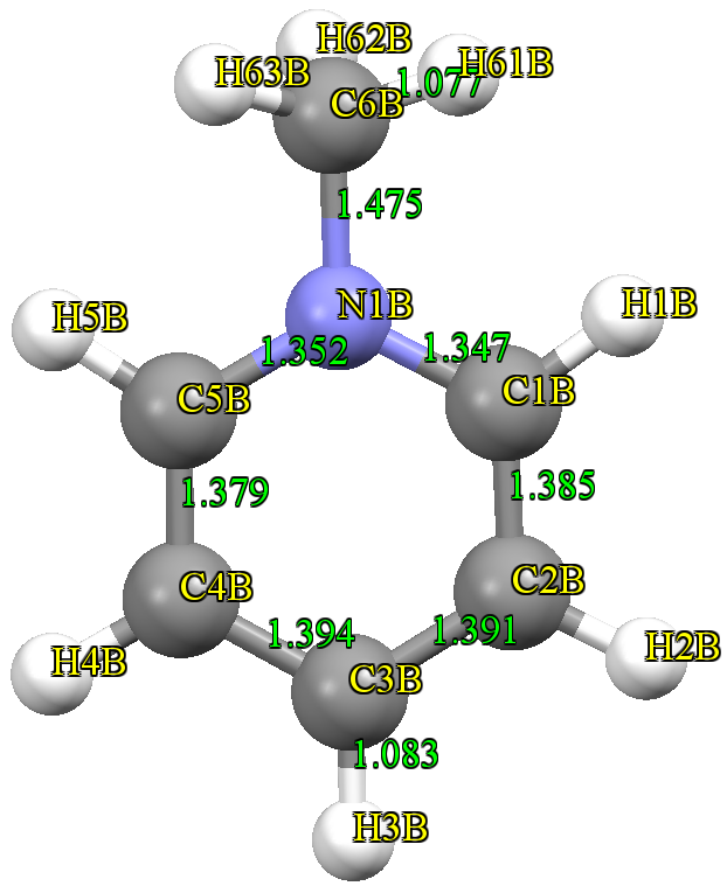

Table S27 Bond orders of $N$-methylpyridium cation in the $N$-MePy $\cdot \mathrm{Cl} 4 \mathrm{Q}$ (triclinic) crystal calculated with B3LYP.

\begin{tabular}{lccrr}
\hline Bonds & Mayer & Fuzzy & Delocalization index & Wiberg (NBO) \\
\hline N1B-C1B & 1.30 & 1.40 & 1.15 & 1.27 \\
C1B-C2B & 1.44 & 1.46 & 1.36 & 1.46 \\
C2B-C3B & 1.39 & 1.44 & 1.37 & 1.43 \\
C3B-C4B & 1.37 & 1.42 & 1.36 & 1.42 \\
C4B-C5B & 1.46 & 1.47 & 1.38 & 1.48 \\
C5B-N1B & 1.29 & 1.39 & 1.14 & 1.26 \\
N1B-C6B & 0.86 & 1.12 & 0.88 & 0.92 \\
C1B-H1B & 0.97 & 0.84 & 0.91 & 0.91 \\
C2B-H2B & 0.95 & 0.86 & 0.94 & 0.90 \\
C3B-H3B & 0.94 & 0.86 & 0.94 & 0.91 \\
C4B-H4B & 0.95 & 0.86 & 0.94 & 0.90 \\
C5B-H5B & 0.97 & 0.84 & 0.91 & 0.91 \\
C6B-H61B & 0.96 & 0.87 & 0.93 & 0.93 \\
C6B-H62B & 0.96 & 0.87 & 0.93 & 0.92 \\
C6B-H63B & 0.96 & 0.87 & 0.93 & 0.93 \\
\hline
\end{tabular}


Table S28 Bond orders of $N$-methylpyridium cation in the $N$-MePy. Cl4Q (triclinic) crystal calculated with M06-2X.

\begin{tabular}{lcccc}
\hline \multicolumn{1}{c}{ Bonds } & Mayer & Fuzzy & Delocalization index & Wiberg (NBO) \\
\hline N1B-C1B & 1.24 & 1.41 & 1.14 & 1.27 \\
C1B-C2B & 1.40 & 1.46 & 1.36 & 1.46 \\
C2B-C3B & 1.39 & 1.44 & 1.37 & 1.43 \\
C3B-C4B & 1.36 & 1.43 & 1.36 & 1.42 \\
C4B-C5B & 1.41 & 1.47 & 1.38 & 1.48 \\
C5B-N1B & 1.23 & 1.39 & 1.14 & 1.26 \\
N1B-C6B & 0.79 & 1.12 & 0.88 & 0.91 \\
C1B-H1B & 0.83 & 0.84 & 0.91 & 0.91 \\
C2B-H2B & 0.80 & 0.85 & 0.94 & 0.90 \\
C3B-H3B & 0.81 & 0.85 & 0.94 & 0.90 \\
C4B-H4B & 0.80 & 0.85 & 0.94 & 0.90 \\
C5B-H5B & 0.83 & 0.84 & 0.91 & 0.91 \\
C6B-H61B & 0.84 & 0.87 & 0.93 & 0.93 \\
C6B-H62B & 0.79 & 0.87 & 0.93 & 0.92 \\
C6B-H63B & 0.84 & 0.87 & 0.93 & 0.93 \\
\hline
\end{tabular}



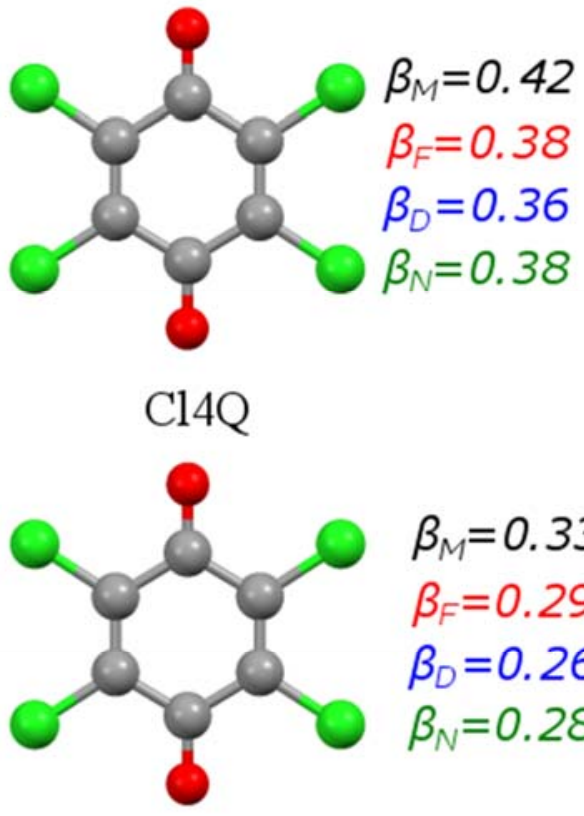

$\beta_{M}=0.33$

$\beta_{F}=0.29$

$\beta_{D}=0.26$

$\beta_{N}=0.28$

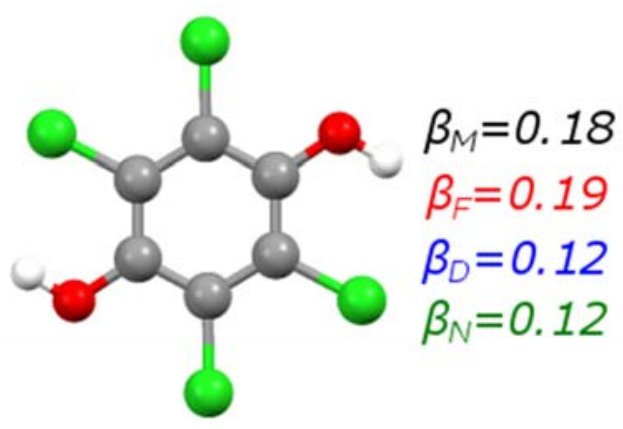

H2Cl4Q

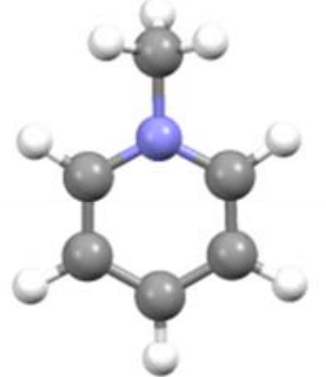

$\beta_{M}=0.15$

$\beta_{F}=0.04$

$\beta_{D}=0.14$

$\beta_{N}=0.11$
$\mathrm{N}-\mathrm{Me}-\mathrm{Py} \bullet \mathrm{Cl} 4 \mathrm{Q}$ (orthorhombic)

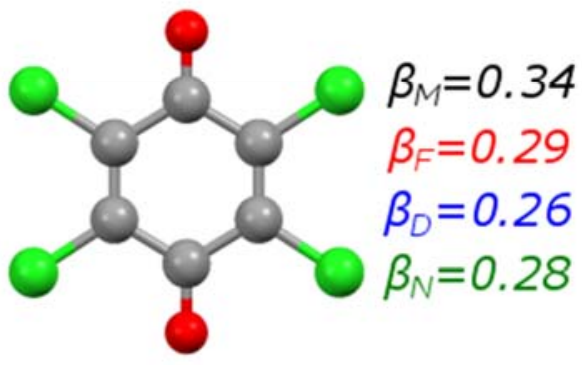

$\mathrm{N}-\mathrm{Me}-\mathrm{Py} \bullet \mathrm{Cl} 4 \mathrm{Q}$ (triclinic)
$\mathrm{N}-\mathrm{Me}-\mathrm{Py} \bullet \mathrm{Cl} 4 \mathrm{Q}$ (orthorhombic)

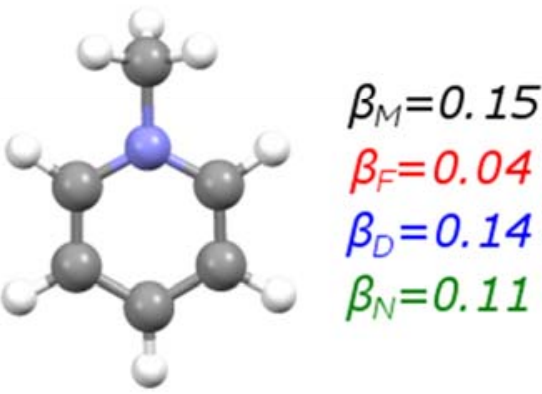

$\mathrm{N}-\mathrm{Me}-\mathrm{Py} \cdot \mathrm{Cl} 4 \mathrm{Q}$ (triclinic)

Figure S30 $\beta_{\mathrm{M}}, \beta_{\mathrm{F}}, \beta_{\mathrm{D}}$ and $\beta_{\mathrm{N}}$ indexes calculated with B3LYP for all molecules belonging to the $\mathrm{Cl}_{4} \mathrm{Q}, \mathrm{H}_{2} \mathrm{Cl}_{4} \mathrm{Q}, N-\mathrm{MePy} \cdot \mathrm{Cl}_{4} \mathrm{Q}$ (orthorhombic) $N$-MePy $\cdot \mathrm{Cl}_{4} \mathrm{Q}$ (triclinic) systems. 


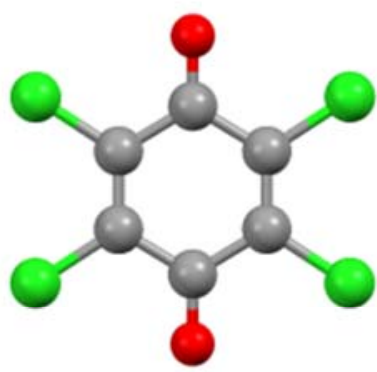

$\beta_{M}=0.40$

$\beta_{F}=0.39$

$\beta_{D}=0.38$

$\beta_{N}=0.40$

Cl4Q

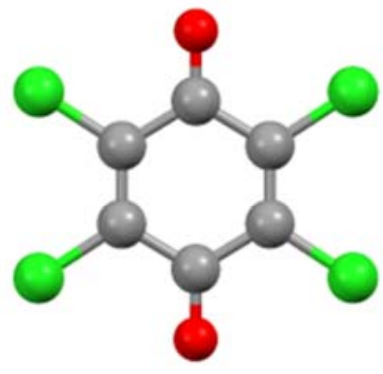

$\beta_{M}=0.29$

$\beta_{F}=0.30$

$\beta_{D}=0.27$

$\beta_{N}=0.29$

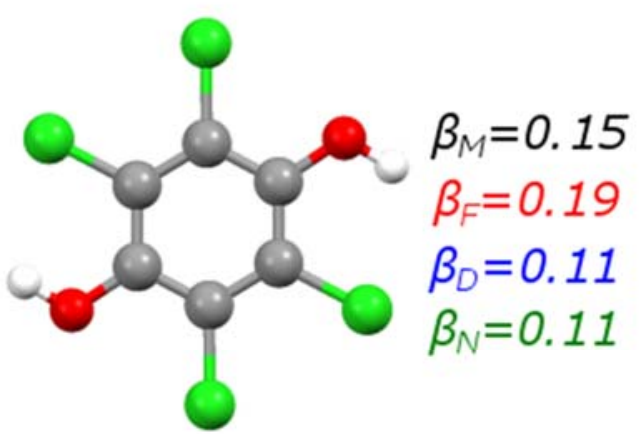

H2Cl4Q

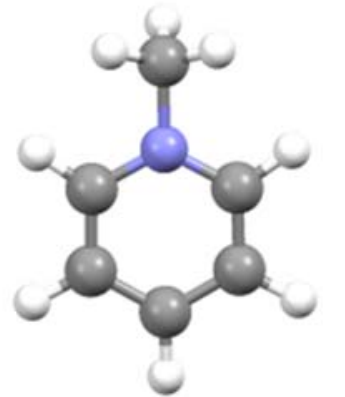

$\beta_{M}=0.21$

$\beta_{F}=0.04$

$\beta_{D}=0.14$

$\beta_{N}=0.10$
$\mathrm{N}-\mathrm{Me}-\mathrm{Py} \bullet \mathrm{Cl} 4 \mathrm{Q}$ (orthorhombic)

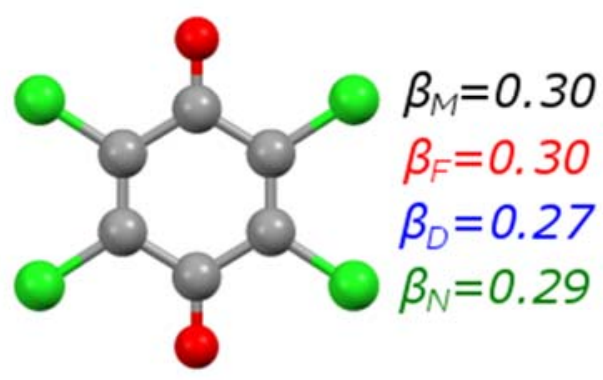

$\mathrm{N}-\mathrm{Me}-\mathrm{Py} \cdot \mathrm{Cl} 4 \mathrm{Q}$ (triclinic)
$\mathrm{N}-\mathrm{Me}-\mathrm{Py} \bullet \mathrm{Cl} 4 \mathrm{Q}$ (orthorhombic)

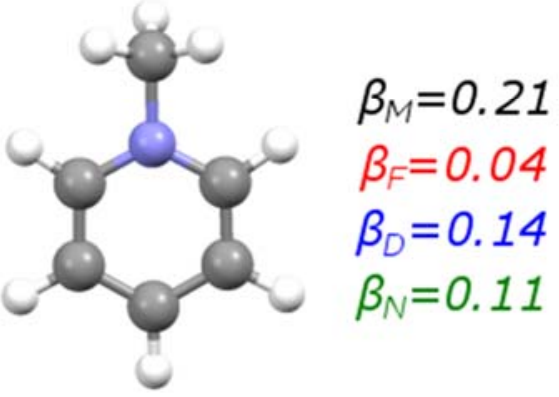

$\mathrm{N}-\mathrm{Me}-\mathrm{Py} \bullet \mathrm{Cl} 4 \mathrm{Q}$ (triclinic)

Figure S31 $\beta_{\mathrm{M}}, \beta_{\mathrm{F}}, \beta_{\mathrm{D}}$ and $\beta_{\mathrm{N}}$ indexes calculated with M06-2X for all molecules belonging to the $\mathrm{Cl}_{4} \mathrm{Q}, \mathrm{H}_{2} \mathrm{Cl}_{4} \mathrm{Q}, N$-MePy$\cdot \mathrm{Cl}_{4} \mathrm{Q}$ (orthorhombic) and $N$-MePy $\cdot \mathrm{Cl}_{4} \mathrm{Q}$ (triclinic) systems.
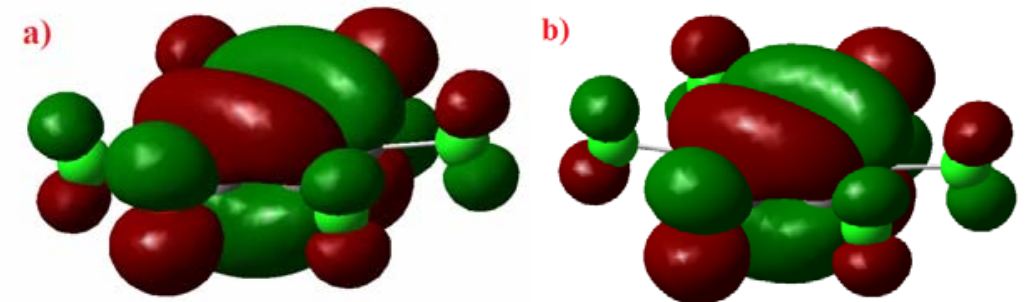

Figure S32 SOMOs of semiquinone in a) orthorhombic and b) triclinic systems. 


\section{INTERACTION ENERGIES}

DFT dimerization energies (DE) were computed as the energy difference between the dimer (homo or hetero) and two monomers (geometries were fixed in both cases to those found in the crystal) at the same level of theory. The advantage of using the def2QZVPP basis set is that BSSE error is minimized. Pixel DE are calculated within a different approach which considers semi-classical expressions for the evaluation of the electrostatic, polarization, dispersive and repulsive terms. In order to perform a correct interpretation of interaction energies it has to be considered that, while no charge transfer is observed for $\mathrm{Cl}_{4} \mathrm{Q}$ and $\mathrm{H}_{2} \mathrm{Cl}_{4} \mathrm{Q}$ systems, this phenomenon is relevant in the case of the $\mathrm{N}-\mathrm{MePy} \cdot \mathrm{Cl}_{4} \mathrm{Q}$ crystals, because of the tetrachlorosemiquinone monoanion and the $\mathrm{N}$ methylpyridinium cation formation. Scheme S1 shows the DFT DE calculated with both functionals for the selected dimers of the semiquinone crystals.

Scheme S1 DFT and PIXEL dimerization energies for each selected dimer. Charge transfer calculated with AIM partition is also reported for heterodimers.

\section{System $N$-MePy $\cdot \mathrm{Cl}_{4} \mathrm{Q}$ (orthorhombic)}

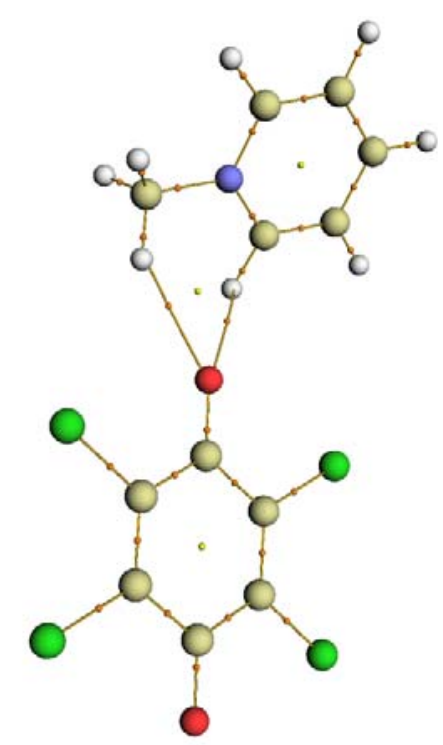

Dimer 1: Intermolecular $\mathrm{O} \cdots \mathrm{H}$ contacts involved.

DE (B3LYP-D3(BJ) $=\mathbf{- 7 1 . 4} \mathrm{kcal} / \mathrm{mol} \mid \mathrm{CT}=0.85$ electrons

$\mathrm{DE}(\mathrm{M} 06-2 \mathrm{X}-\mathrm{D} 3)=\mathbf{- 7 0 . 5} \mathrm{kcal} / \mathrm{mol} \mid \mathrm{CT}=0.96$ electrons 


\begin{tabular}{lccccc}
\hline PIXEL & Electrostatic & Polarization & Dispersion & Repulsion & Total \\
\hline $\mathrm{kcal} / \mathrm{mol}$ & -64.6 & -8.2 & -4.3 & +6.8 & $\mathbf{- 7 0 . 3}$ \\
\hline
\end{tabular}

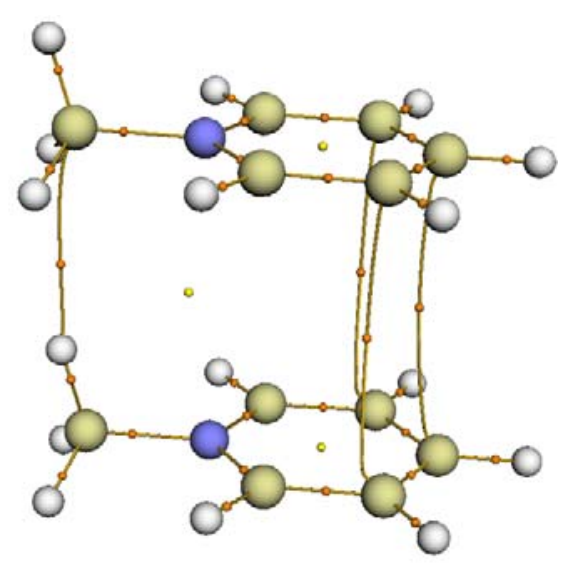

Dimer 2: Intermolecular $\mathrm{C} \cdots \mathrm{C}$ and $\mathrm{C} \cdots \mathrm{H}$ contacts involved. $\mathrm{DE}=-3.6 \mathrm{kcal} / \mathrm{mol}$ DE (B3LYP-D3(BJ) $=+\mathbf{5 9 . 2} \mathrm{kcal} / \mathrm{mol}$

$\mathrm{DE}(\mathrm{M} 06-2 \mathrm{X}-\mathrm{D} 3)=+\mathbf{6 0 . 4} \mathrm{kcal} / \mathrm{mol}$

\begin{tabular}{cccccc} 
PIXEL & Electrostatic & Polarization & Dispersion & Repulsion & Total \\
\hline $\mathrm{kcal} / \mathrm{mol}$ & +65.7 & -6.3 & -4.9 & +2.3 & $\mathbf{+ 5 6 . 7}$ \\
\hline
\end{tabular}

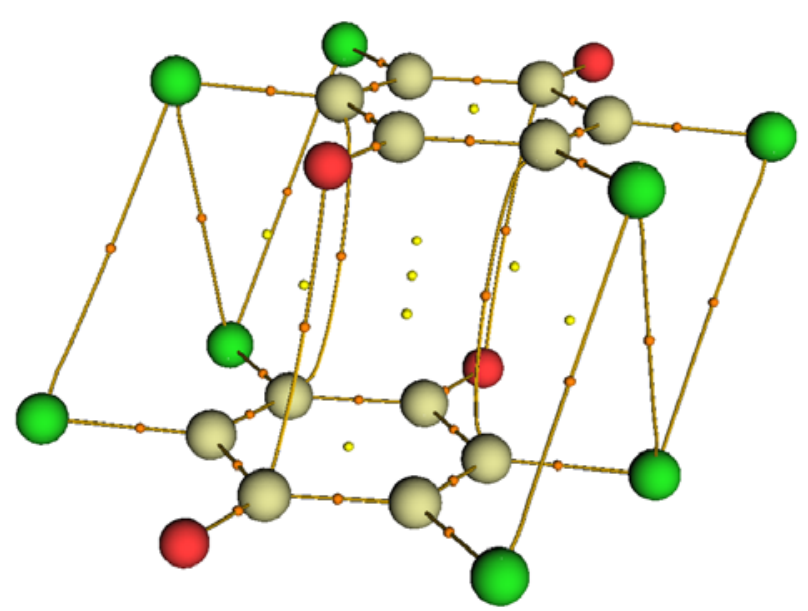

Dimer 3: Intermolecular $\mathrm{C} \cdots \mathrm{C}, \mathrm{O} \cdots \mathrm{C}$ and $\mathrm{Cl} \cdots \mathrm{Cl}$ contacts involved.

DE $($ B3LYP-D3(BJ) $=+\mathbf{4 5 . 1} \mathrm{kcal} / \mathrm{mol}$

DE $($ M06-2X-D3 $)=+\mathbf{4 5 . 3} \mathrm{kcal} / \mathrm{mol}$

\begin{tabular}{cccccc}
\hline PIXEL & Electrostatic & Polarization & Dispersion & Repulsion & Total \\
\hline $\mathrm{kcal} / \mathrm{mol}$ & +56.4 & -9.2 & -17.9 & +19.7 & $\mathbf{+ 4 8 . 9}$ \\
\hline
\end{tabular}




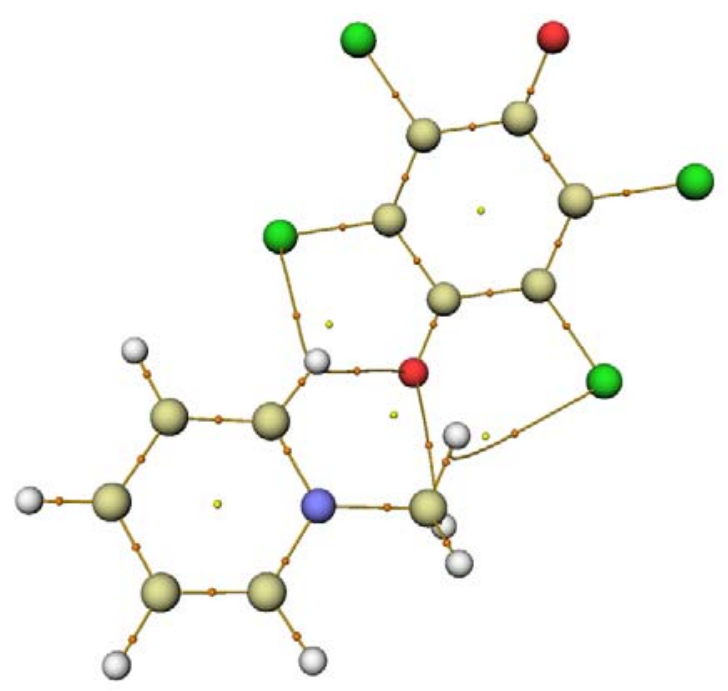

Dimer 4: Intermolecular $\mathrm{Cl} \cdots \mathrm{C}, \mathrm{O} \cdots \mathrm{C}$ and $\mathrm{Cl} \cdots \mathrm{H}$ contacts involved.

DE (B3LYP-D3(BJ) $=\mathbf{- 7 0 . 5} \mathbf{~ k c a l} / \mathrm{mol} \mid \mathrm{CT}=0.85$ electrons

$\mathrm{DE}(\mathrm{M} 06-2 \mathrm{X}-\mathrm{D} 3)=\mathbf{- 6 9 . 2} \mathrm{kcal} / \mathrm{mol} \mid \mathrm{CT}=0.95$ electrons

$\begin{array}{lllll}\text { PIXEL Electrostatic } & \text { Polarization Dispersion Repulsion Total }\end{array}$

\begin{tabular}{llllll}
\hline $\mathrm{kcal} / \mathrm{mol}$ & -60.9 & -7.4 & -6.0 & +4.3 & $\mathbf{- 7 0 . 0}$
\end{tabular}

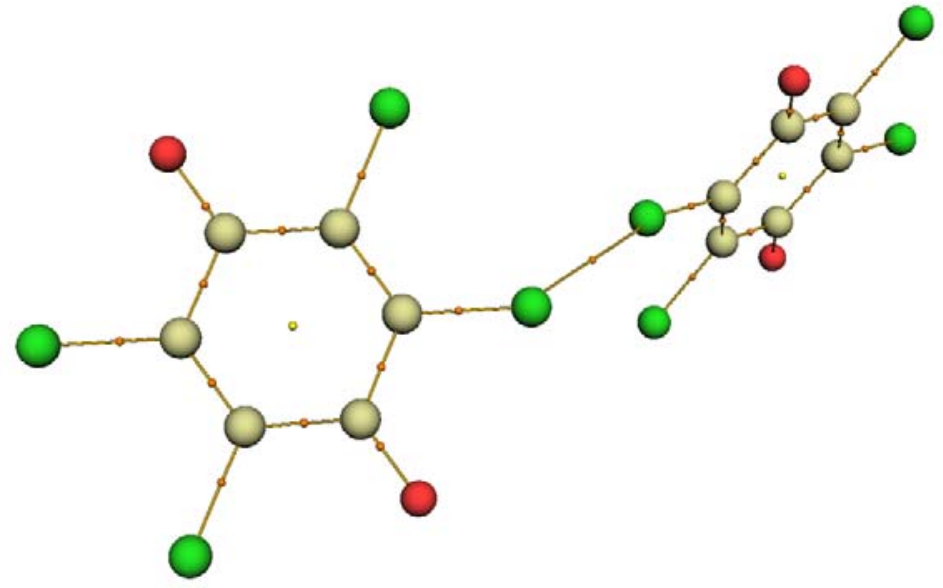

Dimer 5: Intermolecular $\mathrm{Cl} \cdots \mathrm{Cl}$ contacts involved.

DE $(\mathrm{B} 3 \mathrm{LYP}-\mathrm{D} 3(\mathrm{BJ})=+\mathbf{3 3} . \mathbf{5} \mathrm{kcal} / \mathrm{mol}$

$\mathrm{DE}(\mathrm{M} 06-2 \mathrm{X}-\mathrm{D} 3)=\boldsymbol{+} \mathbf{3 3 . 8} \mathrm{kcal} / \mathrm{mol}$

\begin{tabular}{lccccc}
\hline PIXEL & Electrostatic & Polarization & Dispersion & Repulsion & Total \\
\hline $\mathrm{kcal} / \mathrm{mol}$ & +35.4 & -1.5 & -1.9 & +1.4 & $\mathbf{+ 3 3 . 5}$ \\
\hline
\end{tabular}



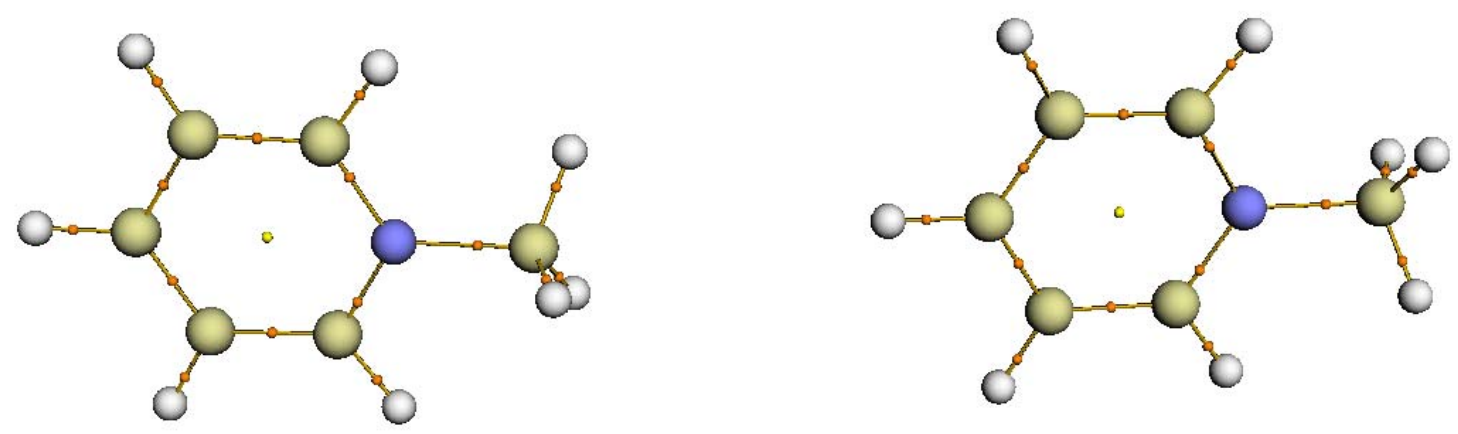

Dimer 6: No intermolecular BCP found.

DE $(B 3 L Y P-D 3(B J)=+38.4 \mathrm{kcal} / \mathrm{mol}$

$\mathrm{DE}(\mathrm{M} 06-2 \mathrm{X}-\mathrm{D} 3)=+\mathbf{3 8 . 5} \mathrm{kcal} / \mathrm{mol}$

PIXEL Electrostatic Polarization Dispersion Repulsion

Total

$\mathrm{kcal} / \mathrm{mol}$

$+39.6$

$-1.1$

$-0.3$

0.0

$+38.2$

\section{System $N-\mathrm{MePy} \cdot \mathrm{Cl}_{4} \mathrm{Q}$ (triclinic)}

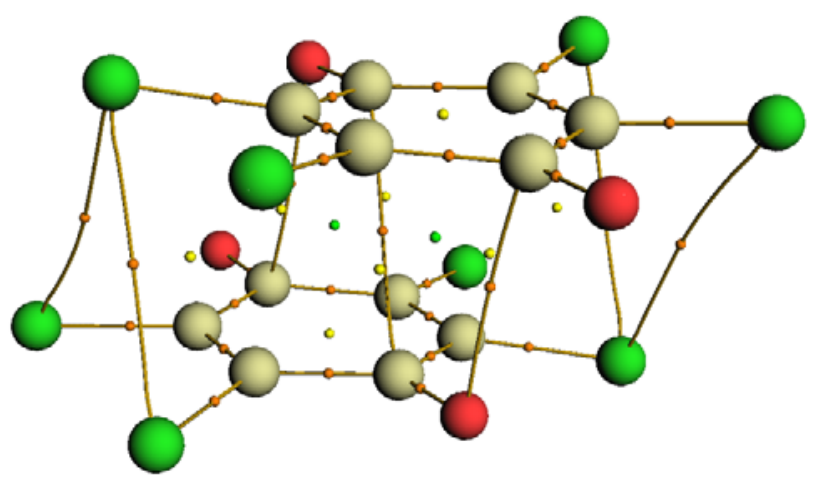

Dimer 1: Intermolecular $\mathrm{C} \cdots \mathrm{C}, \mathrm{Cl} \cdots \mathrm{Cl}$ and $\mathrm{C} \cdots \mathrm{O}$ contacts involved.

DE (B3LYP-D3(BJ) $=+\mathbf{4 5 . 1} \mathrm{kcal} / \mathrm{mol}$

DE $(\mathrm{M} 06-2 \mathrm{X}-\mathrm{D} 3)=+\mathbf{4 6 . 0} \mathrm{kcal} / \mathrm{mol}$

\begin{tabular}{|c|c|c|c|c|}
\hline Electrostatic & Polarization & Dispersion & Repulsion & Total \\
\hline
\end{tabular}

\begin{tabular}{llllll}
\hline $\mathrm{kcal} / \mathrm{mol}$ & +50.4 & -15.5 & -23.0 & +43.7 & $+\mathbf{5 5 . 6}$
\end{tabular}




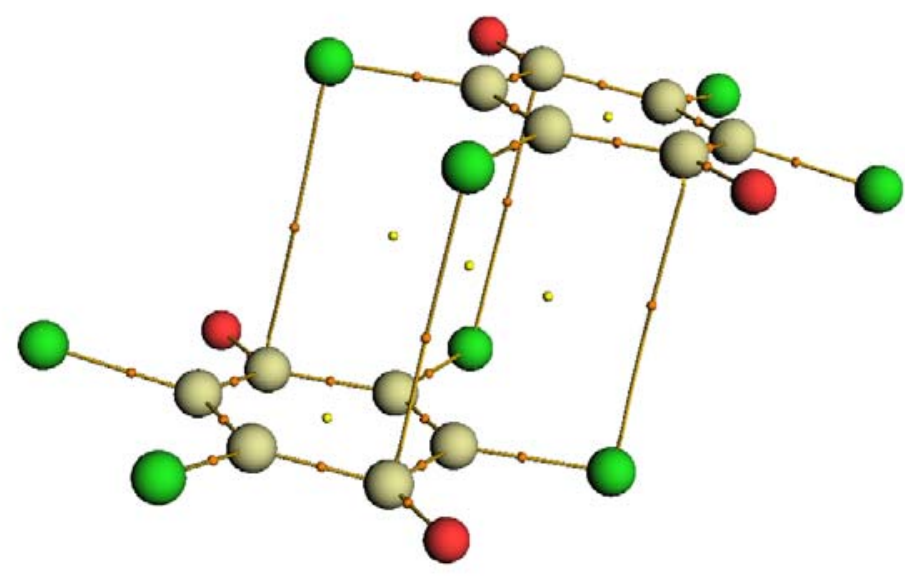

Dimer 2: Intermolecular $\mathrm{Cl} \cdots \mathrm{C}$ contacts involved.

DE $(B 3 L Y P-D 3(B J)=+44.0 \mathrm{kcal} / \mathrm{mol}$

DE $($ M06-2X-D3 $)=+45.7 \mathrm{kcal} / \mathrm{mol}$

\begin{tabular}{rrrrrr}
\hline PIXEL & Electrostatic & Polarization & Dispersion & Repulsion & Total \\
\hline $\mathrm{kcal} / \mathrm{mol}$ & +54.3 & -5.8 & -11.7 & +8.0 & $\mathbf{+ 4 4 . 9}$
\end{tabular}

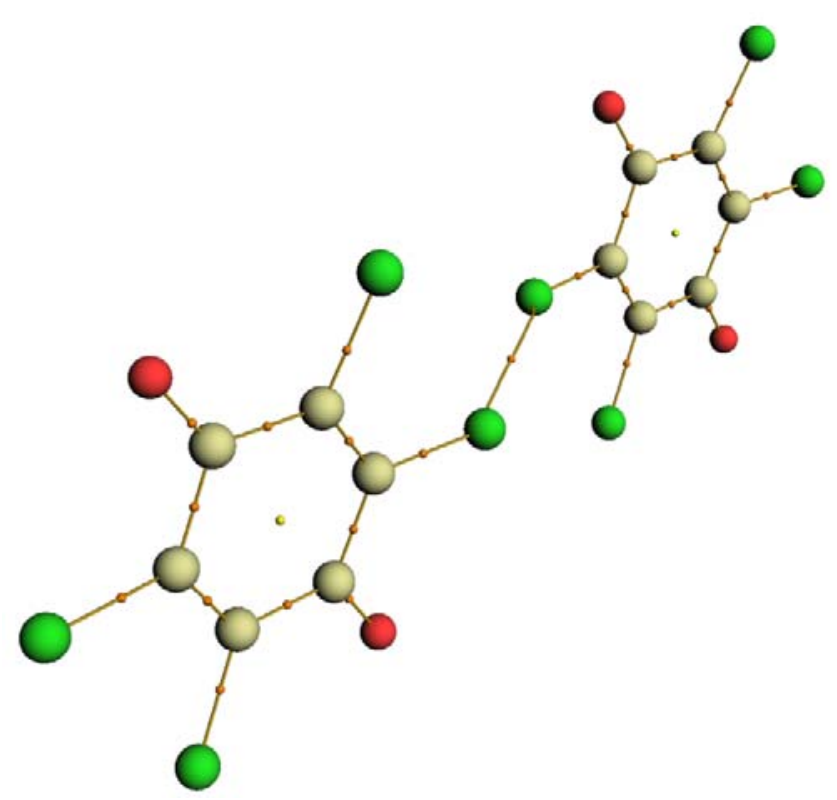

Dimer 3: Intermolecular $\mathrm{Cl} \cdots \mathrm{C}$ contacts involved.

DE $($ B3LYP-D3(BJ) $=+\mathbf{3 4 . 1} \mathrm{kcal} / \mathrm{mol}$

DE $(\mathrm{M} 06-2 \mathrm{X}-\mathrm{D} 3)=\mathbf{+ 3 4 . 5} \mathrm{kcal} / \mathrm{mol}$

\begin{tabular}{rrrrrr}
\hline PIXEL & Electrostatic & Polarization & Dispersion & Repulsion & Total \\
\hline $\mathrm{kcal} / \mathrm{mol}$ & +35.8 & -1.7 & -2.2 & +2.4 & $\mathbf{+ 3 4 . 2}$
\end{tabular}




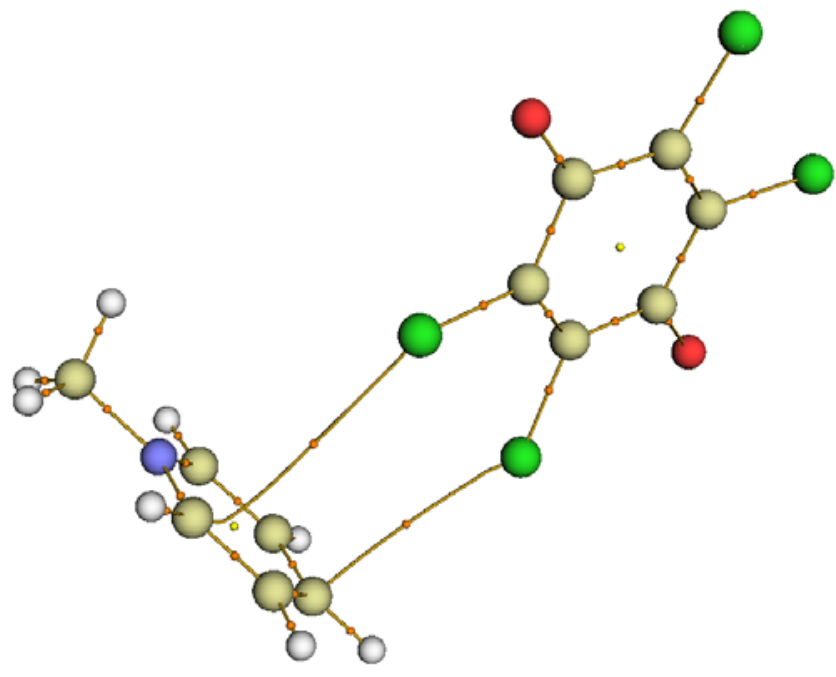

Dimer 4: Intermolecular $\mathrm{Cl} \cdots \mathrm{C}$ contacts involved.

DE $(\mathrm{B} 3 \mathrm{LYP}-\mathrm{D} 3(\mathrm{BJ})=\mathbf{- 5 9 . 3} \mathrm{kcal} / \mathrm{mol} \mid \mathrm{CT}=0.66$ electrons

$\mathrm{DE}(\mathrm{M} 06-2 \mathrm{X}-\mathrm{D} 3)=\mathbf{- 5 3 . 6} \mathrm{kcal} / \mathrm{mol} \mid \mathrm{CT}=0.97$ electrons

\begin{tabular}{rrrrrr}
\hline PIXEL & Electrostatic & Polarization & Dispersion & Repulsion & Total \\
\hline $\mathrm{kcal} / \mathrm{mol}$ & -48.7 & -3.6 & -4.1 & +2.9 & $\mathbf{- 5 3 . 4}$ \\
\hline
\end{tabular}

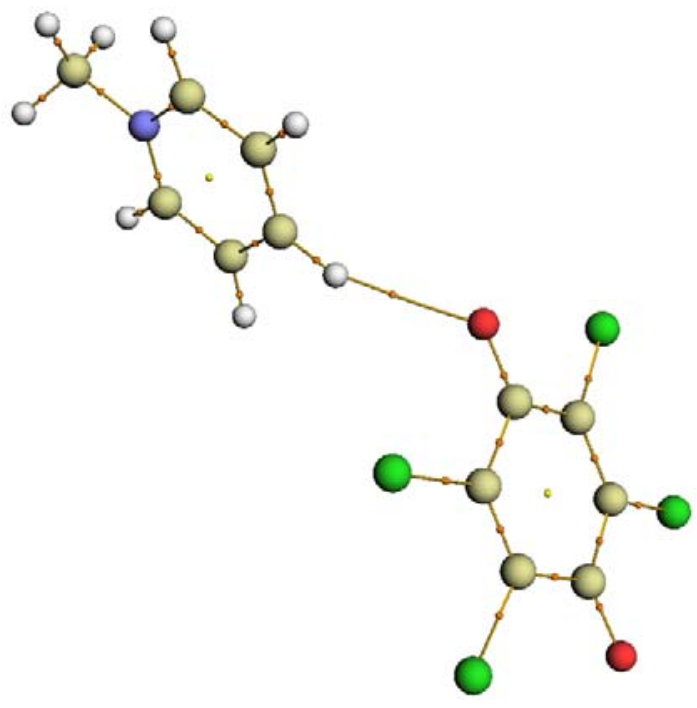

Dimer 5: Intermolecular $\mathrm{O} \cdots \mathrm{H}$ contacts involved.

DE (B3LYP-D3(BJ) $=\mathbf{- 6 1 . 3} \mathrm{kcal} / \mathrm{mol} \mid \mathrm{CT}=0.68$ electrons

$\mathrm{DE}(\mathrm{M} 06-2 \mathrm{X}-\mathrm{D} 3)=\mathbf{- 5 6 . 2} \mathrm{kcal} / \mathrm{mol} \mid \mathrm{CT}=0.97$ electrons 


\begin{tabular}{rrrrrr}
\hline PIXEL & Electrostatic & Polarization & Dispersion & Repulsion & Total \\
\hline $\mathrm{kcal} / \mathrm{mol}$ & -48.9 & -4.0 & -2.2 & +2.4 & $\mathbf{- 5 2 . 7}$ \\
\hline
\end{tabular}

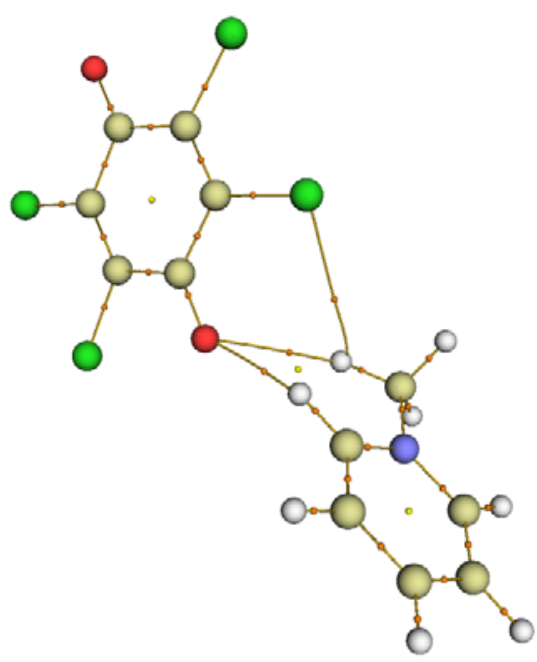

Dimer 6: Intermolecular $\mathrm{O} \cdots \mathrm{H}$ and $\mathrm{Cl} \cdots \mathrm{H}$ contacts involved.

DE (B3LYP-D3(BJ) $=\mathbf{- 7 0 . 8} \mathrm{kcal} / \mathrm{mol} \mid \mathrm{CT}=0.81$ electrons

$\mathrm{DE}(\mathrm{M} 06-2 \mathrm{X}-\mathrm{D} 3)=\mathbf{- 6 9 . 6} \mathrm{kcal} / \mathrm{mol} \mid \mathrm{CT}=0.96$ electrons

\begin{tabular}{rrrrrr}
\hline PIXEL & Electrostatic & Polarization & Dispersion & Repulsion & Total \\
\hline $\mathrm{kcal} / \mathrm{mol}$ & -65.9 & -8.3 & -4.5 & +5.9 & $\mathbf{- 7 2 . 8}$
\end{tabular}

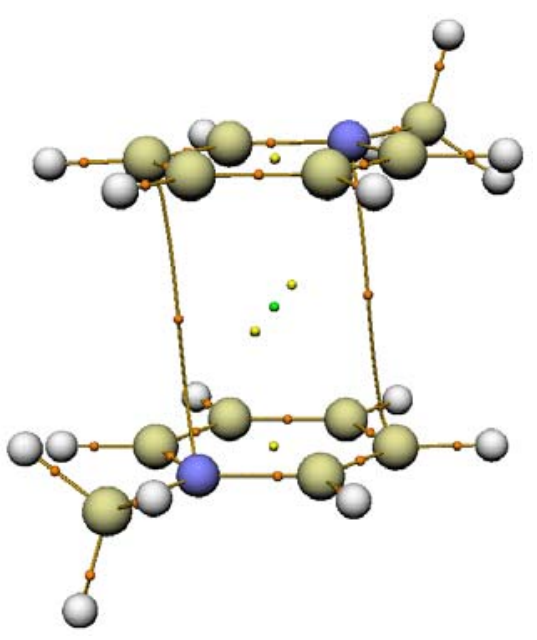

Dimer 7: Intermolecular $\mathrm{N} \cdots \mathrm{C}$ contacts involved.

DE $(B 3 L Y P-D 3(B J)=+59.4 \mathrm{kcal} / \mathrm{mol}$

$\mathrm{DE}(\mathrm{M} 06-2 \mathrm{X}-\mathrm{D} 3)=+\mathbf{5 9 . 9} \mathrm{kcal} / \mathrm{mol}$ 


\begin{tabular}{lrrrrr}
\hline PIXEL & Electrostatic & Polarization & Dispersion & Repulsion & Total \\
\hline $\mathrm{kcal} / \mathrm{mol}$ & +67.2 & -7.3 & -7.1 & +4.2 & $\mathbf{+ 5 7 . 1}$ \\
\hline
\end{tabular}

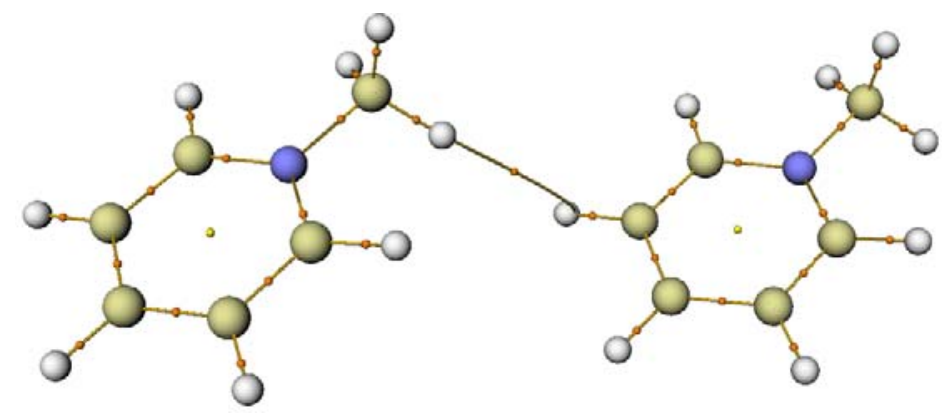

Dimer 8: Intermolecular $\mathrm{H} \cdots \mathrm{H}$ contacts involved.

DE (B3LYP-D3(BJ) $=+\mathbf{4 4 . 4} \mathrm{kcal} / \mathrm{mol}$

DE $(\mathrm{M} 06-2 \mathrm{X}-\mathrm{D} 3)=+\mathbf{4 4 . 7} \mathrm{kcal} / \mathrm{mol}$

\begin{tabular}{lrrrrr}
\hline PIXEL & Electrostatic & Polarization & Dispersion & Repulsion & Total \\
\hline $\mathrm{kcal} / \mathrm{mol}$ & +46.8 & -2.1 & -0.7 & +0.1 & $\mathbf{+ 4 4 . 1}$ \\
\hline
\end{tabular}

DFT tetramerization energies (TE) of the semiquinone species (TE) were computed as the energy difference between the tetramer and four monomers (two anions and two cations, geometries were fixed in both cases to those found in the crystal) at the broken symmetry B3LYP-D3(BJ)/def2QZVPP level of theory. Three types of tetramers were selected: I) Anion-anion, cation-cation and anion-cation close contacts present, II) Anion-anion and anion-cation close contacts present, and III) cation-cation and anion-cation close contacts present (Scheme 1I). As was expected from the dimerization energies reported in our previous results, the favorable anion-cation interaction compensates for the anion-anion and cation-cation repulsion, therefore the tetramer (hence the crystal structure) is stabilized. Just as in the case of the dimers, the wavefunction stability test revealed an open-shell ground state electronic configuration for these complexes. 
Scheme S2 DFT tetramerization energies (TE) for each type of tetramer of the $\mathrm{N}-\mathrm{MePy} \cdot \mathrm{Cl}_{4} \mathrm{Q}$ orthorhombic and triclinic systems.

\section{$\mathrm{N}-\mathrm{MePy} \cdot \mathrm{Cl}_{4} \mathrm{Q}$ (orthorhombic)}

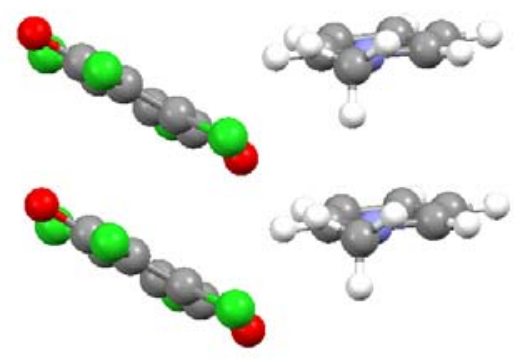

I) $\quad$ TE $(B 3 L Y P-D 3(B J))=\mathbf{- 1 6 1 . 2 ~} \mathrm{kcal} / \mathrm{mol}$

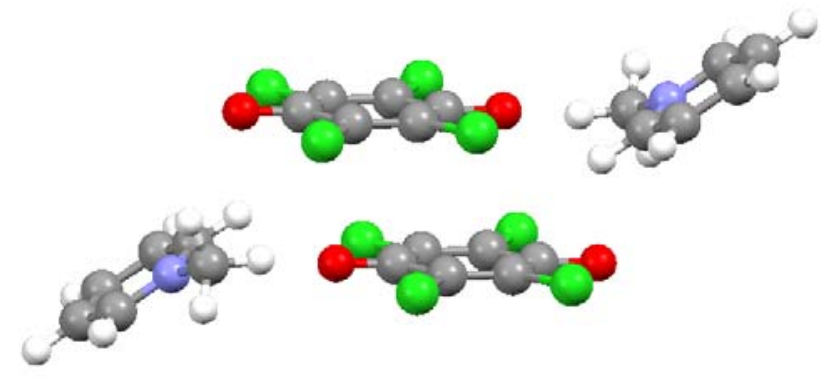

II) $\quad$ TE (B3LYP-D3(BJ)) $=\mathbf{- 1 5 0 . 8} \mathrm{kcal} / \mathrm{mol}$

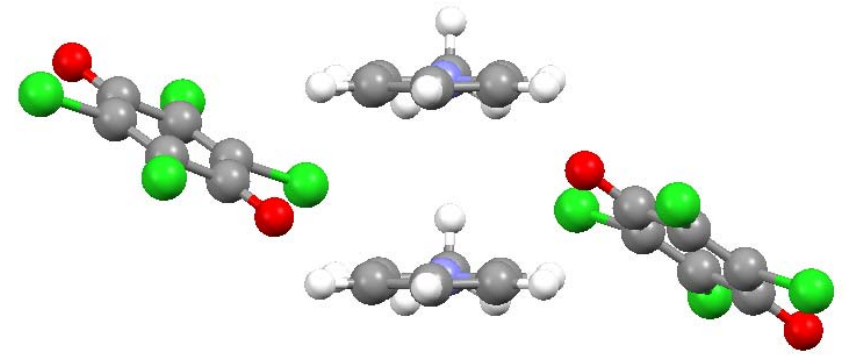

III) $\quad$ TE (B3LYP-D3(BJ)) $=\mathbf{- 1 8 5 . 9 ~} \mathrm{kcal} / \mathrm{mol}$ 


\section{N-Me-Py•Cl4Q (triclinic)}
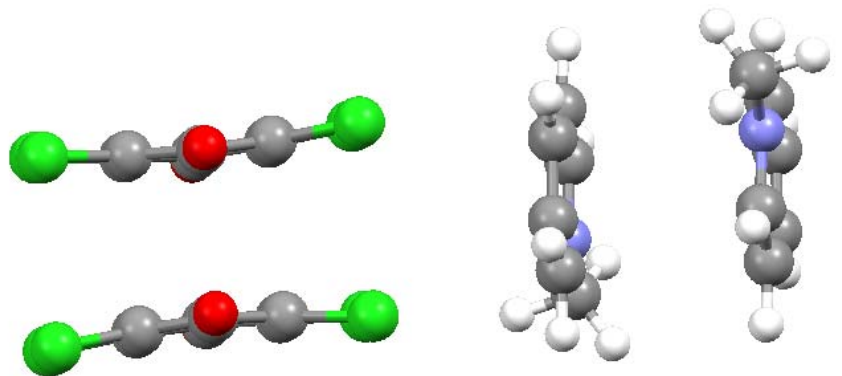

I) $\quad$ TE (B3LYP-D3(BJ) $)=\mathbf{- 1 3 8 . 7} \mathrm{kcal} / \mathrm{mol}$
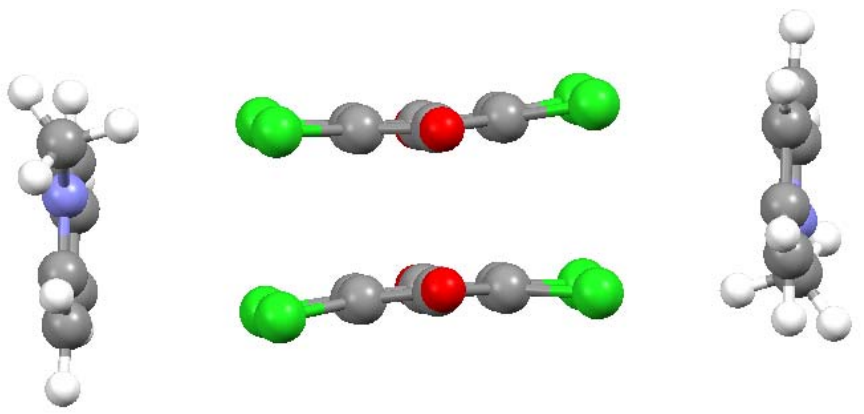

II) $\quad$ TE (B3LYP-D3(BJ)) $=\mathbf{- 1 4 6 . 4 ~ k c a l} / \mathrm{mol}$
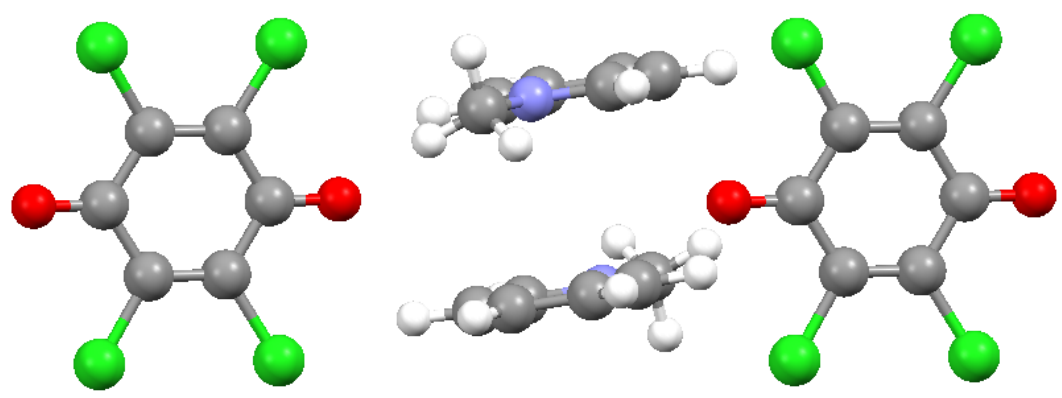

III) $\quad$ TE $(B 3 L Y P-D 3(B J))=\mathbf{- 1 6 2 . 5} \mathrm{kcal} / \mathrm{mol}$ 
Lattice energies and their decomposition in electrostatic, polarization, dispersive and repulsive terms of the $\mathrm{Cl} 4 \mathrm{Q}, \mathrm{H} 2 \mathrm{Cl} 4 \mathrm{Q}$ and $\mathrm{N}-\mathrm{Me}-\mathrm{Py} \cdot \mathrm{Cl} 4 \mathrm{Q}$ (triclinic) systems are reported in Table S30. Percentages of the attractive contributions to the LE are depicted in Figure S28. Just as in the molecular case, LE of the chloranil crystal is dominated by dispersion. Even though this effect is also relevant for the tetrachlorohydroquinone solid, polarization and electrostatics contribute to almost half of the energetic stabilization, result of the hydrogen bonds formation. By contrast, in the $\mathrm{N}-\mathrm{Me}-\mathrm{Py} \cdot \mathrm{Cl} 4 \mathrm{Q}$ (triclinic) system the predominant interaction has an electrostatic origin, consequence of charge transfer. Although, LE of the N-Me-Py ${ }^{-C l 4 Q}$ (orthorhombic) crystal couldn't be computed for the reasons explained in the Details and protocols of quantum chemical computation of the main article, it is expected to display a similar behavior to that of the N-Me$\mathrm{Py} \cdot \mathrm{Cl}$ LQ (triclinic) solid.

Table S29 Decomposition analysis of lattice energies of the $\mathrm{Cl}_{4} \mathrm{Q}, \mathrm{H}_{2} \mathrm{Cl}_{4} \mathrm{Q}$ and $\mathrm{N}-\mathrm{MePy} \cdot \mathrm{Cl}_{4} \mathrm{Q}$ (triclinic) systems calculated with PIXEL. All values in $\mathrm{kcal} / \mathrm{mol}$.

\begin{tabular}{lrrrrr}
\hline System & Electrostatic & Polarization & Dispersion & Repulsion & Total \\
\hline C14Q & -12.5 & -4.3 & -32.5 & 24.9 & $\mathbf{- 2 4 . 4}$ \\
H2Cl4Q & -22.1 & -11.0 & -40.8 & 37.4 & $\mathbf{- 3 6 . 4}$ \\
$\begin{array}{l}\text { N-Me-Py•C14Q } \\
\text { (triclinic) }\end{array}$ & -61.3 & -8.6 & -32.5 & 32.1 & $\mathbf{- 7 0 . 4}$ \\
\hline
\end{tabular}

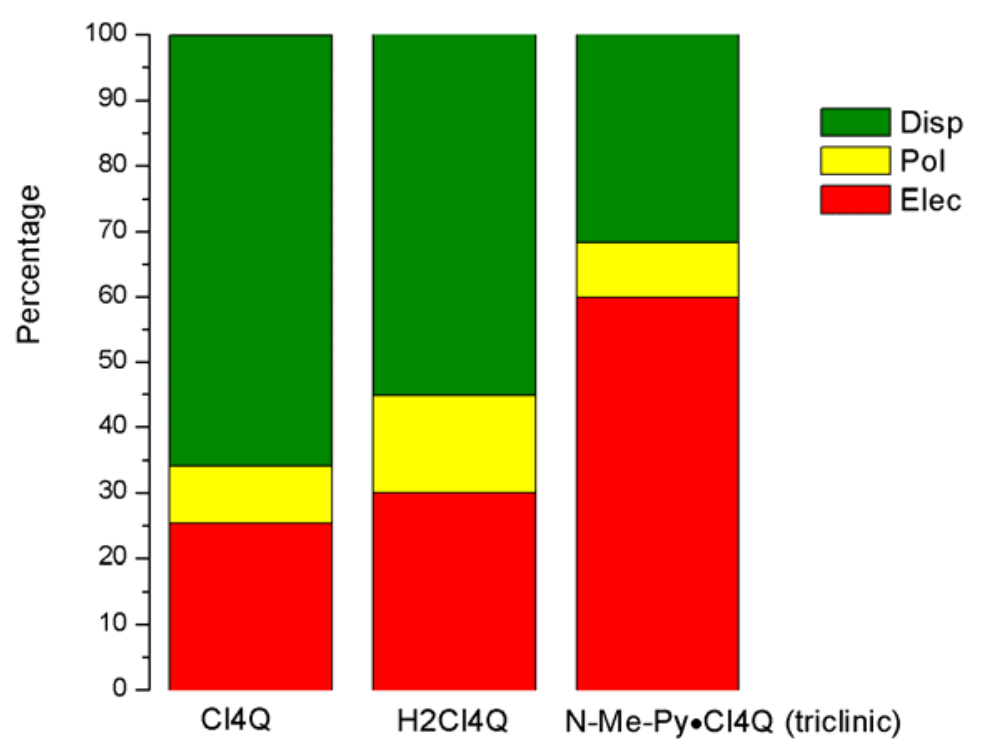

Figure S33 Percentages of the dispersive (Disp), polarization (Pol) and electrostatic (Elec) contributions to the attractive components of the lattice energies of the $\mathrm{Cl}_{4} \mathrm{Q}, \mathrm{H}_{2} \mathrm{Cl}_{4} \mathrm{Q}$ and $\mathrm{N}$ $\mathrm{MePy} \cdot \mathrm{Cl}_{4} \mathrm{Q}$ (triclinic) systems calculated with PIXEL. 


\section{CASPT2 computations}

CASPT2/aug-cc-pvdz calculations for the closest contact dimers of the semiquinone from the orthorombic and triclinic crystals were carried out to assess their multiconfigurational nature. The weights of the most important configurations are provided in Tables S31 and S32, revealing the multireferencial character of both semiquinone systems. CASSCF wavefunctions (active space of 10 electrons in $10 \pi$-orbitals conforming the active space) were used as references for the CASPT2 computations. Cholesky decomposition for the evaluation of the two-electron integral was employed. The occupation of the ten $\pi$ active orbitals is indicated by the number and spin of the electrons in each one ( 2 means two paired electrons; 0 no electrons; " $u$ " a single electron with up spin and "d" a single electron with down spin).

Table S30 Configurations with non-negligible weights of the semiquinone dimer taken from the orthohombic systems obtained from CASPT2 calculations.

\begin{tabular}{cccc}
\hline Configuration & Occupation & Coefficient & Weight \\
\hline 1 & 222200000 & -0.803930 & 0.646304 \\
27 & 2222020000 & 0.477195 & 0.227715 \\
43 & $222 \mathrm{udud} 000$ & 0.053558 & 0.002868 \\
78 & $2 \mathrm{u} 22 \mathrm{du} 00 \mathrm{~d} 0$ & -0.052513 & 0.002758 \\
104 & 2220202000 & 0.053388 & 0.002850 \\
107 & 2220200200 & 0.050254 & 0.002525 \\
121 & $22 \mathrm{ud} 20 \mathrm{ud} 00$ & 0.100880 & 0.010177 \\
133 & $2 \mathrm{u} 2 \mathrm{~d} 2 \mathrm{ud} 000$ & 0.070228 & 0.004932 \\
150 & $\mathrm{u} 22 \mathrm{~d} 2 \mathrm{u} 0 \mathrm{~d} 00$ & -0.067819 & 0.004599 \\
180 & $2 \mathrm{ud} 22 \mathrm{u} 0 \mathrm{~d} 00$ & 0.066296 & 0.004395 \\
193 & $\mathrm{u} 2 \mathrm{~d} 22 \mathrm{ud} 000$ & -0.065494 & 0.004289 \\
226 & $\mathrm{ud} 2220 \mathrm{ud} 00$ & -0.061943 & 0.003837 \\
2003 & $22 \mathrm{ud} 02 \mathrm{ud} 00$ & -0.060301 & 0.003636 \\
\hline
\end{tabular}


Table S31 Configurations with non-negligible weights of the semiquinone dimer taken from the triclinic systems obtained from CASPT2 calculations.

\begin{tabular}{cccc}
\hline Configuration & Occupation & Coefficient & Weight \\
\hline 1 & 222200000 & 0.865446 & 0.748997 \\
43 & 2222020000 & -0.344742 & 0.118847 \\
82 & $222 \mathrm{udud} 000$ & 0.060674 & 0.003681 \\
104 & $2 \mathrm{u} 22 \mathrm{du} 000 \mathrm{~d}$ & 0.051799 & 0.002683 \\
107 & 2220202000 & -0.059547 & 0.003546 \\
121 & 2220200200 & -0.053769 & 0.002891 \\
133 & $22 \mathrm{ud} 20 \mathrm{ud} 00$ & 0.108331 & 0.011736 \\
140 & $2 \mathrm{u} 2 \mathrm{~d} 2 \mathrm{ud} 000$ & -0.078524 & 0.006166 \\
150 & $2 \mathrm{u} 2 \mathrm{~d} 200 \mathrm{ud} 0$ & 0.052956 & 0.002804 \\
154 & $\mathrm{u} 22 \mathrm{~d} 2 \mathrm{u} 0 \mathrm{~d} 00$ & -0.076069 & 0.005787 \\
164 & $\mathrm{u} 22 \mathrm{~d} 20 \mathrm{u} 0 \mathrm{~d} 0$ & 0.054455 & 0.002965 \\
167 & 2202202000 & -0.051565 & 0.002659 \\
180 & 2202200200 & -0.051016 & 0.002603 \\
184 & $2 \mathrm{ud} 22 \mathrm{u} 0 \mathrm{~d} 00$ & 0.071029 & 0.005045 \\
193 & $2 \mathrm{ud} 220 \mathrm{u} 0 \mathrm{~d} 0$ & -0.052669 & 0.002774 \\
200 & $\mathrm{u} 2 \mathrm{~d} 22 \mathrm{ud} 000$ & 0.071703 & 0.005141 \\
226 & $\mathrm{u} 2 \mathrm{~d} 2200 \mathrm{ud} 0$ & -0.053634 & 0.002877 \\
\hline $\mathrm{ud} 2220 \mathrm{ud} 00$ & -0.067580 & 0.004567 \\
\hline
\end{tabular}

